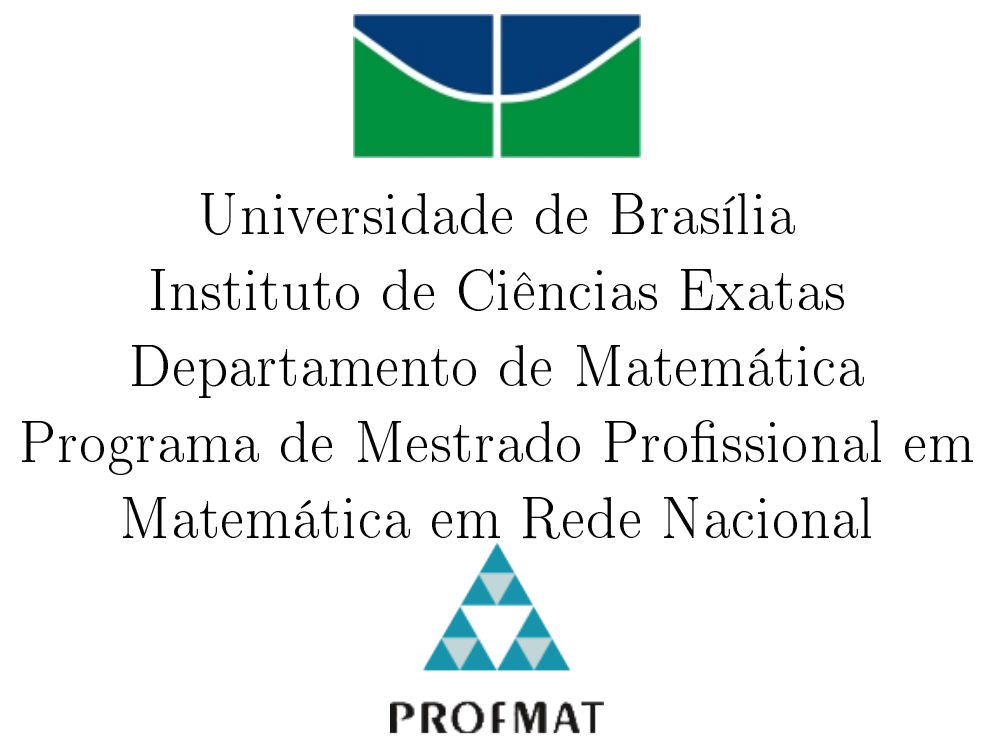

\title{
Recorrências: uma abordagem sobre sequências recursivas para aplicações no Ensino Médio
}

Israel Carley da Silva 


\section{Israel Carley da Silva}

\section{Recorrências: uma abordagem sobre sequências recursivas para aplicações no Ensino Médio}

Dissertação apresentada ao Departamento de Matemática da Universidade de Brasília, como parte dos requisitos do Programa de Mestrado Profissional em Matemática em Rede Nacional PROFMAT, para obtenção do grau de Mestre.

Orientador: Prof. Dr. Helder de Carvalho Matos

Brasília

2015 
Ficha catalográfica elaborada automaticamente, com os dados fornecidos pelo(a) autor(a)

\section{Recorrências: uma abordagem sobre sequências} recursivas para aplicações no Ensino Médio / Israel Carley da Silva; orientador Helder de Carvalho Matos. -- Brasília, 2015.

$85 \mathrm{p}$.

Dissertação (Mestrado - Mestrado Profissional em Matemática) -- Universidade de Brasília, 2015.

1. Recorrências. 2. Sequências Numéricas. 3. Números de Fibonacci. 4. Números Figurados. I. Matos, Helder de Carvalho, orient. II. Título. 
Universidade de Brasília

Instituto de Ciências Exatas

Departamento de Matemática

\section{Recorrências: uma abordagem sobre sequências recursivas para aplicações no Ensino Médio}

por

\section{ISRAEL CARLEY DA SILVA*}

Dissertação apresentada ao Departamento de Matemática da Universidade de Brasília, como parte dos requisitos do "Programa" de Mestrado Profissional em Matemática em Rede Nacional - PROFMAT, para obtenção do grau de

\section{MESTRE}

Brasília, 07 de julho de 2015.

Comissão Examinadora:
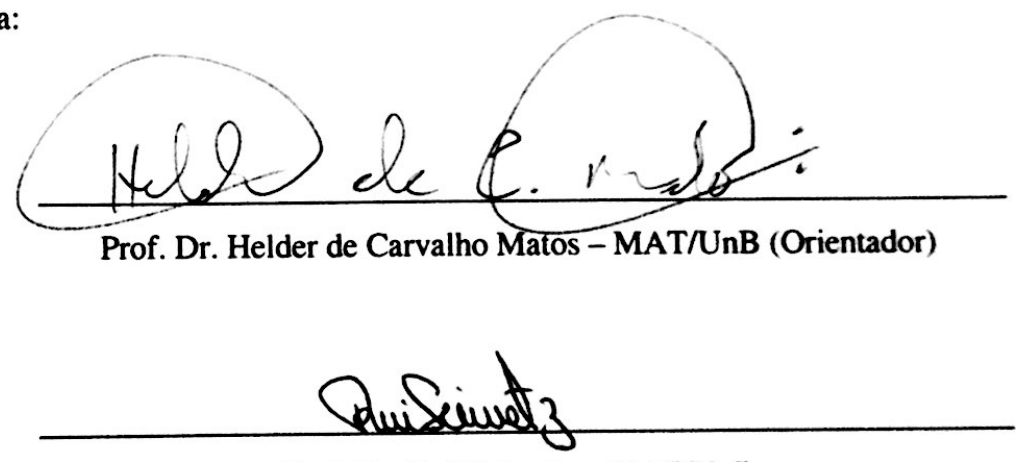

Prof. Dr. Rui Seimetz - MAT/UnB

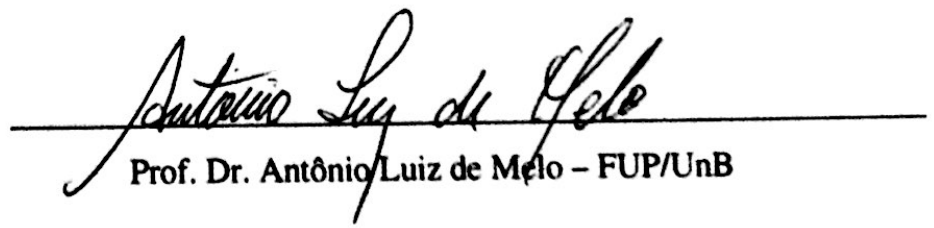

* O autor foi bolsista CAPES durante a elaboração desta dissertação. 
Todos os direitos reservados. Proibido a reprodução total ou parcial desse trabalho sem a autorização da Universidade, do autor e do orientador.

Israel Carley da Silva graduou-se em Matemática pela Universidade de Pernambuco, especializou-se em Educação Matemática pela Universidade Federal de Rondônia e atua como professor na Secretaria de Educação do Distrito Federal. 
"O livro da natureza foi escrito exclusivamente com figuras e símbolos matemáticos." - Galileu Galilei 


\section{Agradecimentos}

Agradeço primeiramente ao Eterno, o Grande Espírito manifestado em todas as coisas como inteligência infinita do Universo por nos presentear com essa linguagem tão bela: a Matemática.

Agradeço a minha mãe Marli pelo apoio incondicional em todos os momentos. A minha filha Fernanda pelo imenso carinho e sorriso revigorante. A minha irmã Caline, pelas colaborações valiosas. Ao meu pai, Fernando, às minhas irmãs e irmãos pelo auxílio prestado e palavras de incentivo.

Ao Dr. Helder, meu orientador, pelas dicas importantes para o desenvolvimento desse trabalho. Aos professores do Departamento de Matemática da Universidade de Brasília que colaboraram com seus grandes ensinamentos nas disciplinas do curso. Aos amigos e amigas do PROFMAT pelas inúmeras contribuições durante os estudos, pelos longos períodos que passamos estudando, independentemente de dia, hora ou lugar.

Agradeço à CAPES pelo apoio financeiro durante a elaboração desse trabalho. À Secretaria de Educação do Distrito Federal pelo período a mim concedido para dedicação ao curso do mestrado. Aos alunos que me auxiliaram na produção desse trabalho, acreditando na proposta e desenvolvendo parte essencial da pesquisa. Aos colegas professores com os quais trabalho. Agradeço a todos os entes que direta ou indiretamente nos ajudaram, auxiliando nos trabalhos relacionados ao curso. 


\section{Dedicatória}

Dedico esse trabalho a minha mãe Marli e minha filha Fernanda. 


\section{Resumo}

Neste trabalho apresentamos uma abordagem sobre sequências recursivas, ou simplesmente recorrências. Discorremos sobre recorrências lineares, principalmente as de primeira e segunda ordem, estudando soluções e apresentando propriedades e fazendo paralelos com algumas sequências comuns ao cotidiano do estudante de Matemática. Apresentamos também, casos clássicos desse tipo de sequências como os números de Fibonacci e de Lucas; os números figurados: poligonais e piramidais; e ainda, aplicações em áreas como a Combinatória e Matemática Financeira.

No trabalho ainda abordamos uma proposta de exercícios a alunos do Ensino Médio. Relatamos a experiência de atividades em sala de aula, as dificuldades encontradas, resultados apresentados, bem como os relatos das impressões que os alunos tiveram ao estudar esse tema.

Palavras-Chaves: Recorrências; sequências numéricas; números de Fibonacci; números figurados. 


\section{Abstract}

We present in this paper an approach to recursive sequences, or simply recurrences. We discuss linear recurrences, especially the first and second order, studying solutions and presenting properties and making parallels with some common sequences to the mathematics student daily. We also present, classics examples of such sequences as Fibonacci numbers and Lucas numbers, the figured numbers: polygonal and pyramidal, and also applications in areas as Combinatory and Mathematical Finance.

At work even we approach a proposed exercises to high school students. We report the activities of experience in the classroom, the difficulties encountered, the results, as well as the reports of the impressions that the students had to study this subject.

Keywords: Recurrences; numerical sequences; Fibonacci numbers; figurate numbers. 


\section{Sumário}

$\begin{array}{ll}\text { Introdução } & 1\end{array}$

1 Fundamentação Teórica sobre Recorrências $\quad 4$

1.1 Sequências . . . . . . . . . . . . . . . . . . . . 4

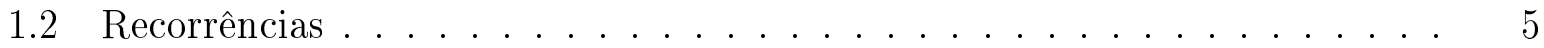

1.3 Recorrências lineares homogêneas de $1^{\mathrm{a}}$ ordem . . . . . . . . . . . 7

1.4 Recorrências lineares não-homogêneas de $1^{\text {a }}$ ordem . . . . . . . . . . . . 10

1.5 Transformação da recorrência $x_{n+1}=g(n) x_{n}+h(n)$ em $y_{n+1}=y_{n}+f(n)$. 13

1.6 Recorrências Lineares de $1^{\text {a }}$ Ordem com Coeficientes Constantes . . . . . . 14

2 Recorrências Lineares de $2^{\text {a }}$ Ordem $\quad 17$

2.1 Recorrências Lineares de $2^{\text {a }}$ Ordem Homogêneas de Coeficientes Constantes 17

$2.1 .1 \quad$ Caso $\alpha \neq \beta \ldots \ldots \ldots \ldots \ldots \ldots$

2.1 .2 Caso $\alpha=\beta \ldots \ldots \ldots \ldots \ldots \ldots$

2.2 Recorrências da Forma: $x_{n+2}+p x_{n+1}+q x_{n}=f(n) \ldots \ldots . \ldots 26$

2.3 Recorrências Lineares de Ordem k . . . . . . . . . . . . . . 30

3 Exemplos Clássicos de Recorrências 35

3.0 .1 Princípio da Indução Finita . . . . . . . . . . . . . . . . 35

3.1 A Torre de Hanói . . . . . . . . . . . . . . . . . . . . 36

3.2 Combinações de Elementos Geométricos . . . . . . . . . . . . . 39

3.3 Combinatória . . . . . . . . . . . . . . . . . . . 42

3.3.1 Permutações Simples . . . . . . . . . . . . . . . . 42

3.3.2 Permutações Caóticas . . . . . . . . . . . . . . . 43

3.4 A Sequência de Fibonacci . . . . . . . . . . . . . . . 47

3.5 Os Números de Lucas . . . . . . . . . . . . . . . . . . . . . . 51 
4 Um Pouco Além das Progressões $\quad \mathbf{5 4}$

4.1 Somas Polinomiais . . . . . . . . . . . . . . . 54

4.2 Progressões Aritméticas de Ordem k . . . . . . . . . . . . . 57

4.3 O Problema dos Números Poligonais . . . . . . . . . . . . . . 59

4.4 Números Piramidais . . . . . . . . . . . . . . . . . . 62

5 Aplicações de Recorrências no Ensino Médio $\quad 65$

5.1 Metodologia das Aplicações em Sala de Aula . . . . . . . . . . . . . 65

5.2 Problemas Propostos Envolvendo Recorrências . . . . . . . . . . . . 70

5.3 Análise de Alunos Sobre Algumas Questões . . . . . . . . . . . . 79

Considerações Finais $\quad 82$

$\begin{array}{ll}\text { Referências } & 84\end{array}$ 


\section{Introdução}

Esse trabalho trata do estudo das sequências numéricas. Mais precisamente aquelas em que os termos são obtidas por meio de uma regra matemática aplicada aos termos anteriores. Essas sequências serão definidas como recorrências.

Analisando alguns livros didáticos, [7], [12], [19], utilizados no Ensino Médio no Brasil, observamos que os autores tratam rapidamente de sequências numéricas em geral. O assunto é apresentado para dar base ao estudo das progressões aritméticas e progressões geométricas, comumente chamadas de PA e PG, respectivamente. Esses são os exemplos mais comuns ao aluno do Ensino Médio e às vezes os únicos a serem abordados como sequências. Nesse trabalho tentaremos expandir essa visão apresentando outros casos que podem ser explorados em sala de aula.

Esse trabalho é uma alternativa à expansão do estudo desse tema, no qual faremos propostas de exercícios para serem trabalhados com os alunos. Apresentaremos um pouco da experiência obtida com o tema em três turmas do segundo ano do Ensino Médio em uma escola pública do Distrito Federal.

No primeiro capítulo faremos as primeiras definições. Discorreremos sobre detalhes de recorrências lineares de primeira ordem, dentre as quais estarão as conhecidas PA e PG.

No capítulo seguinte, apresentaremos uma abordagem sobre recorrências lineares de segunda ordem. Pouco exploradas nos livros didáticos, essas recorrências, como veremos, fazem um paralelo com equações polinomiais. E as soluções que encontraremos podem estimular o interesse também pelo estudo das raízes de equações polinomiais.

O terceiro capítulo trará exemplos clássicos de aplicações das recorrências, como a Combinatória e a famosa sequência de Fibonacci. Muito conhecida dos professores, mas pouco explorada na Educação Básica, a sequência de Fibonacci é sempre um atrativo para 
o estudo de sequências, haja visto suas muitas propriedades matemáticas. Além disso, essa sequência pode ser observada em padrões da natureza e seres vivos.

O quarto capítulo é uma expansão do estudo das progressões aritméticas. Trataremos das progressões de segunda ordem, fazendo uma generalização para as de ordens superiores. Como aplicações veremos o exemplo dos números figurados, dentre eles os triangulares que podem ajudar a resolver muitos outros problemas.

No quinto e último capítulo faremos propostas de exercícios a serem trabalhados com alunos do Ensino Médio. Apresentaremos relatos de aulas em que o assunto desse trabalho foi exposto, discutido e estudado. Além disso, vamos relatar as experiências dos alunos, suas impressões pessoais sobre o tema, as análises de determinados problemas sob a ótica discente e as principais dificuldades que eles apresentam ao estudar recorrências.

Justificamos a escolha desse tema mediante a grande necessidade de se explorar áreas da Matemática não muito difundidas nas salas de aula da Educação Básica, como são as recorrências. Desejamos proporcionar aos estudantes a descoberta e o aprimoramento de diversas habilidades, como está previsto nos Parâmetros Curriculares Nacionais (1998):

"O ensino de Matemática deve garantir o desenvolvimento de capacidades como: observação, estabelecimento de relações, comunicação (diferentes linguagens), argumentação e validação de processos e o estímulo às formas de raciocínio como intuição, indução, dedução, analogia e estimativa." ([5], p.56)

A partir dessa reflexão, percebemos que o estudo das recorrências pode ser voltado para a melhoria da capacidade de observação e para o desenvolvimento de habilidades. Dentre elas, comunicação e argumentação podem despertar nos estudantes da Educação Básica, e mais especificamente no Ensino Médio, o interesse e o amadurecimento da resolução de problemas. Esse princípio é descrito nos Parâmetros Curriculares Nacionais (2002):

"A resolução de problemas é peça central para o ensino de matemática, pois o pensar e o fazer se mobilizam e se desenvolvem quando o indivíduo está engajado ativamente no enfrentamento de desafios. Esta competência não se desenvolve quando propomos apenas exercícios de aplicação de conceitos e técnicas matemáticas, pois, neste caso, o que está em ação é uma simples transposição analógica: o aluno busca na memória um exercício semelhante e desenvolve passos análogos aos daquela situação, o que não garante que seja capaz de usar seus conhecimentos em situações diferentes ou mais complexas." ([6], p.112) 
Com este trabalho e as reflexões dos exemplos propostos temos o objetivo de instruir e elencar métodos, caminhos e exemplos de como promover o ensino de recorrências no Ensino Médio. Queremos ampliar a gama de possibilidades da Matemática no processo de ensino-aprendizagem desse público. A proposta é destinada a um estudo mais aprofundado, para as aulas nas quais se possa trabalhar temas diversificados, ou ainda, para treinamento de olimpíadas nas escolas. 


\section{Capítulo 1 \\ Fundamentação Teórica sobre Recorrências}

Primeiramente faz-se necessário definir algumas expressões que aparecerão no decorrer do trabalho.

\subsection{Sequências}

Sejam $\mathbb{R}$ o conjunto dos números reais e $\mathbb{N}=\{1,2,3,4, \ldots\}$ o conjunto dos números naturais.

Definição 1.1.1. Seja $x: \mathbb{N} \longrightarrow \mathbb{R}$ uma função, onde cada $n \in \mathbb{N}$ associa-se a um número real $x(n)$. A lista dos valores $x(1), x(2), x(3), \ldots, x(n), \ldots$ é chamada sequência de números reais.

De modo geral, a sequência de números reais será indicada por seus valores de forma ordenada. Esses valores são denominados termos da sequência:

$$
X=(x(1), x(2), x(3), \ldots, x(n), \ldots)
$$

Neste trabalho denotaremos a sequência $X$ por $\left(x_{n}\right)$ e $x_{n}$ indicará o $n$-ésimo termo da sequência. Portanto:

$$
X=\left(x_{n}\right)=\left(x_{1}, x_{2}, x_{3}, \ldots, x_{n}, \ldots\right)
$$

Em alguns casos apresentados no trabalho a sequência partirá de um termo $x_{0}$. Então, nesses casos a posição $n$ de cada termo será dada pelos números do conjunto $\mathbb{Z}_{+}$, o conjunto dos números inteiros não-negativos. 


\subsection{Recorrências}

Definição 1.2.1. Uma sequência é dita recorrente, ou simplesmente "recorrência", quando a partir de um certo termo, todos os termos são dados em função do(s) termo(s) ante$\operatorname{rior}(e s)$.

As recorrências podem ser apresentadas dos seguintes modos:

- Através de uma equação de recorrência que, a partir de um certo termo, determina cada termo posterior em função dos anteriores. Por exemplo: Uma sequência cujo primeiro termo é $x_{1}=1$ e cada termo a partir do segundo é dado por:

$$
x_{n}=2 x_{n-1}+2, \quad\left(x_{n}\right)=(1,4,10,22,46, \ldots) .
$$

- Através de uma expressão, ou "fórmula fechada", que associa o termo $x_{n}$ a cada número natural $n$. Por exemplo:

$$
x_{n}=3 n+2, \quad\left(x_{n}\right)=(5,8,11,14,17, \ldots) .
$$

Primeiramente, devemos observar que uma mesma relação de recorrência pode gerar infinitas sequências distintas. Logo, para que uma sequência seja descrita numericamente, a partir da relação de recorrência, é necessário que sejam informados os primeiros termos a partir dos quais os demais elementos serão obtidos.

Também é importante notar que nem toda sequência de números reais apresenta uma regra bem definida ou conhecida. Além disso, há sequências que possuem uma certa regra, porém, não se pode definir, ou não se definiu, uma equação associada a ela. Neste caso, a sequência pode ser apresentada por meio de uma propriedade comum a todos os seus termos. Como por exemplo: A sequência dos números primos, $\left(x_{n}\right)=(2,3,5,7,11,13, \ldots)$.

As equações de recorrências podem ser classificadas de acordo com a sua ordem, com a homogeneidade e linearidade.

Definição 1.2.2. A ordem de uma recorrência é a diferença entre o maior e o menor dos indices dos termos de sua equação.

A equação $x_{n}=\frac{x_{n-3}}{x_{n-4}}$, com $n \geq 5$ representa uma recorrência de $4^{\text {a }}$ ordem, haja visto a diferença $n-(n-4)=4$. 
Definição 1.2.3. Uma recorrência é dita "homogênea" quando cada termo depende exclusivamente dos anteriores. Em contrapartida, uma recorrência é dita "não-homogênea" quando além de depender dos termos anteriores, cada elemento da sequência também está em função de um termo independente.

Podemos citar, como exemplos, que a equação $x_{n+2}=2 x_{n+1}+x_{n}$ representa uma recorrência homogênea, ao passo que a equação $x_{n+1}=3 x_{n}+1$ representa uma recorrência não-homogênea.

As recorrências ainda podem ser caracterizadas como lineares e não-lineares.

Definição 1.2.4. Uma sequência $\left(x_{n}\right)$ possui equação de recorrência linear de ordem $k$ se estiver escrita na forma:

$$
x_{n+k}=f_{1}(n) x_{n+k-1}+f_{2}(n) x_{n+k-2}+\ldots+f_{k}(n) x_{n}+f_{k+1}(n) \text {, }
$$

onde $f_{i}(n)$ é uma função em $n$ com $i \in \mathbb{N}$ e $1 \leq i \leq k+1$, e ainda $f_{k} \neq 0$.

É fácil ver que se $f_{k+1}(n)=0$ a recorrência linear é homogênea, e no caso $f_{k+1}(n) \neq 0$ a recorrência linear é não-homogênea.

Observemos, a partir da definição 1.2.4., que as equações $x_{n+3}=n x_{n+2}+2 x_{n}$ e $x_{n+1}=x_{n}+2 n$ representam recorrências lineares.

As equações $x_{n+2}=\frac{x_{n+1}}{x_{n}}$ e $x_{n+1}=\left(x_{n}\right)^{2}$ representam recorrências não-lineares.

Definição 1.2.5. Resolver uma equação de recorrência é encontrar uma fórmula fechada para a recorrência. Ou seja, encontrar uma expressão que permita determinar cada $x_{n}$ em função apenas de $n$, sem necessidade de se conhecer os termos anteriores. Essa expressão é dita solução da recorrência.

Nas secções seguintes, veremos alguns exemplos de resolução de recorrências lineares de $1^{\mathrm{a}}$ ordem, e no próximo capítulo discorreremos sobre as de $2^{\mathrm{a}}$ ordem. Alguns dos exemplos remetem a casos clássicos de recorrências, vistos na Educação Básica no Brasil, mesmo que não sejam tratados como tal. Entre as recorrências mais comuns trataremos das sequências denominadas progressões aritméticas e geométricas. Nesse trabalho, daremos ênfase a sua formação recursiva e certas propriedades a elas peculiares. 


\subsection{Recorrências lineares homogêneas de $1^{\mathrm{a}}$ ordem}

Definição 1.3.1. Uma recorrência linear de $1^{a}$ ordem expressa $x_{n+1}$ em função de $x_{n}$, ela será linear se, e somente se, sua equação for da forma:

$$
x_{n+1}=g(n) x_{n}+h(n), \operatorname{com} g(n) \neq 0, \quad \forall n \in \mathbb{N} .
$$

Se $h(n)=0$ temos uma recorrência linear "homogênea" de $1^{a}$ ordem e, no caso contrário, se $h(n) \neq 0$ temos uma recorrência linear "não-homogênea" de $1^{a}$ ordem.

As equações $x_{n+1}=3 x_{n}+n^{2}$ e $x_{n+1}=n x_{n}$ representam recorrências lineares de $1^{\mathrm{a}}$ ordem. A equação $x_{n+1}=\left(x_{n}\right)^{3}$ representa uma recorrência de $1^{\mathrm{a}}$ ordem, porém não-linear.

Exemplo 1.3.1. Resolver a recorrência: $x_{n+1}=g(n) x_{n}$.

Variando os valores de $n$, temos:

$$
\begin{gathered}
x_{2}=g(1) x_{1} \\
x_{3}=g(2) x_{2} \\
x_{4}=g(3) x_{3} \\
\vdots \\
x_{n}=g(n-1) x_{n-1}
\end{gathered}
$$

Multiplicando os termos dos $1^{\circ}$ e $2^{\circ}$ membros das equações, e efetuando as devidas simplificações, temos:

$$
x_{n}=x_{1} \cdot \prod_{i=1}^{n-1} g(i)
$$

Exemplo 1.3.2. Resolver a recorrência: $x_{n+1}=q \cdot x_{n}$, onde $q$ é uma constante real, $g(n)=q, \forall n \in \mathbb{N}$.

Variando os valores de $n$, temos:

$$
\begin{gathered}
x_{2}=q x_{1} \\
x_{3}=q x_{2} \\
x_{4}=q x_{3} \\
\vdots \\
x_{n}=q x_{n-1}
\end{gathered}
$$

Multiplicando os termos dos $1^{\circ}$ e $2^{\circ}$ membros das equações, e efetuando as devidas simplificações, temos:

$$
x_{n}=x_{1} \prod_{i=1}^{n-1} q \quad \text { ou simplesmente: } x_{n}=x_{1} \cdot q^{n-1}
$$


Esta recorrência caracteriza a famosa "progressão geométrica". Cada sequência assim caracterizada tem seus termos determinados se forem definidos o valor do elemento inicial $x_{1}$ e o valor da constante $q$.

Definição 1.3.2. Progressão Geométrica é uma sequência recorrente $\left(x_{n}\right)$, com valores não-nulos, onde o quociente $\frac{x_{n+1}}{x_{n}}$ é constante, para todo $n \in \mathbb{N}$. Esta constante q, tal que $q \in \mathbb{R}-\{0\}$ é chamada de razão da progressão geométrica.

Usaremos a abreviação PG para simplificar a expressão "progressão geométrica".

Como podemos ver em ([7], p. 318), ([12], p. 226) e ([19], p. 229) é comum nos livros didáticos de Ensino Médio no Brasil os autores adotarem a notação $\left(a_{n}\right)$ para a sequência, $q$ para a razão da PG e $a_{n}=a_{1} \cdot q^{n-1}$ para a solução da recorrência, chamada nos livros de "fórmula do termo geral da PG". A opção pela variável $x$ ou $a$, ou outra letra qualquer é uma simples escolha de notação, que não afeta o resultado do estudo.

Proposição 1.3.1. Seja $S_{n}$ a soma dos $n$ primeiros termos de uma $P G$. Se a razão $q=1$,

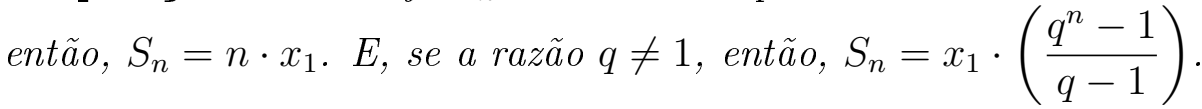

Prova: Os $n$ primeiros termos de uma PG $\left(x_{n}\right)$ são: $\left(x_{1}, x_{1} \cdot q, x_{1} \cdot q^{2}, \ldots, x_{1} \cdot q^{n-1}\right)$. Assim, a soma $S_{n}$ é definida como $S_{n}=x_{1}+x_{1} \cdot q+x_{1} \cdot q^{2}+\ldots+x_{1} \cdot q^{n-1}$.

Primeiramente, queremos provar que se $q=1$, então, $S_{n}=n \cdot x_{1}$.

Substituindo $q=1$, chegamos à soma $S_{n}=x_{1}+x_{1}+x_{1}+\ldots+x_{1}$, onde $x_{1}$ é contado $n$ vezes. Daí, segue que, $S_{n}=n \cdot x_{1}$.

Agora, queremos provar que se $q \neq 1$, então, $S_{n}=x_{1} \cdot\left(\frac{q^{n}-1}{q-1}\right)$.

Multiplicando $S_{n}$ pela constante $q$, temos:

$$
S_{n} \cdot q=x_{1} \cdot q+x_{1} \cdot q^{2}+x_{1} \cdot q^{3}+\ldots+x_{1} \cdot q^{n} .
$$

Observemos agora a diferença $S_{n} \cdot q-S_{n}$ :

$S_{n} \cdot q-S_{n}=\left(x_{1} \cdot q+x_{1} \cdot q^{2}+x_{1} \cdot q^{3}+\ldots+x_{1} \cdot q^{n}\right)-\left(x_{1}+x_{1} \cdot q+x_{1} \cdot q^{2}+\ldots+x_{1} \cdot q^{n-1}\right)$

Subtraindo os $n$ termos dos dois parênteses, chegamos ao resultado simplificado: 


$$
S_{n} \cdot q-S_{n}=x_{1} \cdot q^{n}-x_{1} \Longrightarrow S_{n}(q-1)=x_{1}\left(q^{n}-1\right) \Longrightarrow S_{n}=x_{1} \cdot\left(\frac{q^{n}-1}{q-1}\right)
$$

Com isso, concluímos o que queríamos provar.

Proposição 1.3.2. Se a razão da $P G$ é $q \in \mathbb{R}$ tal que $0<|q|<1$, então a soma dos $n$ primeiros termos dessa $P G$ converge para

$$
S_{n}=\frac{x_{1}}{1-q}
$$

Prova: Sabemos que se $q \neq 1$, então $S_{n}=x_{1} \cdot\left(\frac{q^{n}-1}{q-1}\right)$. Podemos reescrever esta igualdade de forma que:

$$
S_{n}=x_{1} \cdot\left(\frac{1-q^{n}}{1-q}\right) .
$$

Sabemos do Cálculo que se $0<|q|<1$, temos que $q^{n}$ converge para zero quando $n$ tende ao infinito, ou seja:

$$
\text { Se } 0<|q|<1 \text {, então } \lim _{n \rightarrow \infty} q^{n}=0 \text {. }
$$

Logo,

$$
\lim _{n \rightarrow \infty} S_{n}=\lim _{n \rightarrow \infty}\left(x_{1} \cdot\left(\frac{1-q^{n}}{1-q}\right)\right)=x_{1} \cdot\left(\frac{1-0}{1-q}\right)=\frac{x_{1}}{1-q}
$$

Exemplo 1.3.3. Resolver a recorrência: $x_{n+1}=n x_{n}$.

Substituindo os valores de $n$, temos:

$$
\begin{gathered}
x_{2}=1 \cdot x_{1} \\
x_{3}=2 \cdot x_{2} \\
x_{4}=3 \cdot x_{3} \\
\vdots \\
x_{n}=(n-1) \cdot x_{n-1}
\end{gathered}
$$

Multiplicando os termos dos $1^{\circ}$ e $2^{\circ}$ membros das equações, e efetuando as devidas simplificações, temos:

$$
x_{n}=x_{1} \prod_{i=1}^{n-1} i \quad \text { ou apenas: } x_{n}=x_{1} \cdot(n-1) !
$$

Observemos, neste último exemplo, que a recorrência só ficará numericamente definida se for arbitrado um valor para $x_{1}$. Por exemplo, se $x_{1}=1$ então a solução da recorrência é $x_{n}=(n-1)$ !. 


\subsection{Recorrências lineares não-homogêneas de $1^{\mathrm{a}}$ ordem}

As recorrências lineares não-homogêneas de $1^{\mathrm{a}}$ ordem são da forma:

$$
x_{n+1}=g(n) x_{n}+h(n) \text {, onde } g(n) \neq 0 \text { e } h(n) \neq 0, \forall n \in \mathbb{N} \text {. }
$$

Os casos de mais simples resolução são aqueles onde $g(n)=1$. Vejamos alguns exemplos:

Exemplo 1.4.1. Resolver a recorrência: $x_{n+1}=x_{n}+h(n), \forall n \in \mathbb{N}$.

Temos:

$$
\begin{gathered}
x_{2}=x_{1}+h(1) \\
x_{3}=x_{2}+h(2) \\
x_{4}=x_{3}+h(3) \\
\vdots \\
x_{n}=x_{n-1}+h(n-1)
\end{gathered}
$$

Somando os termos das equações, e simplificando devidamente, obtemos:

$$
x_{n}=x_{1}+\sum_{i=1}^{n-1} h(i)
$$

Exemplo 1.4.2. Resolver a recorrência: $x_{n+1}=x_{n}+2^{n}, x_{1}=1$.

Temos:

$$
\begin{gathered}
x_{2}=x_{1}+2^{1} \\
x_{3}=x_{2}+2^{2} \\
x_{4}=x_{3}+2^{3} \\
\vdots \\
x_{n}=x_{n-1}+2^{n-1}
\end{gathered}
$$

Somando os termos das equações, fazendo as devidas simplificações e substituindo-se $x_{1}=1$, obtemos:

$$
x_{n}=1+2^{1}+2^{2}+2^{3}+\ldots+2^{n-1}
$$

Observemos que o resultado é a soma de $n$ termos de uma PG onde $x_{1}=1$ e $q=2$.

Portanto, aplicando o resultado da Proposição 1.3.1., chegamos à solução:

$$
x_{n}=1 \cdot\left(\frac{2^{n}-1}{2-1}\right) \Longrightarrow x_{n}=2^{n}-1
$$


Exemplo 1.4.3. Resolver a recorrência: $x_{n+1}=x_{n}+r, \forall n \in \mathbb{N}$ e $r \in \mathbb{R}-\{0\}$.

Temos:

$$
\begin{gathered}
x_{2}=x_{1}+r \\
x_{3}=x_{2}+r \\
x_{4}=x_{3}+r \\
\vdots \\
x_{n}=x_{n-1}+r
\end{gathered}
$$

Somando os termos das equações, fazendo as devidas simplificações, obtemos:

$$
x_{n}=x_{1}+(n-1) \cdot r
$$

Esta recorrência caracteriza a famosa "progressão aritmética". Cada sequência assim caracterizada tem seus termos determinados se forem arbitrados o valor do elemento inicial $x_{1}$ e o valor da constante $r$.

Definição 1.4.1. Progressão Aritmética é uma sequência recorrente $\left(x_{n}\right)$ onde a diferença $x_{n+1}-x_{n}$ é constante, para todo $n \in \mathbb{N}$. Esta constante $r$, tal que $r \in \mathbb{R}$ é chamada de razão da progressão aritmética.

Usaremos a abreviação PA para simplificar a expressão "progressão aritmética".

Como vimos no comentário acerca da PG, ao observarmos ([7], p. 300), ([12], p. 216) e ([19], p. 218), também é comum, entre os autores brasileiros, a adoção da notação $\left(a_{n}\right)$ para a sequência, $r$ para a razão da PA e $a_{n}=a_{1}+(n-1) \cdot r$ para a solução da recorrência, chamada nos livros de "fórmula do termo geral da PA".

A seguir veremos a definição de uma fórmula fechada para a soma dos $n$ primeiros números naturais. Essa fórmula será importante para provarmos outros resultados que aparecerão no decorrer desse trabalho.

Proposição 1.4.1. Seja $S_{n}$ é soma dos n primeiros números naturais. Se,

$$
S_{n}=1+2+3+\ldots+(n-1)+n \text { então, } S_{n}=\frac{n \cdot(n+1)}{2} .
$$

Prova: Pela comutatividade da adição, podemos escrever a soma $S_{n}$ como:

$$
\begin{gathered}
S_{n}=1+2+3+\ldots+(n-2)+(n-1)+n, \text { ou } \\
S_{n}=n+(n-1)+(n-2)+\ldots+3+2+1
\end{gathered}
$$


Somando as duas equações, obtemos:

$$
2 \cdot S_{n}=(1+n)+(1+n)+\ldots+(1+n)+(1+n)
$$

Como temos $n$ parcelas em cada soma, então temos $n$ parcelas iguais a $(n+1)$ na equação acima. Logo:

$$
\begin{gathered}
2 \cdot S_{n}=(1+n)+(1+n)+\ldots+(1+n)+(1+n) \Longrightarrow 2 \cdot S_{n}=n \cdot(n+1) \Longrightarrow \\
S_{n}=\frac{n \cdot(n+1)}{2}
\end{gathered}
$$

Proposição 1.4.2. Seja $S_{n}$ a soma dos $n$ primeiros termos de uma $P A$ e $r \in \mathbb{R}$ a sua razão. Então:

$$
S_{n}=\frac{\left(x_{1}+x_{n}\right) \cdot n}{2}
$$

Prova: Os $n$ primeiros termos de uma PA $\left(x_{n}\right)$ são:

$$
\left(x_{1}, x_{1}+r, x_{1}+2 r, \ldots, x_{1}+(n-1) \cdot r\right) .
$$

Assim, a soma $S_{n}$ pode ser escrita como $S_{n}=x_{1}+x_{1}+r+x_{1}+2 r+\ldots+x_{1}+(n-1) \cdot r$.

Temos $n$ parcelas iguais a $x_{1}$, assim:

$$
S_{n}=n \cdot x_{1}+r \cdot \sum_{i=1}^{n-1} i
$$

Usando a solução da Proposição 1.4.1., $S_{n}=\frac{n \cdot(n+1)}{2}$ e substituindo a expressão $x_{n}=x_{1}+(n-1) \cdot r$, obtida no Exemplo 1.4.3., temos:

$$
\begin{gathered}
S_{n}=n \cdot x_{1}+\left(\frac{n \cdot(n-1)}{2}\right) \cdot r \\
\Longrightarrow S_{n}=\frac{2 \cdot n \cdot x_{1}+n \cdot(n-1) \cdot r}{2} \\
\Longrightarrow S_{n}=\frac{n \cdot x_{1}+n \cdot x_{1}+n \cdot(n-1) \cdot r}{2} \\
\Longrightarrow S_{n}=\frac{\left(x_{1}+x_{1}+(n-1) \cdot r\right) \cdot n}{2} \\
\Longrightarrow S_{n}=\frac{\left(x_{1}+x_{n}\right) \cdot n}{2}
\end{gathered}
$$




\subsection{Transformação da recorrência $x_{n+1}=g(n) x_{n}+h(n)$ em} $y_{n+1}=y_{n}+f(n)$

Podemos transformar qualquer recorrência linear de $1^{\mathrm{a}}$ ordem em uma outra da forma $x_{n+1}=x_{n}+f(n)$.

Teorema 1.5.1. Se $a_{n}$ é uma solução não-nula de $z_{n+1}=g(n) z_{n}, g(n) \neq 0, \forall n \in \mathbb{N}$, então a substituição $x_{n}=a_{n} y_{n}$ transforma a recorrência $x_{n+1}=g(n) x_{n}+h(n) \mathrm{em}$

$$
y_{n+1}=y_{n}+\frac{h(n)}{g(n) \cdot a_{n}} \text {. }
$$

Demonstração: A substituição $x_{n}=a_{n} y_{n}$ transforma $x_{n+1}=g(n) x_{n}+h(n)$ em $a_{n+1} y_{n+1}=g(n) a_{n} y_{n}+h(n)$.

Mas, $a_{n+1}=g(n) a_{n}$, pois por hipótese $a_{n}$ é uma solução não-nula de $z_{n+1}=g(n) z_{n}$. Daí a equação se transforma em:

$$
g(n) a_{n} y_{n+1}=g(n) a_{n} y_{n}+h(n) \Longleftrightarrow y_{n+1}=y_{n}+\frac{h(n)}{g(n) \cdot a_{n}}
$$

Exemplo 1.5.1. Resolver a recorrência: $x_{n+1}=2 x_{n}+1, x_{1}=2$.

Uma solução não-nula de $z_{n+1}=2 z_{n}$ é $a_{n}=2^{n-1}$. Fazendo a substituição $x_{n}=2^{n-1} \cdot y_{n}$, obtemos:

$$
2^{n} y_{n+1}=2^{n} y_{n}+1 \Longrightarrow y_{n+1}=y_{n}+\frac{1}{2^{n}}
$$

Variando os valores de $n$, segue que:

$$
\begin{gathered}
y_{2}=y_{1}+2^{-1} \\
y_{3}=y_{2}+2^{-2} \\
y_{4}=y_{3}+2^{-3} \\
\vdots \\
y_{n}=y_{n-1}+2^{-(n-1)}
\end{gathered}
$$

Somando as equações, temos:

$$
\begin{gathered}
y_{n}=y_{1}+2^{-1}+2^{-2}+2^{-3}+\ldots+2^{-(n-1)} \Longrightarrow y_{n}=y_{1}+2^{-1} \cdot \frac{\left(2^{-1}\right)^{n-1}-1}{2^{-1}-1} \\
\Longrightarrow y_{n}=y_{1}+1-2^{1-n}
\end{gathered}
$$


Como $x_{n}=2^{n-1} \cdot y_{n}$ e $x_{1}=2$, temos que: $x_{1}=y_{1}=2$. Portanto,

$$
y_{n}=y_{1}+1-2^{1-n} \Longrightarrow y_{n}=3-2^{1-n}
$$

Logo, se $x_{n}=2^{n-1} \cdot y_{n}$ então $x_{n}=2^{n-1} \cdot\left[3-2^{1-n}\right]=3 \cdot 2^{n-1}-1$.

A solução de $x_{n+1}=2 x_{n}+1, x_{1}=2$ é $x_{n}=3 \cdot 2^{n-1}-1$.

Exemplo 1.5.2. Resolver a recorrência: $x_{n+1}=3 x_{n}+3^{n}, x_{1}=2$.

Uma solução não-nula de $z_{n+1}=3 z_{n}$ é $a_{n}=3^{n-1}$. Fazendo a substituição $x_{n}=3^{n-1} \cdot y_{n}$, obtemos:

$$
3^{n} y_{n+1}=3^{n} y_{n}+3^{n} \Longrightarrow y_{n+1}=y_{n}+1
$$

Segue que:

$$
\begin{gathered}
y_{2}=y_{1}+1 \\
y_{3}=y_{2}+1 \\
y_{4}=y_{3}+1 \\
\vdots \\
y_{n}=y_{n-1}+1
\end{gathered}
$$

Somando as equações, temos $y_{n}=y_{1}+(n-1)$.

Como $x_{n}=3^{n-1} \cdot y_{n}$ e $x_{1}=2$, temos que: $x_{1}=y_{1}=2$. Portanto,

$$
y_{n}=y_{1}+(n-1) \Longrightarrow y_{n}=n+1 \text {. }
$$

Logo, se $x_{n}=3^{n-1} \cdot y_{n}$ então $x_{n}=3^{n-1} \cdot(n+1)=3^{n-1} \cdot n+3^{n-1}=3^{n-1} \cdot(n+1)$

A solução de $x_{n+1}=3 x_{n}+3^{n}, x_{1}=2$ é $x_{n}=3^{n-1} \cdot(n+1)$.

\subsection{Recorrências Lineares de $1^{\mathrm{a}}$ Ordem com Coeficientes Constantes}

Seja a recorrência $x_{n+1}=g(n) x_{n}+h(n)$. Vejamos uma caracterização das soluções desse tipo de recorrência quando $g(n)$ e $h(n)$ são constantes reais. Temos $x_{n+1}=a x_{n}+b$, com $a, b \in \mathbb{R}$ e $a \neq 0$. Podemos observar os seguintes casos: 
- Se $a=1$ e $b \neq 0$ a sequência é uma PA de razão $b$. E como vimos no Exemplo 1.4.3. o termo geral é dado por $x_{n}=x_{1}+(n-1) \cdot b, \quad \forall n \in \mathbb{N}$.

- Se $a=1$ e $b=0$, a sequência é constante com termo geral dado por $x_{n}=x_{1}, \forall n \in \mathbb{N}$.

- Se $a \neq 1$ e $b=0$ a sequência é uma PG de razão $a$. E como vimos no Exemplo 1.3.2. o termo geral é dado por $x_{n}=x_{1} \cdot a^{n-1}, \quad \forall n \in \mathbb{N}$.

Nessa subsecção, o caso que mais nos interessa caracterizar em termos de $a$ e $b$ é quando $a \neq 1$ e $b \neq 0$.

Exemplo 1.5.3. Resolver a recorrência: $x_{n+1}=2 x_{n}+3, x_{1}=2$.

Solução: Fazendo $x_{n}=y_{n}+k, \quad k \in \mathbb{R}$, obtemos:

$$
y_{n+1}+k=2 \cdot y_{n}+2 k+3 \Longrightarrow y_{n+1}=2 \cdot y_{n}+k+3
$$

Fazendo $k+3=0$ tem-se $k=-3$. Segue que a equação $y_{n+1}=2 \cdot y_{n}$, que caracteriza uma PG de razão 2 , tem como solução, $y_{n}=2^{n-1} \cdot y_{1}$.

Mas como $x_{n}=y_{n}+k, k=-3$ e $x_{1}=2$, então temos:

$$
x_{n}-k=2^{n-1} \cdot\left(x_{1}-k\right) \Longrightarrow x_{n}+3=2^{n-1} \cdot\left(x_{1}+3\right) \Longrightarrow x_{n}=5 \cdot 2^{n-1}-3
$$

Observando os Exemplos 1.5.1 e 1.5.3, onde os coeficientes são constantes, podemos inferir que as recorrências da forma $x_{n+1}=a x_{n}+b$ têm soluções que atendem a um mesmo formato. A seguir vamos generalizar esse caso e obter uma forma para a solução dessas recorrências.

Proposição 1.6.1. Seja a equação $x_{n+1}=a x_{n}+b$ uma recorrência linear de $1^{a}$ ordem não-homogênea, com coeficientes constantes a e $b, a, b \in \mathbb{R}$, onde $a \neq 0, a \neq 1$ e $b \neq 0$. Podemos encontrar, neste caso, a solução da recorrência em função das constantes a e $b$ e do termo $x_{1}$. Além disso, a solução é dada por $x_{n}=\left(x_{1}-\frac{b}{1-a}\right) \cdot a^{n-1}+\frac{b}{1-a}$.

Prova: Fazendo $x_{n}=y_{n}+k, \quad k \in \mathbb{R}$ a equação $x_{n+1}=a \cdot x_{n}+b$ transforma-se em $y_{n+1}+k=a \cdot\left(y_{n}+k\right)+b$. Reagrupando os termos da equação, obtemos:

$$
y_{n+1}+k=a \cdot y_{n}+a k+b \Longrightarrow y_{n+1}=a \cdot y_{n}+(a-1) \cdot k+b \Longrightarrow y_{n+1}=a \cdot y_{n}+(a-1) \cdot\left(k+\frac{b}{a-1}\right)
$$

Queremos, a partir daí, obter o valor de $k$ para que $y_{n+1}=a \cdot y_{n}$. Assim: 


$$
\left(k+\frac{b}{a-1}\right)=0 \Longrightarrow k=\frac{b}{1-a}
$$

A sequência $y_{n+1}=a \cdot y_{n}$ tem como solução $y_{n}=y_{1} \cdot a^{n-1}$. Como $x_{n}=y_{n}+k$, segue que $x_{n}-k=\left(x_{1}-k\right) \cdot a^{n-1}$. Fazendo a substituição $k=\frac{b}{1-a}$, temos: $x_{n}-\frac{b}{1-a}=$ $\left(x_{1}-\frac{b}{1-a}\right) \cdot a^{n-1}$. Consequentemente, chegamos a solução:

$$
x_{n}=\left(x_{1}-\frac{b}{1-a}\right) \cdot a^{n-1}+\frac{b}{1-a} .
$$

Corolário 1.6.1. A solução de uma recorrência linear de $1^{a}$ ordem $\left(x_{n}\right)$ que possui equação na forma $x_{n+1}=a x_{n}+b$, onde $a \neq 1$ e $b \neq 0$ é dada por: $x_{n}=A \cdot a^{n-1}+B$, onde $A$ e $B$ são constantes reais.

Portanto, para encontrar a solução da equação em questão é suficiente saber o valor de dois termos da sequência e substituir seus valores na expressão geral da solução. Com isso, pode se formar um sistema de equações em A e B.

Observação: Vamos utilizar o Corolário 1.6.1 para encontrar a solução do Exemplo 1.5.3.

Se $x_{n+1}=2 x_{n}+3$, com $x_{1}=2$, então $x_{2}=7$. Se a solução é da forma $x_{n}=A \cdot 2^{n-1}+B$, então podemos escrever o sistema de equações:

$$
\left\{\begin{array} { l } 
{ A \cdot 2 ^ { 1 - 1 } + B = x _ { 1 } } \\
{ A \cdot 2 ^ { 2 - 1 } + B = x _ { 2 } }
\end{array} \Longrightarrow \left\{\begin{array}{l}
A+B=2 \\
2 A+B=7
\end{array}\right.\right.
$$

Subtraindo a primeira da segunda equação obtemos: $A=5$ e por conseguinte $B=-3$.

De fato, a solução da recorrência $x_{n+1}=2 x_{n}+3$, com $x_{1}=2$ é $x_{n}=5 \cdot 2^{n-1}-3$. 


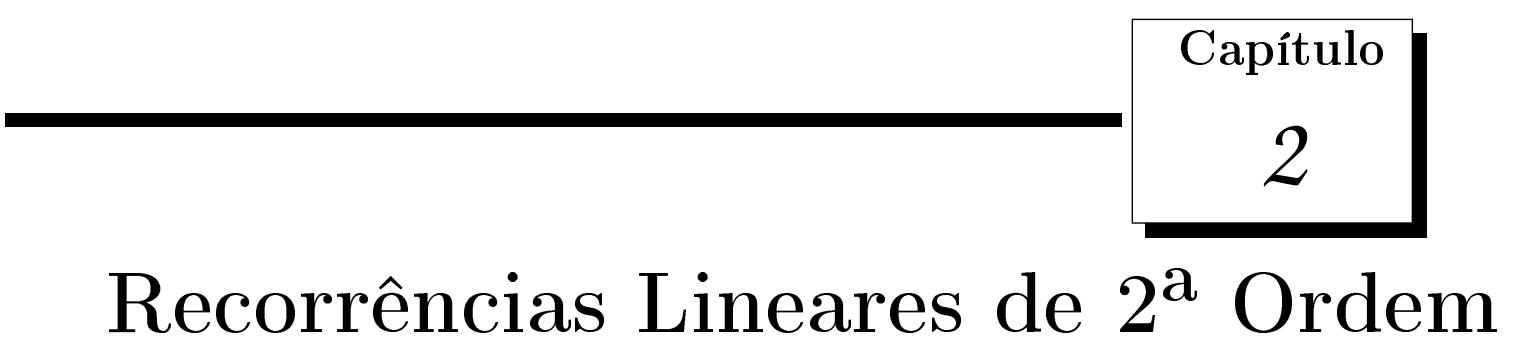

Apresentaremos neste capítulo as caracterizações de recorrências lineares de $2^{\mathrm{a}}$ ordem. Discorreremos sobre a equação característica associada às suas equações. A partir daí, vamos generalizar alguns resultados fundamentais, a fim de facilitar as resoluções desse tipo de sequência. No final do capítulo, usaremos alguns dos resultados obtidos para expandi-los às recorrências lineares de ordens superiores a dois.

Definição 2.0.1. Uma recorrência linear é dita de $2^{a}$ ordem quando cada termo definido pela equação de recorrência depende dos dois termos imediatamente anteriores a ele.

Uma recorrência linear de $2^{\mathrm{a}}$ ordem é dada por:

$$
x_{n+2}=f(n) \cdot x_{n+1}+g(n) \cdot x_{n}+h(n) \text {, }
$$

onde $g(n)$ é uma função não-nula. Se $h(n)=0$ então a recorrência é "homogênea", e se $h(n) \neq 0$ então ela será "não-homogênea".

\subsection{Recorrências Lineares de $2^{\mathrm{a}}$ Ordem Homogêneas de Coeficientes Constantes}

Consideremos a equação de recorrência $x_{n+2}=a \cdot x_{n+1}+b \cdot x_{n}$, onde $a$ e $b$ são constantes reais, com $b \neq 0$. Para cada equação dessa forma vamos associar uma equação do $2^{\circ}$ grau, $x^{2}=a \cdot x+b$, que chamaremos equação característica da recorrência. Denotaremos por $\alpha$ e $\beta$ as raízes da equação característica. Como $b \neq 0$ temos que zero não é raiz da equação característica. Ou seja, se $b \neq 0$ então $\alpha \neq 0$ e $\beta \neq 0$. 
Dada a equação $x^{2}=a \cdot x+b$, temos que se $\alpha$ e $\beta$ são suas raízes, então $a=\alpha+\beta$ e $b=-\alpha \cdot \beta$.

Veremos a seguir, como encontrar a solução de uma recorrência cujos valores iniciais são $x_{0}$ e $x_{1}$ e cuja equação seja da forma:

$$
x_{n+2}=(\alpha+\beta) \cdot x_{n+1}-\alpha \cdot \beta x_{n}
$$

\subsubsection{Caso $\alpha \neq \beta$}

Primeiramente vejamos um exemplo particular de uma recorrência linear de segunda ordem com coeficientes constantes. Depois vamos generalizar o modelo da resolução para quaisquer recorrências com essas características.

Exemplo 2.1.1. Encontrar a solução da recorrência

$$
x_{n}=6 x_{n-1}-8 x_{n-2}, \quad \forall n \geq 2, \operatorname{com} x_{0}=2 \text { e } x_{1}=5
$$

Solução: Primeiramente, observamos que na equação característica $x^{2}=6 x-8$ as raízes são 2 e 4. A partir daí, podemos reescrever a equação de recorrência. E assim,

$$
x_{n}=(2+4) x_{n-1}-(2 \cdot 4) x_{n-2} \Longrightarrow x_{n}-2 x_{n-1}=4\left(x_{n-1}-2 x_{n-2}\right) .
$$

Definindo $y_{n}=\left(x_{n}-2 x_{n-1}\right)$, obtemos:

$$
y_{n}=4 y_{n-1} \Longrightarrow y_{n}=y_{1} \cdot 4^{n-1} \text {. }
$$

Portanto:

$$
x_{n}-2 x_{n-1}=\left(x_{1}-2 x_{0}\right) \cdot 4^{n-1} \Longrightarrow x_{n}-2 x_{n-1}=4^{n-1}
$$

De modo análogo, temos que:

$$
x_{n}=(2+4) x_{n-1}-(2 \cdot 4) x_{n-2} \Longrightarrow x_{n}-4 x_{n-1}=2\left(x_{n-1}-4 x_{n-2}\right) .
$$

Definindo agora $z_{n}=\left(x_{n}-4 x_{n-1}\right)$, obtemos:

$$
z_{n}=2 z_{n-1} \Longrightarrow z_{n}=z_{1} \cdot 2^{n-1} \text {. }
$$

Então:

$$
x_{n}-4 x_{n-1}=\left(x_{1}-4 x_{0}\right) \cdot 2^{n-1} \Longrightarrow x_{n}-4 x_{n-1}=-3 \cdot 2^{n-1}
$$


Multiplicando a equação (1) por 4 e a equação (2) por 2, temos:

$$
\begin{gathered}
\text { (I) } \quad 4 x_{n}-8 x_{n-1}=4^{n} \\
(I I) \quad 2 x_{n}-8 x_{n-1}=-3 \cdot 2^{n}
\end{gathered}
$$

Fazendo $(I)-(I I)$, chegamos à solução da recorrência:

$$
2 x_{n}=4^{n}+3 \cdot 2^{n} \Longrightarrow x_{n}=\frac{4^{n}+3 \cdot 2^{n}}{2}
$$

Podemos generalizar essa resolução. E então teremos uma forma para a solução geral das recorrências lineares de segunda ordem, para o caso em que as raízes da equação característica são distintas.

Considere a equação de recorrência: $x_{n+2}=(\alpha+\beta) x_{n+1}-\alpha \beta x_{n}$, onde $(\alpha+\beta)$ e $(\alpha \beta)$ são coeficientes constantes e $\alpha \neq \beta$. Vamos encontrar uma solução geral para as recorrências dessa forma.

Para isso, primeiramente observemos que:

$$
x_{n+2}=(\alpha+\beta) x_{n+1}-\alpha \beta x_{n} \Longrightarrow x_{n+2}-\alpha x_{n+1}=\beta\left(x_{n+1}-\alpha x_{n}\right)
$$

Se definirmos uma sequência $\left(y_{n}\right)$ tal que $y_{n}=x_{n}-\alpha x_{n-1}$, temos a partir de (1) que: $y_{n+2}=x_{n+2}-\alpha x_{n+1}$ ou $y_{n+2}=\beta y_{n+1}$, que caracteriza uma PG de razão $\beta$ e portanto, tem como uma solução $y_{n}=y_{1} \cdot \beta^{n-1}$. Logo:

$$
y_{n}=y_{1} \cdot \beta^{n-1} \Longrightarrow x_{n}-\alpha x_{n-1}=\left(x_{1}-\alpha x_{0}\right) \beta^{n-1}
$$

De modo análogo temos:

$$
x_{n+2}=(\alpha+\beta) x_{n+1}-\alpha \beta x_{n} \Longrightarrow x_{n+2}-\beta x_{n+1}=\alpha\left(x_{n+1}-\beta x_{n}\right) .
$$

Definindo uma sequência $\left(z_{n}\right)$ tal que $z_{n}=x_{n+1}-\beta x_{n}$, temos que:

$$
z_{n+2}=\alpha z_{n+1} \Longrightarrow z_{n}=z_{1} \cdot \alpha^{n-1} \Longrightarrow x_{n}-\beta x_{n-1}=\left(x_{1}-\beta x_{0}\right) \alpha^{n-1}
$$

Multiplicando a equação (2) por $\beta$ e a equação (3) por $\alpha$ obtemos:

$$
\begin{aligned}
& \text { (I) } \quad \beta x_{n}-\alpha \beta x_{n-1}=\left(x_{1}-\alpha x_{0}\right) \beta^{n} \\
& \text { (II) } \quad \alpha x_{n}-\alpha \beta x_{n-1}=\left(x_{1}-\beta x_{0}\right) \alpha^{n}
\end{aligned}
$$

Fazendo $(I I)-(I)$ :

$$
(\alpha-\beta) x_{n}=\left(x_{1}-\beta x_{0}\right) \alpha^{n}-\left(x_{1}-\alpha x_{0}\right) \beta^{n} \Longrightarrow x_{n}=\frac{\left(x_{1}-\beta x_{0}\right) \alpha^{n}}{(\alpha-\beta)}+\frac{\left(\alpha x_{0}-x_{1}\right) \beta^{n}}{(\alpha-\beta)}
$$


Portanto, a solução da recorrência $x_{n+2}=(\alpha+\beta) x_{n+1}-\alpha \beta x_{n}$, quando $\alpha \neq \beta$, é dada por:

$$
x_{n}=\frac{\left(x_{1}-\beta x_{0}\right) \alpha^{n}}{\alpha-\beta}+\frac{\left(\alpha x_{0}-x_{1}\right) \beta^{n}}{\alpha-\beta} .
$$

Por definição, os termos $\alpha, \beta, x_{0}$ e $x_{1}$ são números reais e $\alpha \neq \beta$. Logo, deduzimos que os termos: $\left(\frac{x_{1}-\beta x_{0}}{\alpha-\beta}\right)$ e $\left(\frac{\alpha x_{0}-x_{1}}{\alpha-\beta}\right)$ também são constantes reais. O Teorema a seguir comprova essa dedução.

Teorema 2.1. Se as raízes da equação característica $x^{2}+p x+q=0$ são $\alpha$ e $\beta$, com $\alpha \neq \beta$, então $x_{n}=A \cdot \alpha^{n}+B \cdot \beta^{n}$ é solução da recorrência $x_{n+2}+p x_{n+1}+q x_{n}=0$, quaisquer que sejam as constantes $A$ e $B$.

Prova: Substituindo $x_{n}=A \cdot \alpha^{n}+B \cdot \beta^{n}$ na recorrência $x_{n+2}+p x_{n+1}+q x_{n}=0$, obtemos: $A \alpha^{n+2}+B \beta^{n+2}+p A \alpha^{n+1}+p B \beta^{n+1}+q A \alpha^{n}+q B \beta^{n}=0$. Agrupando os termos dessa equação temos:

$$
A \alpha^{n} \cdot\left(\alpha^{2}+p \alpha+q\right)+B \beta^{n} \cdot\left(\beta^{2}+p \beta+q\right)=0
$$

Mas, por hipótese $\alpha$ e $\beta$ são raízes de $x^{2}+p x+q=0$, portanto:

$$
A \alpha^{n} \cdot 0+B \beta^{n} \cdot 0=0, \quad \forall A \text { e } B
$$

Podemos, a partir desse último teorema, afirmar que basta conhecer o valor de dois termos de uma recorrência da forma: $x_{n+2}+p x_{n+1}+q x_{n}=0$, onde $\alpha$ e $\beta$ são raízes reais da equação característica, $\operatorname{com} \alpha \neq \beta$, para encontrar a sua solução. Podemos resolver um sistema de equações para encontrar os valores de $A$ e $B$ na solução.

Exemplo 2.1.2. Encontrar a solução da recorrência

$$
x_{n+2}=2 x_{n+1}+3 x_{n}, \quad n \in \mathbb{Z}_{+}, \operatorname{com} x_{0}=2 \text { e } x_{1}=1 .
$$

Solução: Primeiramente, a recorrência equivale a $x_{n+2}-2 x_{n-1}-3 x_{n-2}=0$, cuja equação característica é $x^{2}-2 x-3=0$ e tem como raízes 3 e -1 . A solução da recorrência é da forma $x_{n}=A \alpha^{n}+B \beta^{n}$, onde $\alpha$ e $\beta$ são raízes reais da equação característica. Segue daí que a solução é da forma: $x_{n}=A \cdot 3^{n}+B \cdot(-1)^{n}$.

Como, $x_{0}=2$ e $x_{1}=1$, obtemos o sistema de equações: 


$$
\left\{\begin{array}{l}
2=A+B \\
1=3 A-B
\end{array}\right.
$$

Somando as duas equações temos que: $4 A=3$ e assim: $A=\frac{3}{4}$ e $B=\frac{5}{4}$.

Portanto, a solução da recorrência é $x_{n}=\frac{3^{n+1}+5 \cdot(-1)^{n}}{4}$.

Teorema 2.2. Se as raízes de $x^{2}+p x+q=0$ são $\alpha$ e $\beta$, com $\alpha \neq \beta$, então todas as soluções da recorrência $x_{n+2}+p x_{n+1}+q x_{n}=0$ são da forma $x_{n}=A \alpha^{n}+B \beta^{n}$, onde $A e$ $B$ são constantes.

Prova: Seja $x_{n}$ uma solução qualquer de $x_{n+2}+p x_{n+1}+q x_{n}=0$.

Determinamos as constantes $A$ e $B$, que sejam soluções do sistema:

$$
\left\{\begin{array}{l}
A \alpha+B \beta=x_{1} \\
A \alpha^{2}+B \beta^{2}=x_{2}
\end{array}\right.
$$

Ou seja, $A=\frac{\beta^{2} x_{1}-\beta x_{2}}{\alpha \beta(\beta-\alpha)}$ e $B=\frac{\alpha x_{2}-\alpha^{2} x_{1}}{\alpha \beta(\beta-\alpha)}$.

Sabemos que é possível pois $\alpha \neq \beta, \alpha \neq 0$ e $\beta \neq 0$.

Afirmamos por hipótese que $x_{n}=A \alpha^{n}+B \beta^{n}, \forall n \in \mathbb{N}$. Seja $z_{n}=x_{n}-A \alpha^{n}-B \beta^{n}$, vamos mostrar que $z_{n}=0$, para todo $n \in \mathbb{N}$. Temos:

$$
z_{n+2}+p z_{n+1}+q z_{n}=x_{n+2}+p x_{n+1}+q x_{n}-A \alpha^{n} \cdot\left(\alpha^{2}+p \alpha+q\right)-B \beta^{n} \cdot\left(\beta^{2}+p \beta+q\right)
$$

Se $\alpha$ e $\beta$ são raízes da equação característica $x^{2}+p x+q=0$, então $A \alpha^{n} \cdot\left(\alpha^{2}+p \alpha+q\right)=0$ e $B \beta^{n} \cdot\left(\beta^{2}+p \beta+q\right)=0$. E como, por hipótese, $x_{n}$ é solução de $x_{n+2}+p x_{n+1}+q x_{n}=0$ temos que $z_{n+2}+p z_{n+1}+q z_{n}=0$. Além disso, como: $A \alpha+B \beta=x_{1}$ e $A \alpha^{2}+B \beta^{2}=x_{2}$, temos que $z_{1}=z_{2}=0$.

Mas, se $z_{n+2}+p z_{n+1}+q z_{n}=0$ e $z_{1}=z_{2}=0$, então $z_{n}=0, \forall n \in \mathbb{N}$.

Encontramos um problema a mais se as raízes $\alpha$ e $\beta$ forem complexas. Na solução $x_{n}=A \alpha^{n}+B \beta^{n}$, encontrada nessa secção, as constantes arbitrárias $A$ e $B$ podem ser escritas de maneira que se possa evitar cálculos com números complexos. Veremos a seguir os passos de como proceder nesse caso. 
Um número complexo é da forma $z=a+b i$, com $a, b \in \mathbb{R}$ e onde $i$ é a unidade imaginária, tal que $i^{2}=-1$. Sejam $\alpha$ e $\beta$ raízes complexas da equação característica. Elas são números complexos conjugados. Sendo assim, $\alpha$ é um certo $z_{1}=a+b i$, e $\beta$ seu conjugado, a saber: $z_{2}=a-b i$. De acordo com ([8], p. 154), escrevendo essas raízes na forma trigonométrica, teremos:

$$
\alpha=\rho(\cos \theta+i \operatorname{sen} \theta) \quad \text { e } \beta=\rho(\cos \theta-i \operatorname{sen} \theta) \text {, onde } \rho=\sqrt{a^{2}+b^{2}}
$$

Na forma trigonométrica $\rho$ é o módulo do número complexo e $\theta$ é o argumento tal que $\cos \theta=\frac{a}{\rho}$ e $\operatorname{sen} \theta=\frac{b}{\rho}$.

Ainda segundo ([8], p. 156) a fórmula de De Moivre ${ }^{1}$ representa a potência de um número complexo, da forma como vemos a seguir:

$$
\alpha^{n}=\rho^{n}(\cos (n \theta)+i \operatorname{sen}(n \theta)) \quad \text { e } \quad \beta^{n}=\rho^{n}(\cos (n \theta)-i \operatorname{sen}(n \theta))
$$

Portanto, $x_{n}=A \alpha^{n}+B \beta^{n}=\rho^{n} \cdot[(A+B) \cos (n \theta)+i(A-B) \operatorname{sen}(n \theta)]$.

Fazendo $(A+B)$ e $i(A-B)$ as novas constantes arbitrárias, $A^{\prime}$ e $B^{\prime}$, a solução pode ser escrita da forma:

$$
x_{n}=\rho^{n} \cdot\left[A^{\prime} \cos (n \theta)+B^{\prime} \operatorname{sen}(n \theta)\right]
$$

Exemplo 2.1.3. Encontrar a solução da recorrência $x_{n+2}-2 x_{n+1}+2 x_{n}=0$. Depois encontrar uma solução quando $x_{1}=1$ e $x_{2}=2$ forem os termos iniciais da recorrência.

Solução: A equação característica é $x^{2}-2 x+2=0$ e tem como raízes $1+i$ e $1-i$, que são números complexos de módulo $\rho=\sqrt{2}$ e argumento principal $\theta=\frac{\pi}{4}$. A solução da recorrência é da forma $x_{n}=\rho^{n} \cdot[A \cos (n \theta)+B \operatorname{sen}(n \theta)]$. Segue daí que a solução é a equação:

$$
x_{n}=\sqrt{2^{n}} \cdot\left[A \cos \frac{n \pi}{4}+B \operatorname{sen} \frac{n \pi}{4}\right]
$$

No caso específico em que $x_{1}=1$ e $x_{2}=2$ são os termos iniciais da recorrência, podemos encontrar as constantes $A$ e $B$ através do sistema de equações:

$$
\left\{\begin{array}{l}
x_{1}=\sqrt{2} \cdot\left[A \cos \frac{\pi}{4}+B \operatorname{sen} \frac{\pi}{4}\right]=1 \\
x_{2}=2 \cdot\left[A \cos \frac{\pi}{2}+B \operatorname{sen} \frac{\pi}{2}\right]=2
\end{array}\right.
$$

\footnotetext{
${ }^{1}$ Abraham De Moivre (1667-1754), matemático francês ([3], p. 312).
} 
Resolvendo o sistema, obtemos: $A+B=1$ e $2 B=2$. Assim, $A=0$ e $B=1$.

Portanto, a solução da recorrência $x_{n+2}-2 x_{n+1}+2 x_{n}=0$, com $x_{1}=1$ e $x_{2}=2$ é a equação:

$$
x_{n}=\sqrt{2^{n}} \cdot \operatorname{sen}\left(\frac{n \pi}{4}\right)
$$

\subsubsection{Caso $\alpha=\beta$}

Ainda considerando as recorrências da forma: $x_{n+2}=a \cdot x_{n+1}+b \cdot x_{n}$, onde $a$ e $b$ são constantes reais, podemos nos perguntar:

\section{E quando as raízes da equação característica forem iguais?}

O exemplo a seguir apresenta um caso de raízes iguais. Logo após a resolução, vamos generalizar para quaisquer equações com essa característica.

Exemplo 2.1.4. Encontrar a solução da recorrência

$$
x_{n+2}-6 x_{n+1}+9 x_{n}=0, \quad n \in \mathbb{Z}_{+}, \text {com } x_{0}=1 \text { e } x_{1}=2 .
$$

Solução: Primeiramente, observemos que:

$$
x_{n+2}-6 x_{n+1}+9 x_{n}=0 \Longrightarrow x_{n+2}-3 x_{n+1}=3 \cdot\left(x_{n+1}-3 x_{n}\right) .
$$

Fazendo $y_{n}=x_{n}-3 x_{n-1}$, temos:

$$
y_{n+2}=3 y_{n+1} \Longrightarrow y_{n}=y_{1} \cdot 3^{n-1} \Longrightarrow x_{n}-3 x_{n-1}=\left(x_{1}-3 x_{0}\right) \cdot 3^{n-1} \text {. }
$$

Definindo $x_{n}=3^{n} \cdot z_{n}$ temos:

$$
3^{n} \cdot z_{n}-3^{n} \cdot z_{n-1}=\left(3 z_{1}-3 z_{0}\right) \cdot 3^{n-1} \Longrightarrow z_{n}-z_{n-1}=z_{1}-z_{0}
$$

Visto que $z_{n}$ é uma PA de razão $z_{1}-z_{0}$, segue daí que:

$$
\begin{gathered}
\Longrightarrow z_{n}=z_{0}+n\left(z_{1}-z_{0}\right) \Longrightarrow \frac{x_{n}}{3^{n}}=x_{0}+n\left(\frac{x_{1}}{3}-x_{0}\right) \Longrightarrow x_{n}=x_{0} \cdot 3^{n}+n\left(\frac{x_{1}}{3}-x_{0}\right) \cdot 3^{n} \\
\Longrightarrow x_{n}=3^{n}-n \cdot 3^{n-1} \Longrightarrow x_{n}=3^{n-1} \cdot(3-n)
\end{gathered}
$$

Portanto, a solução da recorrência $x_{n+2}-6 x_{n+1}+9 x_{n}=0$, com $x_{0}=1$ e $x_{1}=2$, é dada por

$$
x_{n}=3^{n-1} \cdot(3-n) .
$$


Vamos generalizar essa resolução para todas as recorrências lineares de segunda ordem, com coeficientes constantes, cuja equação característica possui raízes iguais.

Considere a equação $x_{n+2}=(\alpha+\beta) x_{n+1}-\alpha \cdot \beta x_{n}$, com $\alpha=\beta$. Isso equivale a dizer que a equação característica tem raízes iguais e pode ser escrita como $x_{n+2}=2 \alpha x_{n+1}-\alpha^{2} x_{n}$.

Portanto,

$$
x_{n+2}=2 \alpha x_{n+1}-\alpha^{2} x_{n} \Longrightarrow x_{n+2}-\alpha x_{n+1}=\alpha\left(x_{n+1}-\alpha x_{n}\right)
$$

Definindo $y_{n}=x_{n}-\alpha x_{n-1}$, teremos:

$$
y_{n+2}=\alpha y_{n+1} \Longrightarrow y_{n}=y_{1} \cdot \alpha^{n-1} \Longrightarrow x_{n}-\alpha x_{n-1}=\left(x_{1}-\alpha x_{0}\right) \cdot \alpha^{n-1}
$$

Definindo outra sequência $\left(z_{n}\right)$ de modo que $x_{n}=\alpha^{n} \cdot z_{n}$, obtemos da última equação:

$$
\alpha^{n} \cdot z_{n}-\alpha^{n} \cdot z_{n-1}=\left(\alpha z_{1}-\alpha z_{0}\right) \cdot \alpha^{n-1} \Longrightarrow z_{n}-z_{n-1}=z_{1}-z_{0}
$$

Mas, $z_{n}-z_{n-1}=z_{1}-z_{0}$ caracteriza uma PA de razão $z_{1}-z_{0}$. Daí, $z_{n}=z_{0}+n \cdot\left(z_{1}-z_{0}\right)$. E portanto,

$$
z_{n}=z_{0}+n \cdot\left(z_{1}-z_{0}\right) \Longrightarrow \frac{x_{n}}{\alpha^{n}}=x_{0}+n \cdot\left(\frac{x_{1}}{\alpha}-x_{0}\right) \Longrightarrow x_{n}=x_{0} \alpha^{n}+n \cdot\left(\frac{x_{1}}{\alpha}-x_{0}\right) \alpha^{n} .
$$

Com o resultado que obtivemos para o caso $\alpha=\beta$, podemos generalizar as soluções das recorrências $x_{n+2}-(\alpha+\beta) x_{n+1}+\alpha \cdot \beta x_{n}=0$. As soluções nesse caso são da forma $x_{n}=A \cdot \alpha^{n}+n \cdot B \cdot \alpha^{n}$.

Teorema 2.3. Se as raizes de $x^{2}+p x+q=0$ são iguais, tais que $\alpha=\beta=r$, então $a_{n}=A \cdot r^{n}+n \cdot B \cdot r^{n}$ é solução da recorrência $x_{n+2}+p x_{n+1}+q x_{n}=0$, quaisquer que sejam os valores das constantes $A$ e $B$.

Prova: Se as raízes são iguais então $r=-\frac{p}{2}$. Substituindo $a_{n}=A \cdot r^{n}+n \cdot B \cdot r^{n}$ na recorrência $x_{n+2}+p x_{n+1}+q x_{n}=0$, obtemos:

$A \cdot r^{n+2}+(n+2) \cdot B \cdot r^{n+2}+p \cdot\left(A \cdot r^{n+1}+(n+1) \cdot B \cdot r^{n+1}\right)+q \cdot\left(A \cdot r^{n}+n \cdot B \cdot r^{n}\right)=0$

Agrupando os termos temos que:

$A \cdot r^{n} \cdot\left(r^{2}+p r+q\right)+B \cdot n \cdot r^{n} \cdot\left(r^{2}+p r+q\right)+B \cdot r^{n+1} \cdot(2 r+p)=A \cdot r^{n} \cdot 0+B \cdot n \cdot r^{n} \cdot 0+B \cdot r^{n+1} \cdot 0=0$ 
Teorema 2.4. Se as raizes de $x^{2}+p x+q=0$ são iguais, $\alpha=\beta=r$, então todas as soluções da recorrência $x_{n+2}+p x_{n+1}+q x_{n}=0$ são da forma $a_{n}=A \cdot r^{n}+B \cdot n \cdot r^{n}$, com A e B constantes.

Prova: Seja $y_{n}$ uma solução qualquer de $x_{n+2}+p x_{n+1}+q x_{n}=0$. Daí $A$ e $B$ são as soluções do sistema de equações:

$$
\left\{\begin{array}{l}
A \cdot r+B \cdot r=y_{1} \\
A \cdot r^{2}+2 B \cdot r^{2}=y_{2}
\end{array}\right.
$$

Ou seja, $A=2 \cdot \frac{y_{1}}{r}-\frac{y_{2}}{r^{2}}$ e $B=\frac{y_{2}-r \cdot y_{1}}{r^{2}}$. Isso é possível pois $r \neq 0$.

Afirmamos que $y_{n}=A \cdot r^{n}+n \cdot B \cdot r^{n}$, para todo $n \in \mathbb{N}$, o que provará o teorema. De fato, seja $z_{n}=y_{n}-A \cdot r^{n}-n \cdot B \cdot r^{n}$. Mostraremos que $z_{n}=0$, para todo $n \in \mathbb{N}$. Temos:

$$
\begin{gathered}
z_{n+2}+p z_{n+1}+q z_{n}= \\
\left(y_{n+2}+p y_{n+1}+q y_{n}\right)-A \cdot r^{n}\left(r^{2}+p r+q\right)-n \cdot B \cdot r^{n}\left(r^{2}+p r+q\right)-B \cdot r^{n+1} \cdot(2 r+p) .
\end{gathered}
$$

Nessa soma, temos que $\left(y_{n+2}+p y_{n+1}+q y_{n}\right)=0$, pois $y_{n}$ é solução da recorrência em questão; como $r$ é raiz da equação $x^{2}+p x+q=0$ a segunda e terceira parcela se igualam a zero; e $B \cdot r^{n+1} \cdot(2 r+p)$ também é igual a zero, pois $2 r+p=0$, já que $\alpha=\beta=r$ e $\operatorname{assim} r=-\frac{p}{2}$. Então, $z_{n+2}+p z_{n+1}+q z_{n}=0$.

Além disso, como $A \cdot r+B \cdot r=y_{1}$ e $A \cdot r^{2}+2 B \cdot r^{2}=y_{2}$, temos $z_{1}=z_{2}=0$. Mas, se $z_{n+2}+p z_{n+1}+q z_{n}=0$, então $z_{n}=0$, para todo $n \in \mathbb{N}$.

Exemplo 2.1.5. A recorrência $x_{n+2}-8 x_{n+1}+16 x_{n}=0, n \in \mathbb{Z}_{+}$, tem a equação $x^{2}-8 x+16=0$ como equação característica. As raízes são $\alpha=\beta=4$, portanto todas as soluções da recorrência são da forma $x_{n}=A \cdot 4^{n}+B \cdot n \cdot 4^{n}$.

Observemos um caso particular da recorrência $x_{n+2}-8 x_{n+1}+16 x_{n}=0$, quando $x_{0}=1$ e $x_{1}=2$.

Como todas as soluções da recorrência são da forma $x_{n}=A \cdot 4^{n}+B \cdot n \cdot 4^{n}$ podemos escrever o sistema de equações que resulta na sequência lógica:

$$
\left\{\begin{array} { l } 
{ A \cdot 4 ^ { 0 } + B \cdot 0 \cdot 4 ^ { 0 } = 1 } \\
{ A \cdot 4 ^ { 1 } + B \cdot 1 \cdot 4 ^ { 1 } = 2 }
\end{array} \Longrightarrow \left\{\begin{array} { l } 
{ A = 1 } \\
{ 4 A + 4 B = 2 }
\end{array} \Longrightarrow \left\{\begin{array}{l}
A=1 \\
B=-\frac{1}{2}
\end{array}\right.\right.\right.
$$


Substituímos os valores das constantes $A$ e $B$ e obtemos:

$$
x_{n}=4^{n}-\frac{n \cdot 4^{n}}{2} \Longrightarrow x_{n}=4^{n} \cdot\left(\frac{2-n}{2}\right)
$$

Descrevendo os primeiros termos dessa recorrência, temos

$$
\left(x_{n}\right)=(1,2,0,-32,-256,-1536,-8192, \ldots) .
$$

\subsection{Recorrências da Forma: $x_{n+2}+p x_{n+1}+q x_{n}=f(n)$}

Nessa secção vamos sistematizar as soluções das recorrências lineares não-homogêneas de segunda ordem, onde os coeficientes da parte homogênea são constantes. Essas recorrências são da forma: $x_{n+2}+p x_{n+1}+q x_{n}=f(n)$, com $p, q \in \mathbb{R}, q \neq 0$ e $f(n)$ uma função não-nula.

A seguir enunciaremos um teorema encontrado em ([14], p. 79) e ([16] p. 87-88) que mostra um processo para resolver equações dessa forma.

Teorema 2.5. Se $a_{n}$ é uma solução da recorrência $x_{n+2}+p x_{n+1}+q x_{n}=f(n)$, então a substituição $x_{n}=a_{n}+y_{n}$ transforma a recorrência em $y_{n+2}+p y_{n+1}+q y_{n}=0$.

Prova: Substituindo $x_{n}$ por $a_{n}+y_{n}$ na recorrência em questão, temos:

$$
\left(a_{n+2}+p a_{n+1}+q a_{n}\right)+\left(y_{n+2}+p y_{n+1}+q y_{n}\right)=f(n)
$$

Por hipótese, $a_{n}$ é uma solução de $x_{n+2}+p x_{n+1}+q x_{n}=f(n)$, isso implica na igualdade: $a_{n+2}+p a_{n+1}+q a_{n}=f(n)$. Logo, a equação $(I)$ equivale a $y_{n+2}+p y_{n+1}+q y_{n}=0$.

Por este teorema, a solução de uma recorrência não-homogênea é uma soma de duas parcelas. Vimos na secção anterior como determinar a solução de uma equação homogênea. A solução da equação não-homogênea será determinada por meio de tentativas.

Vejamos alguns exemplos de recorrências da forma $x_{n+2}+p x_{n+1}+q x_{n}=f(n)$, nos quais observaremos diversas situações que enfrentamos ao tentarmos solucionar uma recorrência não-homogênea.

Exemplo 2.2.1. Resolver a equação de recorrência: $x_{n+2}-5 x_{n+1}-6 x_{n}=n+3^{n}$.

Solução: A solução da recorrência é da forma $x_{n}=a_{n}+z_{n}$. 
A equação característica da recorrência homogênea é $x^{2}-5 x-6=0$ cujas raízes são $\alpha=-1$ e $\beta=6$. Segue que a solução da parte homogênea é $a_{n}=A \cdot(-1)^{n}+B \cdot 6^{n}$.

Devemos agora determinar uma solução particular para uma função $\left(z_{n}\right)$ na recorrência $x_{n+2}-5 x_{n+1}-6 x_{n}=n+3^{n}$, para que quando substituirmos $z_{n}$ em $x_{n+2}-5 x_{n+1}-6 x_{n}$ obtenhamos $n+3^{n}$. O problema é definir que tipo de função é $z_{n}$. Observando a recorrência $n+3^{n}$ podemos supor intuitivamente que $z_{n}$ é a soma de um polinômio de $1^{\circ}$ grau com uma exponencial de base 3. Daí, $z_{n}=C n+D+E \cdot 3^{n}$.

Substituímos $z_{n}$ em $x_{n+2}-5 x_{n+1}-6 x_{n}=n+3^{n}$ e obtemos:

$$
\begin{gathered}
C(n+2)+D+E \cdot 3^{n+2}-5 \cdot\left(C(n+1)+D+E \cdot 3^{n+1}\right)-6 \cdot\left(C n+D+E \cdot 3^{n}\right)=n+3^{n} \\
\Longrightarrow-10 C n-3 C-10 D-12 E \cdot 3^{n}=n+3^{n}
\end{gathered}
$$

Com isso, temos que: $-10 C=1,-3 C-10 D=0$ e $-12 E=1$, ou seja:

$$
C=-\frac{1}{10}, D=\frac{3}{100} \text { e } E=-\frac{1}{12} \text {. }
$$

Portanto, a solução da recorrência dada é $x_{n}=A \cdot(-1)^{n}+B \cdot 6^{n}-\frac{n}{10}+\frac{3}{100}-\frac{3^{n}}{12}$.

É importante lembrar que se forem determinados dois termos da sequência, como por exemplo, $x_{0}$ e $x_{1}$ que iniciam a sequência, podemos calcular as constantes $A$ e $B$. E depois disso, descrever todos os termos da recorrência com a solução encontrada.

Por exemplo, na recorrência $x_{n}=A \cdot(-1)^{n}+B \cdot 6^{n}-\frac{n}{10}+\frac{3}{100}-\frac{3^{n}}{12}$, quando $x_{0}=1$ e $x_{1}=1$, podemos escrever o sistema de equações:

$$
\left\{\begin{array} { l } 
{ A \cdot ( - 1 ) ^ { 0 } + B \cdot 6 ^ { 0 } - \frac { 0 } { 1 0 } + \frac { 3 } { 1 0 0 } - \frac { 3 ^ { 0 } } { 1 2 } = 1 } \\
{ A \cdot ( - 1 ) ^ { 1 } + B \cdot 6 ^ { 1 } - \frac { 1 } { 1 0 } + \frac { 3 } { 1 0 0 } - \frac { 3 ^ { 1 } } { 1 2 } = 1 }
\end{array} \Longrightarrow \left\{\begin{array}{l}
A+B=\frac{632}{600} \\
-A+6 B=\frac{792}{600}
\end{array}\right.\right.
$$

Somando as equações, chegamos às igualdades: $B=\frac{1424}{4200}=\frac{178}{525}$ e $A=\frac{3000}{4200}=\frac{5}{7}$.

Portanto, a solução da recorrência é:

$$
x_{n}=\frac{5}{7} \cdot(-1)^{n}+\frac{178}{525} \cdot 6^{n}-\frac{n}{10}+\frac{3}{100}-\frac{3^{n}}{12} .
$$


Exemplo 2.2.2. Resolver a equação de recorrência: $x_{n+2}-5 x_{n+1}+6 x_{n}=n+3^{n}$.

Solução: A solução da recorrência é da forma $x_{n}=a_{n}+z_{n}$.

A equação característica da recorrência homogênea é $x^{2}-5 x+6=0$ cujas raízes são $\alpha=2$ e $\beta=3$. Segue que a solução da parte homogênea é $a_{n}=A \cdot 2^{n}+B \cdot 3^{n}$.

Devemos agora determinar uma solução particular para $z_{n}$ na recorrência em questão, para que quando substituirmos $z_{n}$ em $x_{n+2}-5 x_{n+1}+6 x_{n}$ obtenhamos $n+3^{n}$. Precisamos definir que tipo de função é $z_{n}$. Vamos supor, assim como no exemplo anterior, que $z_{n}$ é da forma $z_{n}=C n+D+E \cdot 3^{n}$. Mas, substituindo $z_{n}$ em $x_{n+2}-5 x_{n+1}+6 x_{n}$ temos:

$C(n+2)+D+E \cdot 3^{n+2}-5 \cdot\left(C(n+1)+D+E \cdot 3^{n+1}\right)+6 \cdot\left(C n+D+E \cdot 3^{n}\right)=n+3^{n}$

$$
\Longrightarrow 2 C n-3 C+2 D=n+3^{n}
$$

Essa é uma igualdade impossível. Pois a solução encontrada independe de $E$, e assim $z_{n}$ não é da forma $z_{n}=C n+D+E \cdot 3^{n}$. A solução suposta não tem como dar certo, pois queremos obter constantes $C$ e $D$, tais que $C n+D=n$ e um termo $E \cdot 3^{n}$, para igualar a $3^{n}$. Mas, $E \cdot 3^{n}$ é uma solução da homogênea, com $A=0$ e $B=E$, substituindoa na equação encontramos um termo nulo e não uma exponencial que se possa igualar a $3^{n}$.

Para solucionar esse impasse, ([14], p. 81) afirma que sempre quando algum bloco não atender as expectativas, seja feita uma correção "aumentando o grau", isto é, multiplicando o bloco por $n$. Fazendo isso, tentemos portanto uma solução da forma $z_{n}=C n+D+E \cdot n \cdot 3^{n}$.

Substituindo novamente obtemos: $2 C n-3 C+2 D+3 E \cdot 3^{n}=n+3^{n}$.

Com isso, temos que: $2 C=1,-3 C+2 D=0$ e $3 E=1$, ou seja,

$$
C=\frac{1}{2}, D=\frac{3}{4} \text { e } E=\frac{1}{3} \text {. }
$$

Portanto, a solução da recorrência dada é

$$
x_{n}=A \cdot 2^{n}+B \cdot 3^{n}+\frac{n}{2}+\frac{3}{4}+\frac{n \cdot 3^{n}}{3} .
$$

Essa equação nos apresenta uma classe com infinitas recorrências. Vejamos um caso particular dessa recorrência quando tivermos $x_{0}=1$ e $x_{1}=1$, sendo esses os dois valores iniciais. Para calcular as constantes $A$ e $B$, escrevemos o sistema de equações: 


$$
\left\{\begin{array} { l } 
{ A \cdot 2 ^ { 0 } + B \cdot 3 ^ { 0 } + \frac { 0 } { 2 } + \frac { 3 } { 4 } + \frac { 0 \cdot 3 ^ { 0 } } { 3 } = 1 } \\
{ A \cdot 2 ^ { 1 } + B \cdot 3 ^ { 1 } + \frac { 1 } { 2 } + \frac { 3 } { 4 } + \frac { 1 \cdot 3 ^ { 1 } } { 3 } = 1 }
\end{array} \Longrightarrow \left\{\begin{array}{l}
A+B=\frac{1}{4} \\
2 A+3 B=-\frac{5}{4}
\end{array}\right.\right.
$$

Resolvendo o sistema, chegamos às igualdades: $A=2$ e $B=-\frac{7}{4}$. E portanto, a solução da recorrência nesse caso é:

$$
x_{n}=2 \cdot 2^{n}-\frac{7}{4} \cdot 3^{n}+\frac{n}{2}+\frac{3}{4}+\frac{n \cdot 3^{n}}{3} .
$$

Exemplo 2.2.3. Apresentar uma equação para o termo geral da sequência definida por $x_{n+2}=2 x_{n}+5$, com $x_{0}=3$ e $x_{1}=7$. Através da solução encontrada apresentar o valor de $x_{20}$.

Solução: A equação característica da parte homogênea é $x^{2}-2=0$.

As raízes dessa equação são $\alpha=\sqrt{2}$ e $\beta=-\sqrt{2}$. Segue que a solução da parte homogênea é $a_{n}=A \cdot \sqrt{2^{n}}+B \cdot(-1)^{n} \cdot \sqrt{2^{n}}$.

Determinemos uma solução particular $z_{n}$ da equação $x_{n+2}-2 x_{n}=5$. Observando a equação é fácil ver que $z_{n}$ é um polinômio constante. Tentemos $z_{n}=C$ e fazendo a substituição na equação $x_{n+2}-2 x_{n}=5$, obtemos: $C=-5$.

Já que a solução da recorrência $x_{n}$ é a soma $a_{n}+z_{n}$, vemos que a solução procurada é

$$
x_{n}=A \cdot \sqrt{2^{n}}+B \cdot(-1)^{n} \cdot \sqrt{2^{n}}-5 .
$$

Atribuindo os valores dados: $x_{0}=3$ e $x_{1}=7$. Vamos calcular as constantes $A$ e $B$ :

$$
\begin{aligned}
& x_{0}=A+B-5=3 \Longrightarrow A+B=8 \\
& x_{1}=A \sqrt{2}-B \sqrt{2}-5=7 \Longrightarrow A-B=6 \sqrt{2} .
\end{aligned}
$$

Resolvendo o sistema de equações:

$$
\left\{\begin{array}{l}
A+B=8 \\
A-B=6 \sqrt{2}
\end{array}\right.
$$

Encontramos as constantes $A=4+3 \sqrt{2}$ e $B=4-3 \sqrt{2}$. Logo, a solução é:

$$
x_{n}=(4+3 \sqrt{2}) \cdot \sqrt{2^{n}}+(4-3 \sqrt{2}) \cdot(-1)^{n} \cdot \sqrt{2^{n}}-5 .
$$


Para encontrarmos o valor de $x_{20}$, calculemos:

$$
\begin{aligned}
& x_{20}=(4+3 \sqrt{2}) \cdot \sqrt{2^{20}}+(4-3 \sqrt{2}) \cdot(-1)^{20} \cdot \sqrt{2^{20}}-5 \\
& \Longrightarrow x_{20}=(4+3 \sqrt{2}) \cdot 2^{10}+(4-3 \sqrt{2}) \cdot(-1)^{20} \cdot 2^{10}-5 \\
& \Longrightarrow x_{20}=4 \cdot 2^{10}+3 \sqrt{2} \cdot 2^{10}+4 \cdot 2^{10}-3 \sqrt{2} \cdot 2^{10}-5 \\
& \Longrightarrow x_{20}=8 \cdot 2^{10}-5=8 \cdot 1024-5=8187 .
\end{aligned}
$$

Portanto, $x_{20}=8187$.

\subsection{Recorrências Lineares de Ordem k}

Os resultados que encontramos nas primeiras secções desse capítulo podem ser generalizados para recorrências lineares de qualquer ordem.

Podemos expandir o conceito de equação característica. De modo geral, para cada recorrência linear de ordem $k$ de equação $x_{n+k}+q_{1} \cdot x_{n+k-1}+\ldots+q_{k-1} \cdot x_{n+1}+q_{k} \cdot x_{n}=0$, com $q_{k} \neq 0$ tem-se o polinômio característico $x^{k}+q_{1} \cdot x^{k-1}+\ldots+q_{k-1} \cdot x+q_{k}$ e a equação $x^{k}+q_{1} \cdot x^{k-1}+\ldots+q_{k-1} \cdot x+q_{k}=0$ é denominada equação característica.

Definição 2.3.1. Uma recorrência linear é dita de "ordem k" quando cada termo da sequência recorrente é obtido a partir dos $k$ termos imediatamente anteriores a ele. Tal recorrência tem como equação uma da forma:

$$
x_{n+k}=g_{1}(n) x_{n+k-1}+g_{2}(n) x_{n+k-2}+g_{3}(n) x_{n+k-3}+\cdots+g_{k}(n) x_{n}+f(n) \text {, }
$$

onde $g_{k}(n)$ é uma função não nula.

Como já vimos, se $f(n)=0$ a recorrência é dita homogênea, caso contrário será nãohomogênea.

Quando as funções $g_{i}(n)$, com $1 \leq i \leq k$, são constantes e $f(n)=0$, a recorrência pode ser escrita da forma:

$$
x_{n+k}=q_{1} x_{n+k-1}+q_{2} x_{n+k-2}+q_{3} x_{n+k-3}+\cdots+q_{k} x_{n} .
$$


Fazendo as mudanças adequadas de seus coeficientes, essa equação pode-se ser reescrita da forma: $x_{n+k}+q_{1} x_{n+k-1}+\cdots+q_{k-1} x_{n+1}+q_{k} x_{n}=0$, com $q_{k} \neq 0$. E, conforme vimos na secção 2.1, associada a ela a equação característica $x^{k}+q_{1} x^{k-1}+\cdots+q_{k-1} x+q_{k}=0$.

Neste capítulo vimos que a solução de uma recorrência linear homogênea de segunda ordem tem como solução: $x_{n}=A \cdot \alpha^{n}+B \cdot \beta^{n}$, onde $\alpha$ e $\beta$ são raízes de sua equação característica. A seguir, expandiremos esse conceito para as recorrências lineares homogêneas de qualquer ordem.

Teorema 2.6. Se $\alpha_{1}, \alpha_{2}, \alpha_{3}, \ldots, \alpha_{k-1}, \alpha_{k}$ são raízes da equação característica

$$
x^{k}+q_{1} x^{k-1}+\cdots+q_{k-1} x+q_{k}=0 \text {, ent } \tilde{a} o x_{n}=C_{1} \alpha_{1}^{n}+C_{2} \alpha_{2}^{n}+C_{3} \alpha_{3}^{n}+\cdots+C_{k} \alpha_{k}^{n}
$$

é solução da recorrência para quaisquer valores de $C_{i}, i \in \mathbb{N} e 1 \leq i \leq k$.

Prova: Substituindo $x_{n}=C_{1} \alpha_{1}^{n}+C_{2} \alpha_{2}^{n}+C_{3} \alpha_{3}^{n}+\cdots+C_{k} \alpha_{k}^{n}$ na equação de recorrência $x_{n+k}+q_{1} x_{n+k-1}+\cdots+q_{k-1} x_{n+1}+q_{k} x_{n}=0$ e agrupando convenientemente os termos, obtemos:

$$
\begin{gathered}
C_{1} \alpha_{1}^{n-k}\left(\alpha_{1}^{k}+q_{1} \alpha_{1}^{k-1}+q_{2} \alpha_{1}^{k-2}+\cdots+q_{k}\right)+C_{2} \alpha_{2}^{n-k}\left(\alpha_{2}^{k}+q_{1} \alpha_{2}^{k-1}+q_{2} \alpha_{2}^{k-2}+\cdots+q_{k}\right)+ \\
\cdots+C_{k} \alpha_{k}^{n-k}\left(\alpha_{k}^{k}+q_{1} \alpha_{k}^{k-1}+q_{2} \alpha_{k}^{k-2}+\cdots+q_{k}\right)=0
\end{gathered}
$$

Mas, $\alpha_{1}, \alpha_{2}, \alpha_{3}, \ldots, \alpha_{k-1}, \alpha_{k}$ são raízes da equação $x^{k}+q_{1} x^{k-1}+\cdots+q_{k-1} x+q_{k}=0$, isso implica que:

$$
C_{1} \alpha_{1}^{n-k} \cdot 0+C_{2} \alpha_{2}^{n-k} \cdot 0+\cdots+C_{k} \alpha_{k}^{n-k} \cdot 0=0
$$

Teorema 2.7. Se $\alpha_{1}, \alpha_{2}, \alpha_{3}, \ldots, \alpha_{k-1}, \alpha_{k}$ são raízes distintas e não nulas da equação característica $x^{k}+q_{1} x^{k-1}+\cdots+q_{k-1} x+q_{k}=0$, então todas as soluções da recorrência $x_{n+k}+q_{1} x_{n+k-1}+\cdots+q_{k-1} x_{n+1}+q_{k} x_{n}=0$ são da forma:

$$
x_{n}=C_{1} \alpha_{1}^{n}+C_{2} \alpha_{2}^{n}+C_{3} \alpha_{3}^{n}+\cdots+C_{k} \alpha_{k}^{n} \text {, com } C_{i} \text { constantes, } i \in \mathbb{N} e 1 \leq i \leq k .
$$

Prova: Seja $a_{n}$ uma solução qualquer da recorrência:

$$
x_{n+k}+q_{1} x_{n+k-1}+q_{2} x_{n+k-2} \cdots+q_{k-1} x_{n+1}+q_{k} x_{n}=0 .
$$


Pelo Teorema 2.6 podemos formar um sistema de equações:

$$
\left\{\begin{array}{l}
a_{1}=C_{1} \alpha_{1}+C_{2} \alpha_{2}+C_{3} \alpha_{3}+\cdots+C_{k} \alpha_{k} \\
a_{2}=C_{1} \alpha_{1}^{2}+C_{2} \alpha_{2}^{2}+C_{3} \alpha_{3}^{2}+\cdots+C_{k} \alpha_{k}^{2} \\
a_{3}=C_{1} \alpha_{1}^{3}+C_{2} \alpha_{2}^{3}+C_{3} \alpha_{3}^{3}+\cdots+C_{k} \alpha_{k}^{3} \\
\vdots \\
a_{k}=C_{1} \alpha_{1}^{k}+C_{2} \alpha_{2}^{k}+C_{3} \alpha_{3}^{k}+\cdots+C_{k} \alpha_{k}^{k}
\end{array}\right.
$$

Esse sistema tem solução. Como vemos em ([20], p. 263), se as raízes $\alpha_{1}, \alpha_{2}, \alpha_{3}, \ldots, \alpha_{k}$ são distintas e não-nulas, então o determinante $V$, representado abaixo, é não-nulo. Ainda de acordo com [20], o chamado determinante de Vandermonde ${ }^{2}$ tem seu valor dado por:

$$
V=\left|\begin{array}{ccccc}
\alpha_{1} & \alpha_{2} & \alpha_{3} & \cdots & \alpha_{k} \\
\alpha_{1}^{2} & \alpha_{2}^{2} & \alpha_{3}^{2} & \cdots & \alpha_{k}^{2} \\
\alpha_{1}^{3} & \alpha_{2}^{3} & \alpha_{3}^{3} & \cdots & \alpha_{k}^{3} \\
\vdots & \vdots & \vdots & \ddots & \vdots \\
\alpha_{1}^{k} & \alpha_{2}^{k} & \alpha_{3}^{k} & \cdots & \alpha_{k}^{k}
\end{array}\right|=\prod_{1 \leq i<j \leq k}\left(\alpha_{j}-\alpha_{i}\right)
$$

Seja $z_{n}=a_{n}-C_{1} \alpha_{1}^{n}-C_{2} \alpha_{2}^{n}-C_{3} \alpha_{3}^{n}-\cdots-C_{k} \alpha_{k}^{n}$. Vamos provar que $z_{n}=0$, para todo $n$, o que provará o teorema.

Substituindo $z_{n}$ na equação $x_{n+k}+q_{1} x_{n+k-1}+\cdots+q_{k-1} x_{n+1}+q_{k} x_{n}=0$, temos que:

$$
\begin{gathered}
z_{n+k}+q_{1} z_{n+k-1}+\cdots+q_{k-1} z_{n+1}+q_{k} z_{n}= \\
\left(a_{n+k}+q_{1} a_{n+k-1}+q_{2} a_{n+k-2} \cdots+q_{k-1} a_{n+1}+q_{k} a_{n}\right) \\
-C_{1} \alpha_{1}^{n-k}\left(\alpha_{1}^{k}+q_{1} \alpha_{1}^{k-1}+q_{2} \alpha_{1}^{k-2}+\cdots+q_{k}\right)-C_{2} \alpha_{2}^{n-k}\left(\alpha_{2}^{k}+q_{1} \alpha_{2}^{k-1}+q_{2} \alpha_{2}^{k-2}+\cdots+q_{k}\right) \\
-\cdots-C_{k} \alpha_{k}^{n-k}\left(\alpha_{k}^{k}+q_{1} \alpha_{k}^{k-1}+q_{2} \alpha_{k}^{k-2}+\cdots+q_{k}\right)=0 .
\end{gathered}
$$

O primeiro parêntese é igual a zero visto que $a_{n}$ é solução de

$$
x_{n+k}+q_{1} x_{n+k-1}+\cdots+q_{k-1} x_{n+1}+q_{k} x_{n}=0
$$

e os demais parênteses são iguais a zero porque $\alpha_{1}, \alpha_{2}, \alpha_{3}, \ldots, \alpha_{k-1}, \alpha_{k}$ são raízes da equação $x^{k}+q_{1} x^{k-1}+\cdots+q_{k-1} x+q_{k}=0$.

Como $C_{1} \alpha_{1}+C_{2} \alpha_{2}+C_{3} \alpha_{3}+\cdots+C_{k} \alpha_{k}=a_{1}$ e $C_{1} \alpha_{1}^{2}+C_{2} \alpha_{2}^{2}+C_{3} \alpha_{3}^{2}+\cdots+C_{k} \alpha_{k}^{2}=a_{2}$, temos que $z_{1}=z_{2}=0$. Portanto,

se $z_{n+k}+q_{1} z_{n+k-1}+\cdots+q_{k-1} z_{n+1}+q_{k} z_{n}=0$ e $z_{1}=z_{2}=0$, então $z_{n}=0$ para todo $n$.

\footnotetext{
${ }^{2}$ Em homenagem a Alexandre-Theóphile Vandermonde (1735-1796), matemático francês.
} 
A complexidade da solução de uma recorrência da forma:

$$
x_{n+k}+q_{1} x_{n+k-1}+\cdots+q_{k-1} x_{n+1}+q_{k} x_{n}=0, \operatorname{com} q_{k} \neq 0
$$

aumenta conforme for maior também a complexidade da solução da equação característica:

$$
x^{k}+q_{1} x^{k-1}+\cdots+q_{k-1} x+q_{k}=0 .
$$

Exemplo 2.3.1. Resolver a equação de recorrência: $x_{n+3}=3 x_{n+2}+x_{n+1}-3 x_{n}, n \geq 0$. Depois, de posse da solução geral, vamos encontrar a equação dessa recorrência no caso em que $x_{0}=0, x_{1}=1$ e $x_{2}=2$.

Solução: A recorrência pode ser reescrita como $x_{n+3}-3 x_{n+2}-x_{n+1}+3 x_{n}=0 \mathrm{e}$ associamos a ela a equação característica $x^{3}-3 x^{2}-x+3=0$. Reagrupando os termos convenientemente obtemos $(x-3)(x+1)(x-1)=0$. Resolvendo a equação característica chegamos às raízes $\alpha_{1}=3, \alpha_{2}=-1$ e $\alpha_{3}=1$.

Aplicando o Teorema 2.7 as soluções da recorrência $x_{n+3}-3 x_{n+2}-x_{n+1}+3 x_{n}=0$ são da forma $x_{n}=A \alpha_{1}^{n}+B \alpha_{2}^{n}+C \alpha_{3}^{n}$. Daí, substituindo as raízes encontradas, obtemos:

$$
x_{n}=A \cdot 3^{n}+B \cdot(-1)^{n}+C \text {, onde } A, B \text { e } C \text { são constantes arbitrárias. }
$$

Agora vamos encontrar a solução particular no caso em que $x_{0}=0, x_{1}=1$ e $x_{2}=2$ são os termos iniciais dessa recorrência. Podemos escrever o sistema:

$$
\left\{\begin{array}{l}
A+B+C=0 \\
3 A-B+C=1 \\
9 A+B+C=2
\end{array}\right.
$$

Resolvendo esse sistema obtemos $A=\frac{1}{4}, B=-\frac{1}{4}$ e $C=0$. Consequentemente a solução da recorrência nesse caso será:

$$
x_{n}=\frac{1}{4} \cdot 3^{n}+\left(-\frac{1}{4}\right) \cdot(-1)^{n} \Longrightarrow x_{n}=\frac{3^{n}+(-1)^{n+1}}{4} .
$$

Descrevendo os primeiros termos da recorrência, temos $\left(x_{n}\right)=(0,1,2,7,20,61,182, \ldots)$.

Em caso de multiplicidade de raízes, expandimos o conceito que verificamos na subsecção 2.1.2 e aplicamos o que [14] nos sugere: multiplicar um dos termos com raízes múltiplas por $n$. Vejamos um exemplo no qual poderemos aplicar essa técnica. 
Exemplo 2.3.2. Resolver a equação de recorrência: $x_{n+3}=2 x_{n+2}+4 x_{n+1}-8 x_{n}$, $n \geq 0$, onde $x_{0}=0, x_{1}=1$ e $x_{2}=2$.

Solução: A recorrência pode ser reescrita como $x_{n+3}-2 x_{n+2}-4 x_{n+1}+8 x_{n}=0$ e associamos a ela a equação característica $x^{3}-2 x^{2}-4 x+8=0$. Reagrupando os termos convenientemente obtemos $(x-2)(x-2)(x+2)=0$. Assim chegamos às raízes $\alpha_{1}=\alpha_{2}=2$ e $\alpha_{3}=-2$.

Aplicando o Teorema 2.7 as soluções da recorrência $x_{n+3}-2 x_{n+2}-4 x_{n+1}+8 x_{n}=0$ são da forma $x_{n}=A \alpha_{1}^{n}+B \alpha_{2}^{n}+C \alpha_{3}^{n}$. Mas, ao montarmos o sistema com os valores iniciais teríamos um problema no qual o sistema não teria solução única. Nesse caso, usaremos a técnica sugerida por [14] de multiplicarmos por $n$ uma das parcelas da solução com a mesma raiz. Nesse exemplo, como $\alpha_{1}=\alpha_{2}=\gamma$ a solução será da forma: $x_{n}=A \gamma^{n}+n \cdot B \gamma^{n}+C \alpha_{3}^{n}$. Substituindo as raízes encontradas, obtemos:

$$
x_{n}=A \cdot 2^{n}+n \cdot B \cdot 2^{n}+C \cdot(-2)^{n}, \text { ou ainda: } x_{n}=2^{n} \cdot\left[A+n \cdot B+C \cdot(-1)^{n}\right]
$$

onde $A, B$ e $C$ são constantes arbitrárias.

Agora vamos encontrar a solução particular no caso em que $x_{0}=0, x_{1}=1$ e $x_{2}=2$ são os termos iniciais dessa recorrência. Podemos escrever o sistema:

$$
\left\{\begin{array}{l}
A+C=0 \\
2 A+2 B-2 C=1 \\
4 A+8 B+4 C=2
\end{array}\right.
$$

Resolvendo esse sistema obtemos $A=\frac{1}{8}, B=\frac{1}{4}$ e $C=-\frac{1}{8}$. Consequentemente a solução da recorrência nesse caso será:

$$
\begin{gathered}
x_{n}=\frac{1}{8} \cdot 2^{n}+\frac{1}{4} \cdot n \cdot 2^{n}-\frac{1}{8} \cdot(-2)^{n} \quad \Longrightarrow \quad x_{n}=2^{n}\left(\frac{1}{8}+\frac{n}{4}+\frac{(-1)^{n+1}}{8}\right) \\
x_{n}=2^{n}\left(\frac{2 n+1+(-1)^{n+1}}{8}\right) \Longrightarrow x_{n}=2^{n-3}\left(2 n+1+(-1)^{n+1}\right)
\end{gathered}
$$

Descrevendo numericamente essa recorrência, temos

$$
\left(x_{n}\right)=(0,1,2,8,16,48,96,256,512, \ldots) .
$$




\section{Capítulo 3 \\ Exemplos Clássicos de Recorrências}

Neste capítulo veremos alguns dos exemplos de recorrências mais comuns. Analisaremos seus aspectos e procuraremos encontrar soluções para diversos problemas relacionados a esses exemplos, usando os conceitos sobre recorrência que foram apresentados nos primeiros capítulos. Porém, antes de discorrer sobre tais exemplos, apresentaremos o Princípio da Indução Finita, que nos ajudará a ratificar algumas soluções encontradas.

\subsubsection{Princípio da Indução Finita}

O Princípio da Indução Finita é um recurso matemático para verificar a validade de um resultado, cuja equação está em função de $n, n \in \mathbb{N}$. Ao discorrer sobre esse princípio, ([13], p. 37) afirma que ela é base de um eficiente método de demonstração de proposições referentes a números naturais.

O Princípio da Indução Finita está associado à ideia de recorrência. Na referência [11] vemos o comentário de que a ideia é análoga ao que conhecemos por "efeito dominô". Essa analogia é comentada da seguinte maneira:

\footnotetext{
"Imaginemos uma fileira de peças de dominó, onde a quantidade de peças é razoavelmente grande. A disposição é tal que se a primeira peça tomba, ela derruba a próxima peça e, o fato de uma peça tombar, faz com que a peça da frente também tombe. Assim, é fácil concluir que todas as peças desta fileira de dominós tombarão." ([11], 2008, p. 81)
}

Sobre o Princípio da Indução Finita, ([13], p. 37) o descreve como o "axioma da indução". A seguir descreveremos o Princípio da Indução conforme está definido na referência ([13], p. 37). 
Definição 3.0.2. Seja $P(n)$ uma função proposicional relativa a número natural $n$. Suponhamos que:

i) $P(1)$ é válida;

ii) Para todo $n \in \mathbb{N}$, a validade de $P(n)$ implica a validade de $P(n+1)$.

Então, $P(n)$ é válida para todo $n \in \mathbb{N}$.

De fato, se chamarmos de $X$ o conjunto dos números naturais $n$ para os quais $P(n)$ é válida, veremos que $1 \in X$ em virtude de i) e que em virtude de ii) se $n \in X$, então $(n+1) \in X$. Logo, pelo axioma da indução, concluímos que $X=\mathbb{N}$.

\subsection{A Torre de Hanói}

De acordo com [18] a Torre de Hanói é um jogo inventado por Édouard Lucas ${ }^{1}$ em 1882. O cenário do jogo consiste em três eixos verticais como ilustrado na Figura 1; e discos de diâmetros diferentes, alocados inicialmente em um dos eixos em ordem crescente de tamanho, de cima para baixo. As regras incluem que apenas um disco seja movido em cada passo e que em qualquer situação os discos com diâmetros menores "sempre" estejam sobre os de diâmetros maiores. O objetivo do jogo é mover a pilha de discos do eixo inicial para outro, usando para isso o menor número de movimentos possível. Ao fim dos movimentos a pilha deve estar em outro eixo, na mesma ordem crescente de tamanho da configuração inicial.

As figuras a seguir nos ajudam a entender a posição inicial e a movimentação dos discos no jogo. O exemplo representado na Figura 1 corresponde ao modelo da disposição inicial de uma pilha com três discos.

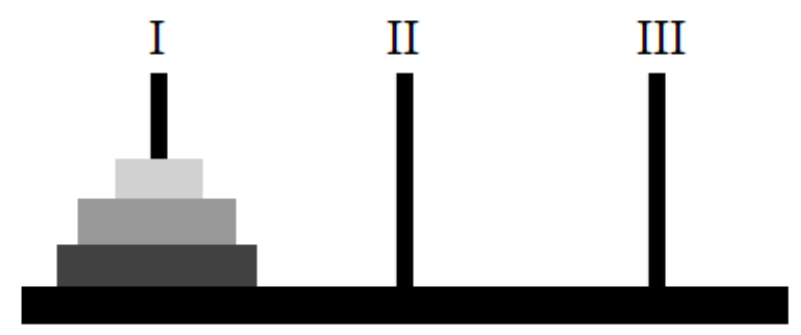

Figura 3.1.1. Torre de Hanói

Na Figura 2 ilustraremos o modo com são realizados os movimentos do jogo. Nesse caso específico, para transportarmos uma pilha de três discos para outro eixo são necessários, no mínimo, sete movimentos.

\footnotetext{
${ }^{1}$ François Édouard Anatole Lucas (1842-1891), matemático francês.
} 

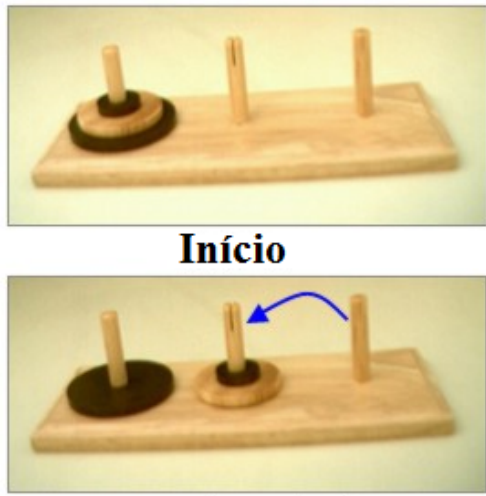

Movimento 3

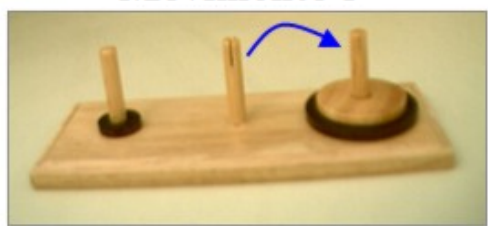

Movimento 6

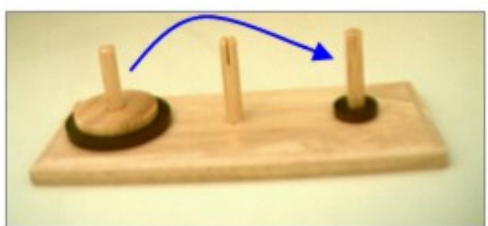

Movimento 1

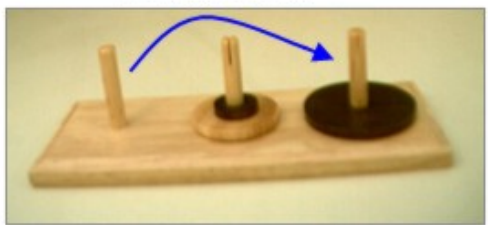

Movimento 4

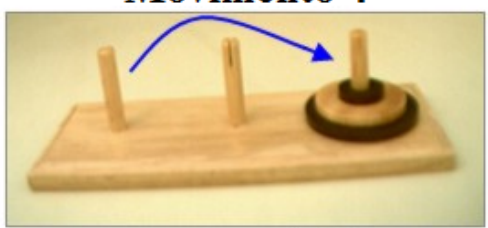

Movimento 7

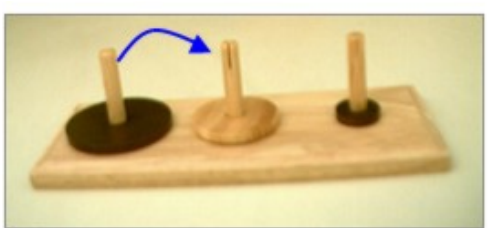

Movimento 2

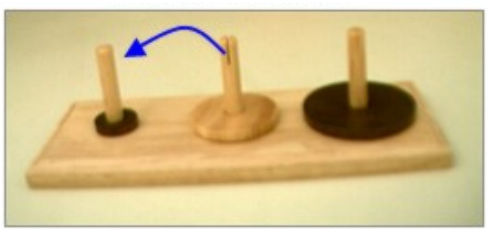

Movimento 5

Figura 3.1.2. Movimentos na Torre de Hanói

O jogo "A Torre de Hanói" pode ser usado por professores que desejam melhorar e desenvolver o pensamento cognitivo de seus alunos, na procura de padrões matemáticos e soluções generalizadas. Pode ser aplicado em pequenos grupos ou individualmente, para proporcionar a observação de algoritmos matemáticos e em que se fundamentam suas fórmulas. É um jogo simples, de fácil entendimento, e pode ser aplicado em diferentes níveis de ensino e faixas etárias.

Diante da problemática desse jogo, e em face do presente estudo de recorrências é imediato fazermos o seguinte questionamento:

Qual é o número mínimo de movimentos para se transportar $n$ discos de um eixo para outro na Torre de Hanói?

Solução: Consideremos os eixos I, II e III e que no jogo se mova a pilha de discos de I para III. Primeiramente, observemos que para $n=1$ o número de movimentos é 1 . De fato, para mover um disco do eixo I para o eixo III basta apenas um único movimento. Para $n=2$, temos que mover o disco menor para o eixo auxiliar central, mover o disco maior para o eixo III e finalmente mover o disco menor para sobre o disco maior, totalizando "três" movimentos.

Seja, portanto, $x_{n}$ o número de movimentos para mudar uma torre de $n$ discos do eixo I para o eixo III. É possível expressar $x_{n}$ em função de $x_{n-1}$. Se temos $n$ discos no eixo I, sabemos que precisamos mover $n-1$ discos para o eixo central usando $x_{n-1}$ movimentos. 
Depois, movemos o disco maior para o eixo III e logo após, procedemos a movimentação dos $n-1$ discos do eixo central para seu destino final usando novamente os $x_{n-1}$ movimentos para isso necessário. Portanto, movemos os $n$ discos usando $2 \cdot x_{n-1}+1$ movimentos. Assim, chegamos à equação $x_{n}=2 x_{n-1}+1$, onde $x_{n}$ é o número de movimentos necessários para mover os $n$ discos da Torre de Hanói.

Resolvendo a equação da recorrência $x_{n}=2 x_{n-1}+1$, com $x_{1}=1$. Conforme vimos no primeiro capítulo, a solução da recorrência é da forma $x_{n}=\alpha 2^{n-1}+\beta$, com $\alpha$ e $\beta$ constantes. Como $x_{1}=1$ e $x_{2}=3$, temos que $\alpha+\beta=1$ e $2 \alpha+\beta=3$, assim $\alpha=2$ e $\beta=-1$. Logo, $x_{n}=2^{n}-1$.

Portanto, para mover $n$ discos da Torre de Hanói de um eixo para outro são necessários $2^{n}-1$ movimentos.

Já provamos, no primeiro capítulo, a veracidade da solução da recorrência $x_{n}=2 x_{n-1}+1$ dada que é $x_{n}=2^{n}-1$. Mas, vamos supor que de posse apenas da solução, o estudioso da Torre de Hanói queira determinar que o número mínimo para o movimento de $n$ discos seja realmente $2^{n}-1$. Assim, ele pode evocar o Princípio da Indução Finita para provar que a proposição é verdadeira.

Proposição 3.1.1. O número de movimentos necessários para se mover $n$ discos na Torre de Hanói é $2^{n}-1$. Daí, $P(n)=2^{n}-1$.

Prova: Vamos demonstrar a afirmação por indução em $n$. Primeiro, vemos se é verdade para $n=1$. De fato, $P(1)=2^{1}-1=1$, e haja visto que para movimentar um disco é necessário um único movimento. Temos que $P(1)$ é verdadeiro.

Agora, supomos por hipótese que $P(n)$ seja válida até um certo $n$ natural. Queremos agora provar que $P(n)$ implica $P(n+1)$. Para que sejam movimentados $n+1$ discos do eixo I ao III é necessário mover $n$ discos para o eixo central usando, pela hipótese de indução: $2^{n}-1$ movimentos, a seguir o disco de maior diâmetro é movimentado para o eixo III em um movimento e logo após, faz-se a movimentação dos $n$ discos do eixo central para o eixo III, usando-se, novamente pela hipótese de indução: $2^{n}-1$ movimentos. Assim, para mover $n+1$ discos na Torre de Hanói são necessários: $\left(2^{n}-1\right)+1+\left(2^{n}-1\right)=2 \cdot 2^{n}-1=2^{n+1}-1$. Portanto, $P(n+1)=2^{n+1}-1$. E se, $P(n)$ implica $P(n+1)$, então a proposição $P(n)=2^{n}-1$ é verdadeira para todo $n \in \mathbb{N}$. 


\subsection{Combinações de Elementos Geométricos}

Podemos observar exemplos de recorrências em problemas da Geometria. Nesse capítulo, no qual descrevemos alguns exemplos gerais de aplicação da ideia das recorrências em diversos temas matemáticos, vamos discorrer sobre dois problemas relativos à Geometria.

Exemplo 3.2.1. Divisão do Plano por $n$ Retas: Qual o maior número de partes em que um plano pode ser dividido por $n$ retas?

Solução: Primeiramente, observemos que o maior número de partes é obtida quando os pontos de intersecção entre as retas são todos distintos. Seja $x_{n}$ o número de partes em que o plano é dividido por $n$ retas concorrentes quando os pontos de concorrência são distintos. A primeira situação é que para $n=1$ temos $x_{1}=2$, pois uma reta divide um plano em duas regiões, uma de cada lado da reta. A partir daí, para atender as condições requeridas e obtermos o maior número de novas regiões possíveis, cada reta acrescentada deve intersectar todas as retas já existentes. A figura a seguir ilustra os primeiros estágios dessa divisão recorrente.

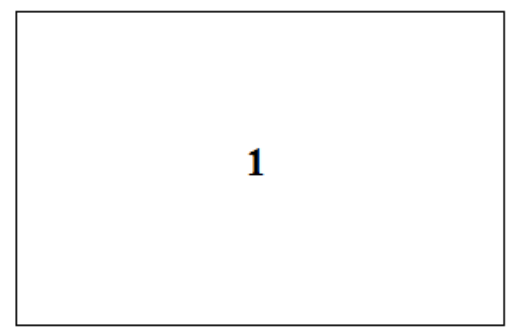

0 retas -1 região

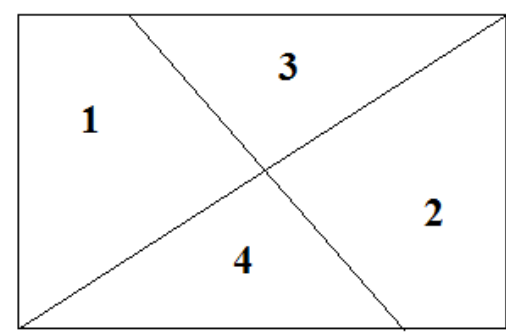

2 retas -4 regiões

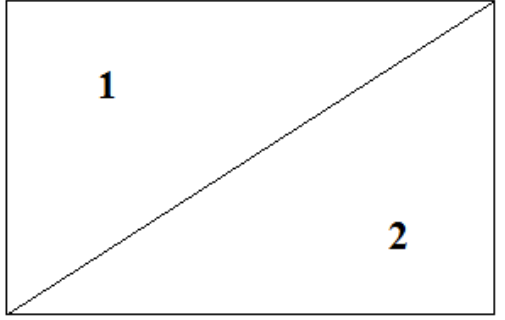

1 reta -2 regiões

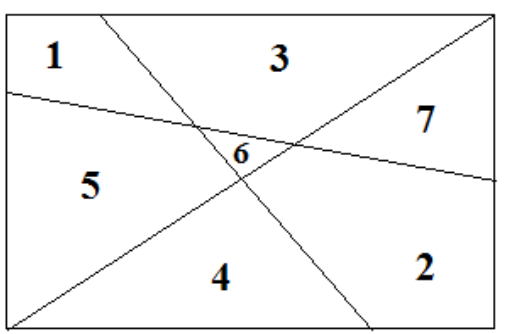

4 retas -7 regiões

Figura 3.2.1. Divisão do Plano em Retas

Suponhamos que $n-1$ retas concorrentes entre si estão presentes no plano, dividindo-o em $x_{n-1}$ partes. Acrescentando uma reta $t$ que intersecte todas as $n-1$ já existentes, os $n-1$ pontos de intersecção determinarão $n$ intervalos na reta. Cada intervalo corresponde a exatamente uma região que ela atravessa dentre as $x_{n-1}$ já existentes. Assim, esses intervalos extinguem a região por onde passam, dividindo-a em duas novas regiões. 
Portanto, a reta $t$ elimina $n$ regiões ao mesmo tempo em que gera mais $2 n$ regiões. Com isso, obtemos a equação de recorrência: $x_{n}=x_{n-1}-n+2 n$, que equivale a equação $x_{n}=x_{n-1}+n$.

Resolvendo a equação $x_{n}=x_{n-1}+n, \operatorname{com} x_{1}=2$ e $x_{0}=1$ :

$$
\begin{gathered}
x_{1}=1+1 \\
x_{2}=x_{1}+2 \\
x_{3}=x_{2}+3 \\
x_{4}=x_{3}+4 \\
\vdots \\
x_{n}=x_{n-1}+n
\end{gathered}
$$

Somando as equações e simplificando adequadamente, obtemos:

$$
x_{n}=1+\sum_{i=1}^{n} i \Longrightarrow x_{n}=1+\frac{n(n+1)}{2}
$$

Portanto, $n$ retas podem dividir o plano em no máximo: $x_{n}=1+\frac{n(n+1)}{2}$ regiões.

Proposição 3.2.1. O maior número de regiões em que o plano fica dividido por $n$ retas é dado por $1+\frac{n(n+1)}{2}$.

Prova: Vamos demonstrar a proposição $P(n)=1+\frac{n(n+1)}{2}$ por indução em $n$.

Primeiro, verificamos a validade para o caso base da indução $n=1$. De fato, $P(1)$ é verdadeira. Pois $P(1)=1+\frac{1(1+1)}{2}=2$, haja visto que "uma" reta divide o plano em "duas" regiões.

Agora, supomos por hipótese que $P(n)$ seja válida até um certo $n$ natural. Queremos agora provar que $P(n)$ implica $P(n+1)$. Supondo que já existam $n$ retas no plano, ao acrescentarmos uma reta nova, que intersecte as outras em $n$ pontos, essa reta ficará dividida em $n+1$ intervalos. Cada um desses intervalos passa por $n+1$ regiões, anteriormente determinadas, eliminando-as e dividindo-as em duas. Essa nova reta acrescenta $n+1$ regiões às já existentes, que por hipótese são $1+\frac{n(n+1)}{2}$. Portanto,

$$
P(n+1)=1+\frac{n(n+1)}{2}+(n+1)=1+\frac{n(n+1)}{2}+\frac{2(n+1)}{2}=1+\frac{(n+1)(n+2)}{2} .
$$

E se, $P(n)$ implica $P(n+1)$, então a proposição $P(n)=1+\frac{n(n+1)}{2}$ é verdadeira para todo $n \in \mathbb{N}$. 
Exemplo 3.2.2. Divisão do Plano por $n$ Círculos: Qual o maior número de regiões em que o plano pode ser dividido por $n$ círculos?

A figura seguinte ilustra os primeiros estágios da divisão do plano em círculos.

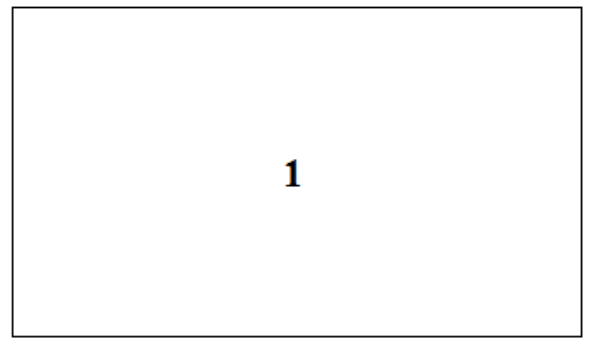

0 círculos - 1 região

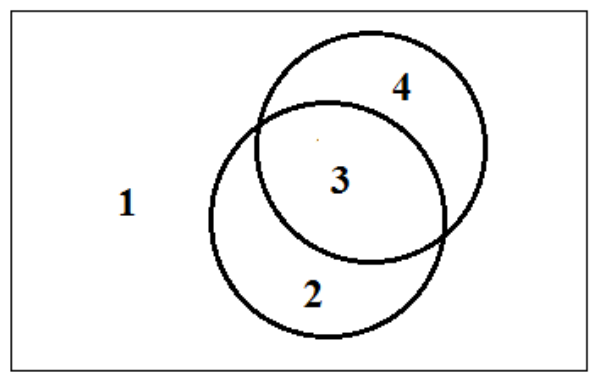

2 círculos - 4 regiões

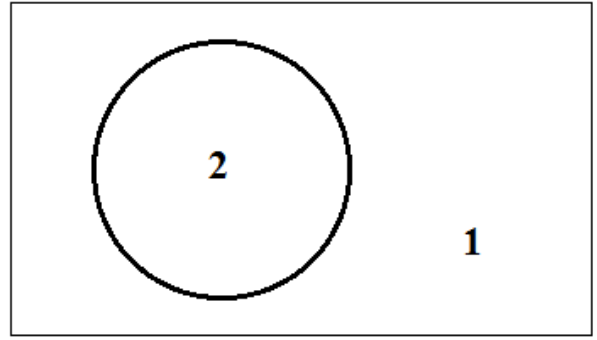

1 círculo - 2 regiões

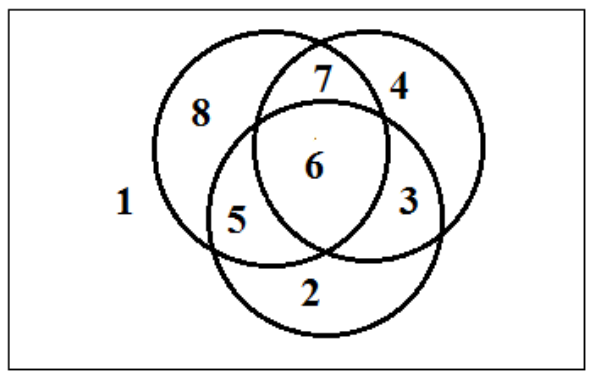

3 círculos -8 regiões

Figura 3.2.2. Divisão do Plano em Círculos

Solução: Seja $n$ o número de círculos no plano e $x_{n}$ o número máximo de regiões em que o plano é dividido por eles. Observemos que $x_{1}=2$, pois um círculo divide o plano em duas regiões, uma exterior e outra interior a ele. A partir daí, cada círculo que se acrescenta pode ser dividido em no máximo $2 n$ arcos pelos $n$ arcos já existentes. Cada um destes arcos subdivide em duas partes uma região existente, determinando assim $2 n$ regiões. Assim, a equação recursiva no número máximo de regiões determinadas por $n$ círculos é dada por $x_{n+1}=x_{n}+2 n$.

Resolvendo a recorrência:

$$
\begin{gathered}
x_{1}=2 \\
x_{2}=x_{1}+2 \\
x_{3}=x_{2}+4 \\
x_{4}=x_{3}+6 \\
\vdots \\
x_{n}=x_{n-1}+2(n-1)
\end{gathered}
$$

Somando-se as equações e fazendo as simplificações adequadas, obtemos:

$$
x_{n}=2+(2+4+6+\ldots+2(n-1)) .
$$


A soma $(2+4+6+\ldots+2(n-1))$ é a soma dos $(n-1)$ primeiros termos da PA cujo primeiro termo e razão são iguais a 2 . Usando a fórmula: $S_{n}=\frac{\left(x_{1}+x_{n}\right) \cdot n}{2}$, obtemos:

$$
S=\frac{(2+2(n-1)) \cdot(n-1)}{2} \Longrightarrow S=\frac{2 n \cdot(n-1)}{2} \Longrightarrow S=n^{2}-n
$$

Segue que a solução da recorrência é $x_{n}=n^{2}-n+2$.

Portanto, o número máximo de regiões que $n$ círculos divide o plano é $n^{2}-n+2$.

\subsection{Combinatória}

\subsubsection{Permutações Simples}

Denominaremos o termo "permutação simples" como o arranjo de $n$ elementos distintos em $n$ posições. Assim, formulamos a questão:

De quantos modos $n$ elementos distintos podem ocupar $n$ posições?

Solução: Podemos representar por $x_{n}$ o número de permutações com $n$ elementos distintos e por $x_{n-1}$ o número de permutações de $n-1$ elementos distintos. Fazendo todas as permutações de $n-1$ elementos distintos, podemos posicionar um novo elemento em $n$ lugares diferentes. A saber: antes de cada um dos $n-1$ elementos, que implica em $n-1$ posições ou no fim da lista anterior desses $n-1$ elementos. Segue que o número de permutações de $n$ elementos distintos pode ser expressado pela equação de recorrência: $x_{n}=n \cdot x_{n-1}$. Resolvendo a equação:

$$
\begin{gathered}
x_{2}=2 x_{1} \\
x_{3}=3 x_{2} \\
x_{4}=4 x_{3} \\
\vdots \\
x_{n}=n x_{n-1}
\end{gathered}
$$

Multiplicando telescopicamente as equações e fazendo as devidas adequações, temos a solução:

$$
x_{n}=2 \cdot 3 \cdot 4 \cdot \ldots \cdot n \Longrightarrow x_{n}=n !
$$

Portanto, $n$ elementos distintos podem ocupar $n$ posições de $n$ ! modos diferentes. 


\subsubsection{Permutações Caóticas}

Suponhamos agora que queiramos reposicionar $n$ elementos distintos em $n$ posições, porém que nenhum dos elementos ocupe a sua posição original.

Definição 3.3.1. "Permutação caótica" ou "desarranjo" é a permutação dos elementos $a_{1}, a_{2}, a_{3}, \ldots, a_{n}$ em $n$ posições em que nenhum elemento $a_{i}, i \in 1,2,3, \ldots, n$ ocupa sua posição original, ou seja, a i-ésima posição.

Seja $x_{n}$ o número de permutações caóticas. Quando $n=1$, temos somente um elemento e não existe modo de "desarranjá-lo", portanto $x_{1}=0$. Quando $n=2$, podemos desarranjar os elementos $a_{1}$ e $a_{2}$ apenas de um modo: $a_{2} a_{1}$. Assim, $x_{2}=1$. Quando $n=3$, podemos permutar os elementos $a_{1}, a_{2}$ e $a_{3}$ de $3 !=6$ maneiras: $a_{1} a_{2} a_{3}, a_{1} a_{3} a_{2}, a_{2} a_{1} a_{3}$, $a_{2} a_{3} a_{1}, a_{3} a_{1} a_{2}$ e $a_{3} a_{2} a_{1}$ das quais apenas $a_{2} a_{3} a_{1}$ e $a_{3} a_{1} a_{2}$ são desarranjos. Portanto, $x_{3}=2$. Prosseguindo com a análise de casos particulares, podemos verificar que $x_{4}=9$ e $x_{5}=44$. À partir daí, as possibilidades se tornam muito numerosas, de tal forma que precisamos deduzir matematicamente a lei de formação de $x_{n}$.

A seguir, reproduziremos como relatado em [10] e [17], o modo como Leonard Euler ${ }^{2}$ raciocinou a dedução do valor de $x_{n}$. Seja $a_{1}, a_{2}, a_{3}, a_{4}, a_{5}, \ldots$ um arranjo inicial de $n$ elementos. Rearranjando-os de modo que nenhum retorne à sua posição original, existem $n-1$ opções para a primeira posição, já que nela não pode estar o $a_{1}$. Suponha que o primeiro elemento seja $a_{2}$. Assim, $x_{n}$ será dado pelo produto do número de variações das demais letras por $n-1$, já que existem $n-1$ opções para o $a_{1}$. Sendo $a_{2}$ a primeiro elemento de um "desarranjo", temos duas possibilidades:

1. O segundo elemento é $a_{1}$. Nesse caso, precisamos rearranjar os $n-2$ elementos restantes de modo que nenhum volte à sua posição de origem. Ora, esse é o mesmo problema do qual partimos, reduzido de dois elementos, havendo portanto, $x_{n-2}$ formas de fazê-lo.

2. O segundo elemento não é $a_{1}$. O problema agora é rearranjar os $n-1$ elementos restantes que ficarão à direita de $a_{2}$, isso pode ser feito de $x_{n-1}$ maneiras.

Como os rearranjos das duas alternativas pertencem a conjuntos disjuntos, temos que, quando $a_{2}$ é o primeiro elemento, existem $x_{n-1}+x_{n-2}$ desarranjos possíveis. Como há $n-1$ opções para o primeiro elemento, temos:

$$
x_{n}=(n-1)\left(x_{n-1}+x_{n-2}\right)
$$

\footnotetext{
${ }^{2}$ Leonard Euler (1707-1783), matemático alemão
} 
Obtivemos uma equação de recorrência que resolve o problema. Porém, precisamos resolver a equação de modo a fornecer $x_{n}$ em função de $n$ unicamente.

Fazendo $n=3$ em $x_{n}$, temos:

$$
x_{3}=2\left(x_{2}+x_{1}\right) \Longrightarrow x_{3}=2 x_{2}+2 x_{1}
$$

Podemos reescrever a expressão de modo a obter:

$$
x_{3}=\left(-x_{2}+3 x_{2}\right)+2 x_{1} \Longrightarrow x_{3}-3 x_{2}=-x_{2}+2 x_{1} \Longrightarrow x_{3}-3 x_{2}=-\left(x_{2}-2 x_{1}\right)
$$

Analogamente, para $n=4$ e $n=5$, temos:

$$
\begin{aligned}
& x_{4}-4 x_{3}=-\left(x_{3}-3 x_{2}\right) \\
& x_{5}-5 x_{4}=-\left(x_{4}-4 x_{3}\right)
\end{aligned}
$$

Logo, temos para todo $n \geq 3, n \in \mathbb{N}$ :

$$
\begin{gathered}
x_{3}-3 x_{2}=-\left(x_{2}-2 x_{1}\right) \\
x_{4}-4 x_{3}=-\left(x_{3}-3 x_{2}\right) \\
x_{5}-5 x_{4}=-\left(x_{4}-4 x_{3}\right) \\
\vdots \\
x_{n}-n x_{n-1}=-\left(x_{n-1}-(n-1) x_{n-2}\right)
\end{gathered}
$$

Multiplicando essas $n-2$ igualdade, obtemos:

$$
\begin{gathered}
\left(x_{3}-3 x_{2}\right)\left(x_{4}-4 x_{3}\right)\left(x_{5}-5 x_{4}\right) \cdots\left(x_{n}-n x_{n-1}\right)= \\
(-1)^{n-2}\left(x_{2}-2 x_{1}\right)\left(x_{3}-3 x_{2}\right)\left(x_{4}-4 x_{3}\right) \cdots\left(x_{n-1}-(n-1) x_{n-2}\right) \\
\Longrightarrow x_{n}-n x_{n-1}=(-1)^{n-2}\left(x_{2}-2 x_{1}\right)
\end{gathered}
$$

Como $(-1)^{n-2}=(-1)^{n}, \forall n \in \mathbb{Z}$ e $x_{2}-2 x_{1}=1-2 \cdot 0=1$, podemos escrever a equação de recorrência:

$$
x_{n}-n x_{n-1}=(-1)^{n} \Longrightarrow x_{n}=n x_{n-1}+(-1)^{n}, \quad \forall n \geq 3
$$

Notemos que $x_{n}=n x_{n-1}+(-1)^{n}$ é verdadeira para $n=2$. De fato, vimos como caso particular que $x_{2}=1$ e por outro lado $x_{2}=2 x_{1}+(-1)^{2}=2 \cdot 0+1=1$. Observemos ainda, que o mesmo não ocorre para $n=1$, pois para $x_{1}=0$, teríamos:

$$
x_{1}=1 \cdot x_{0}+(-1)^{1}=1 \cdot 0-1=-1 \neq 0 \text { que é um absurdo. }
$$


Da igualdade $x_{n}=n x_{n-1}+(-1)^{n}, \quad \forall n \geq 2$, podemos obter:

$$
\begin{aligned}
& x_{2}=2 x_{1}+1=2 \cdot 0+1=1 \\
& x_{3}=3 x_{2}-1=3 \cdot 1-1 \\
& x_{4}=4 x_{3}+1=4(3 \cdot 1-1)+1=4 \cdot 3-4+1 \\
& x_{5}=5 x_{4}-1=5(4 \cdot 3-4+1)-1=5 \cdot 4 \cdot 3-5 \cdot 4+5-1 \\
& x_{6}=6 x_{5}+1=6(5 \cdot 4 \cdot 3-5 \cdot 4+5-1)+1=6 \cdot 5 \cdot 4 \cdot 3-6 \cdot 5 \cdot 4+6 \cdot 5-6+1
\end{aligned}
$$

Observemos que:

$$
\begin{aligned}
& 1=2 !\left(\frac{1}{2 !}\right) \\
& 3 \cdot 1-1=3 !\left(\frac{1}{2 !}-\frac{1}{3 !}\right) \\
& 4 \cdot 3-4+1=4 !\left(\frac{1}{2 !}-\frac{1}{3 !}+\frac{1}{4 !}\right) \\
& 5 \cdot 4 \cdot 3-5 \cdot 4+5-1=5 !\left(\frac{1}{2 !}-\frac{1}{3 !}+\frac{1}{4 !}-\frac{1}{5 !}\right) \\
& 6 \cdot 5 \cdot 4 \cdot 3-6 \cdot 5 \cdot 4+6 \cdot 5-6+1=6 !\left(\frac{1}{2 !}-\frac{1}{3 !}+\frac{1}{4 !}-\frac{1}{5 !}+\frac{1}{6 !}\right) .
\end{aligned}
$$

E segue dessa observação que:

$$
\begin{aligned}
& x_{2}=2 !\left(\frac{1}{2 !}\right) \\
& x_{3}=3 !\left(\frac{1}{2 !}-\frac{1}{3 !}\right) \\
& x_{4}=4 !\left(\frac{1}{2 !}-\frac{1}{3 !}+\frac{1}{4 !}\right) \\
& x_{5}=5 !\left(\frac{1}{2 !}-\frac{1}{3 !}+\frac{1}{4 !}-\frac{1}{5 !}\right) \\
& x_{6}=6 !\left(\frac{1}{2 !}-\frac{1}{3 !}+\frac{1}{4 !}-\frac{1}{5 !}+\frac{1}{6 !}\right) .
\end{aligned}
$$

Podemos então formular a proposição a seguir.

Proposição 3.3.1. Seja $x_{n}$ o número de permutações caóticas, então:

$$
x_{n}=n !\left(\frac{1}{2 !}-\frac{1}{3 !}+\frac{1}{4 !}-\frac{1}{5 !}+\ldots+(-1)^{n} \frac{1}{n !}\right), \forall n \geq 2
$$

Prova: Vamos provar a afirmação por indução em $n$. De fato, a proposição é válida para o caso base da indução $n=2$, pois: 


$$
x_{2}=2 !\left(\frac{1}{2 !}\right)=1
$$

Suponhamos agora que a proposição, que temos por hipótese, seja válida até um certo natural $n$, ou seja:

$$
x_{n}=n !\left(\frac{1}{2 !}-\frac{1}{3 !}+\frac{1}{4 !}-\frac{1}{5 !}+\ldots+(-1)^{n} \frac{1}{n !}\right)
$$

Queremos agora provar que a proposição $P(n)$ implica $P(n+1)$. Para isso, multiplicamos ambos os membros da igualdade por $(n+1)$, o que nos fornece:

$$
(n+1) x_{n}=(n+1) n !\left(\frac{1}{2 !}-\frac{1}{3 !}+\frac{1}{4 !}-\frac{1}{5 !}+\ldots+(-1)^{n} \frac{1}{n !}\right)
$$

Obtivemos anteriormente a equação $x_{n}=n x_{n-1}+(-1)^{n}$ que descreve a recorrência do problema em questão nesse tópico. E, portanto:

$$
x_{n}=n x_{n-1}+(-1)^{n} \Longrightarrow x_{n+1}=(n+1) x_{n}+(-1)^{n+1} \Longrightarrow(n+1) x_{n}=x_{n+1}-(-1)^{n+1} .
$$

Assim,

$$
\begin{aligned}
& x_{n+1}-(-1)^{n+1}=(n+1) n !\left(\frac{1}{2 !}-\frac{1}{3 !}+\frac{1}{4 !}-\frac{1}{5 !}+\ldots+(-1)^{n} \frac{1}{n !}\right) \\
& \Longrightarrow x_{n+1}=(n+1) !\left(\frac{1}{2 !}-\frac{1}{3 !}+\frac{1}{4 !}-\frac{1}{5 !}+\ldots+(-1)^{n} \frac{1}{n !}\right)+(-1)^{n+1} \\
& \Longrightarrow x_{n+1}=(n+1) !\left(\frac{1}{2 !}-\frac{1}{3 !}+\frac{1}{4 !}-\frac{1}{5 !}+\ldots+(-1)^{n} \frac{1}{n !}\right)+(-1)^{n+1} \frac{(n+1) !}{(n+1) !} \\
& \Longrightarrow x_{n+1}=(n+1) !\left(\frac{1}{2 !}-\frac{1}{3 !}+\frac{1}{4 !}-\frac{1}{5 !}+\ldots+(-1)^{n+1} \frac{1}{(n+1) !}\right)
\end{aligned}
$$

Com isso, provamos que a proposição $P(n)$ :

$x_{n}=n !\left(\frac{1}{2 !}-\frac{1}{3 !}+\frac{1}{4 !}-\frac{1}{5 !}+\ldots+(-1)^{n} \frac{1}{n !}\right), \forall n \geq 2$ é verdadeira.

Lembrando do caso particular que $x_{1}=0$ podemos, finalmente, definir para todo $n \geq 1$ que:

$$
x_{n}=n !\left(1-\frac{1}{1 !}+\frac{1}{2 !}-\frac{1}{3 !}+\frac{1}{4 !}-\frac{1}{5 !}+\ldots+(-1)^{n} \frac{1}{(n) !}\right)
$$




\subsection{A Sequência de Fibonacci}

Quando se trata de sequências recursivas, um dos exemplos mais famosos e conhecidos entre os professores de Matemática é a sequência de Fibonacci. Nascido em Pisa, na Itália, Leonardo Fibonacci (1170-1240), também conhecido como Leonardo Pisano ou Leonardo de Pisa, de acordo com ([3], p. 186) "foi sem dúvida o matemático mais original e capaz do mundo cristão medieval" . Ainda segundo [3], seu pai foi um importante mercador de Pisa e representava os interesses comerciais de sua cidade em Bugia, na atual Argélia, norte da África. Devido às viagens do pai, Leonardo percorreu todo o Mediterrâneo, conhecendo nestes lugares diversas culturas e familiarizando-se com a Matemática árabe, que era então mais desenvolvida do que a Matemática da Europa.

Conhecendo a cultura árabe, Leonardo impressionou-se com os algarismos indo-arábicos, e considerava mais vantajoso utilizá-los em comparação aos sistemas numéricos então usados na Europa para registrar os números e operar com eles. Tornou-se um dos responsáveis pela divulgação do sistema de numeração decimal na Europa, por meio de seu livro Liber Abaci escrito em 1202. Neste livro, Fibonacci apresentou um tratamento da Aritmética e da Álgebra Elementar. Entre os problemas deste livro está o dos coelhos: "Quantos pares de coelhos serão produzidos num ano, à partir de um único casal, se cada casal procria a cada mês um novo casal que se torna produtivo depois de dois meses?" Podemos visualizar na tabela a seguir como a sequência do problema em questão se forma.

Tabela 3.3.1 - O problema dos coelhos de Fibonacci

\begin{tabular}{|c|c|c|}
\hline $\mathrm{N}^{\mathrm{o}}$ de Meses $(\mathrm{n})$ & Indicação da Reprodução dos Casais & $\mathrm{N}^{\circ}$ de Casais $\left(F_{n}\right)$ \\
\hline 1 & $C_{1}$ & 1 \\
\hline 2 & $C_{1}$ & 1 \\
\hline 3 & $\begin{array}{c}C_{1} \\
\downarrow \\
C_{2}\end{array}$ & 2 \\
\hline 4 & $\begin{array}{ll}C_{1} & C_{2} \\
\downarrow & \\
C_{3} & \\
\end{array}$ & 3 \\
\hline 5 & $\begin{array}{ccc}C_{1} & C_{2} & C_{3} \\
\downarrow & \downarrow & \\
C_{4} & C_{5} & \\
\end{array}$ & 5 \\
\hline 6 & $\begin{array}{ccccc}C_{1} & C_{2} & C_{3} & C_{4} & C_{5} \\
\downarrow & \downarrow & \downarrow & & \\
C_{6} & C_{7} & C_{8} & & \\
\end{array}$ & 8 \\
\hline
\end{tabular}


Consideremos que os coelhos não morrem, tal problema dá a origem à mundialmente famosa "sequência de Fibonacci", que indica a quantidade de casais existentes em cada mês: $\left(F_{n}\right)=(1,1,2,3,5,8,13,21,34,55,89,144, \ldots)$. Ao longo dos séculos verificou-se que essa sequência possui propriedades belas e significativas. ([3], p. 186) relata que "a sequência se aplica também a questões de filotaxia e crescimento orgânico."

Observemos a sequência $\left(F_{n}\right)=(1,1,2,3,5,8,13,21,34,55,89,144, \ldots)$. É fácil ver que a relação de recorrência é dada, à partir do terceiro mês, pela soma do número de casais dos dois meses anteriores. Ou seja, $F_{n+2}=F_{n+1}+F_{n}$, com $F_{1}=F_{2}=1$.

Podemos definir a sequência de Fibonacci por uma recorrência linear homogênea de segunda ordem tal que: $F_{n+2}=F_{n+1}+F_{n}$, com $F_{1}=F_{2}=1$. Vamos resolver a equação de recorrência a fim de encontrar uma fórmula fechada que possibilite determinar qualquer termo da sequência.

Solução: A equação da recorrência pode ser reescrita como $F_{n+2}-F_{n+1}-F_{n}=0$, cuja equação característica é $x^{2}-x-1=0$, que por sua vez tem como raízes:

$$
\alpha=\frac{1+\sqrt{5}}{2} \text { e } \beta=\frac{1-\sqrt{5}}{2} \text {. }
$$

As soluções de uma recorrência com tal expressão são da forma:

$$
F_{n}=A \cdot\left(\frac{1+\sqrt{5}}{2}\right)^{n}+B \cdot\left(\frac{1-\sqrt{5}}{2}\right)^{n} .
$$

Além disso, a sequência de Fibonacci tem $F_{1}=F_{2}=1$. E assim podemos montar o sistema:

$$
\left\{\begin{array}{l}
A \cdot\left(\frac{1+\sqrt{5}}{2}\right)+B \cdot\left(\frac{1-\sqrt{5}}{2}\right)=1 \\
A \cdot\left(\frac{1+\sqrt{5}}{2}\right)^{2}+B \cdot\left(\frac{1-\sqrt{5}}{2}\right)^{2}=1
\end{array}\right.
$$

Resolvendo o sistema chegamos às constantes $A=\frac{1}{\sqrt{5}}$ e $B=-\frac{1}{\sqrt{5}}$.

Portanto, a solução da recorrência é dada por:

$$
F_{n}=\frac{1}{\sqrt{5}} \cdot\left(\frac{1+\sqrt{5}}{2}\right)^{n}-\frac{1}{\sqrt{5}} \cdot\left(\frac{1-\sqrt{5}}{2}\right)^{n}
$$


Esta fórmula é conhecida por fórmula de Binet ${ }^{3}$, que a descobriu em 1843.

Observemos que o resultado obtido é uma solução para um caso particular da recorrência $x_{n+2}=x_{n+1}+x_{n}$. Caso esse, que nessa secção chamamos de sequência de Fibonacci.

Os números de Fibonacci tem muitas propriedades que são temas de estudos desde a Idade Média até os dias atuais. Nesta secção vamos analisar algumas dessas propriedades.

Proposição 3.4.1. A soma dos n primeiros números de Fibonacci é igual ao (n+2)-ésimo número de Fibonacci menos uma unidade.

Prova: Vamos provar por indução em $n$ o que queremos demonstrar:

$$
\sum_{i=1}^{n} F_{i}=F_{n+2}-1
$$

Primeiro vejamos o caso base da indução. Para $n=1$ a propriedade é verdadeira pois: $F_{1}=F_{3}-1=2-1=1$.

Supondo que a propriedade seja válida até um certo $n$, vamos provar que é verdadeira para $n+1$, ou seja, que $P(n)$ implica $P(n+1)$, que provará o que queremos. Temos que:

$$
F_{1}+F_{2}+F_{3}+\ldots+F_{n}=F_{n+2}-1 \text {. }
$$

Se somarmos $F_{n+1}$ aos dois lados da igualdade, obteremos:

$$
F_{1}+F_{2}+F_{3}+\ldots+F_{n}+F_{n+1}=F_{n+2}+F_{n+1}-1 .
$$

Mas, pela própria relação de recorrência: $F_{n+2}+F_{n+1}=F_{n+3}$. Assim, podemos verificar que:

$$
F_{1}+F_{2}+F_{3}+\ldots+F_{n}+F_{n+1}=F_{n+3}-1 \text {. }
$$

Portanto, $P(n)$ implica $P(n+1)$ e pelo Princípio da Indução Finita podemos afirmar que é verdadeira a proposição:

$$
\sum_{i=1}^{n} F_{i}=F_{n+2}-1
$$

\footnotetext{
${ }^{3}$ Jacques Philippe Marie Binet (1786-1856), matemático francês que foi um dos precursores no estudo dos fundamentos da teoria matricial.
} 
A seguir apresentaremos uma proposição que generaliza esse resultado para toda sequência que tem como relação de recorrência a equação $x_{n+2}=x_{n+1}+x_{n}$.

Proposição 3.4.2. Seja $\left(x_{n}\right)$ uma sequência tal que $x_{n+2}=x_{n+1}+x_{n}$, para todo $n \in \mathbb{N}$. A soma dos $n$ primeiros termos de $\left(x_{n}\right)$ é igual ao $(n+2)$-ésimo termo menos o segundo termo.

Prova: Vamos provar por indução em $n$ o que queremos demonstrar:

$$
\sum_{i=1}^{n} x_{i}=x_{n+2}-x_{2}
$$

Verificando o caso base da indução, para $n=1$ a propriedade é verdadeira pois:

$$
x_{1}+x_{2}=x_{3} \Longrightarrow x_{1}=x_{3}-x_{2}
$$

Supondo que a propriedade seja válida até um certo $n$, vamos provar que é verdadeira para $n+1$, ou seja, que $P(n) \Rightarrow P(n+1)$, que provará o que queremos. Temos que:

$$
x_{1}+x_{2}+x_{3}+\ldots+x_{n}=x_{n+2}-x_{2} .
$$

Se somarmos $x_{n+1}$ aos dois lados da igualdade, obteremos:

$$
x_{1}+x_{2}+x_{3}+\ldots+x_{n}+x_{n+1}=x_{n+2}+x_{n+1}-x_{2} .
$$

Mas, pela própria relação de recorrência: $x_{n+2}+x_{n+1}=x_{n+3}$. Assim, podemos verificar que:

$$
x_{1}+x_{2}+x_{3}+\ldots+x_{n}+x_{n+1}=x_{n+3}-x_{2} .
$$

Como $P(n) \Rightarrow P(n+1)$ podemos afirmar que é verdadeira a proposição:

$$
\sum_{i=1}^{n} x_{i}=x_{n+2}-x_{2}
$$




\subsection{Os Números de Lucas}

A equação de recorrência $x_{n+2}=x_{n+1}+x_{n}$ representa uma classe de infinitas sequências. Como pudemos ver na secção 1.2 uma sequência ficará numericamente definida se forem informados os primeiros termos, a partir dos quais a equação construirá a recorrência.

Ao matemático francês, Édouard Lucas ${ }^{4}$ é atribuída uma sequência recursiva que aqui denotaremos por $\left(L_{n}\right)$. Essa sequência possui a mesma equação da sequência de Fibonacci, porém os termos iniciais são: $L_{1}=1$ e $L_{2}=3$. Tendo vivido séculos depois de Leonardo Fibonacci, Lucas estudou as propriedades da famosa sequência. Foi o próprio Lucas que batizou a sequência do problema dos coelhos com o nome do autor do Liber Abaci. Ele passou a estudar o comportamento da recorrência se ela começasse com outros valores, comprovando que de fato algumas das propriedades se mantém.

Seguindo a lei de recorrência $L_{n+2}=L_{n+1}+L_{n}$ e atribuindo os valores $L_{1}=1$ e $L_{2}=3$, a sequência de Lucas fica descrita numericamente da seguinte maneira:

$$
\left(L_{n}\right)=(1,3,4,7,11,18,29,47, \ldots)
$$

Uma vez que a equação de recorrência é igual à de Fibonacci, podemos afirmar que a solução também será da forma:

$$
L_{n}=A \cdot\left(\frac{1+\sqrt{5}}{2}\right)^{n}+B \cdot\left(\frac{1-\sqrt{5}}{2}\right)^{n} .
$$

Além disso, a sequência de Lucas tem como valores iniciais os números $L_{1}=1$ e $L_{2}=3$. Logo, podemos montar o sistema:

$$
\left\{\begin{array}{l}
A \cdot\left(\frac{1+\sqrt{5}}{2}\right)+B \cdot\left(\frac{1-\sqrt{5}}{2}\right)=1 \\
A \cdot\left(\frac{1+\sqrt{5}}{2}\right)^{2}+B \cdot\left(\frac{1-\sqrt{5}}{2}\right)^{2}=3
\end{array}\right.
$$

Resolvendo o sistema chegamos às constantes $A=1$ e $B=1$.

Portanto, o termo geral da sequência de Lucas é dado por:

$$
L_{n}=\left(\frac{1+\sqrt{5}}{2}\right)^{n}+\left(\frac{1-\sqrt{5}}{2}\right)^{n}
$$

\footnotetext{
${ }^{4}$ François Édouard Anatole Lucas (1842-1891), matemático francês.
} 
Agora vamos observar se há alguma relação entre as duas sequências:

$$
\left(F_{n}\right)=(1,1,2,3,5,8,13,21, \ldots) \quad \text { e } \quad\left(L_{n}\right)=(1,3,4,7,11,18,29,47, \ldots)
$$

Analisando as duas recorrências podemos notar um padrão a partir do segundo número de Lucas. Podemos ver que:

$$
L_{2}=F_{1}+F_{3}, L_{3}=F_{2}+F_{4}, L_{4}=F_{3}+F_{5}, L_{5}=F_{4}+F_{6}, L_{6}=F_{5}+F_{7}, \ldots
$$

A partir dessas observações podemos formular a Proposição a seguir, a qual provaremos com o Princípio da Indução.

Proposição 3.5.1. Os números de Lucas e os números de Fibonacci se relacionam sob a fórmula:

$$
L_{n}=F_{n-1}+F_{n+1}, \forall n \geq 2
$$

Prova: Para o caso base da indução $n=2$ temos que a Proposição é válida. De fato:

$$
L_{2}=F_{1}+F_{3} \Longrightarrow 3=1+2 .
$$

Agora supomos que a proposição seja válida até um certo $n$ natural. Queremos mostrar que a validade de $P(n)$ implica na validade de $P(n+1)$. Ou seja, que o fato de $L_{n}=F_{n-1}+F_{n+1}$ ser válido até um certo $n$ implica em $L_{n+1}=F_{n}+F_{n+2}$.

Observemos que pela hipótese de indução e pelo fato de ser válido até um natural $n$ temos:

$$
\begin{gathered}
L_{n}=F_{n-1}+F_{n+1} \\
L_{n-1}=F_{n-2}+F_{n}
\end{gathered}
$$

Somando as equações (I) e (II), temos que:

$$
L_{n}+L_{n-1}=F_{n-1}+F_{n-2}+F_{n+1}+F_{n}
$$

E pela lei de recorrência das duas sequências:

$$
L_{n+1}=F_{n}+F_{n+2}
$$

Portanto, a proposição é válida para todo $n$ natural. 
Consideremos agora as soluções que encontramos nesse capítulo para as sequências de Fibonacci e de Lucas:

$$
F_{n}=\frac{1}{\sqrt{5}} \cdot\left(\frac{1+\sqrt{5}}{2}\right)^{n}-\frac{1}{\sqrt{5}} \cdot\left(\frac{1-\sqrt{5}}{2}\right)^{n} \text { e } L_{n}=\left(\frac{1+\sqrt{5}}{2}\right)^{n}+\left(\frac{1-\sqrt{5}}{2}\right)^{n}
$$

Fazendo: $\alpha=\frac{1+\sqrt{5}}{2}$ e $\beta=\frac{1-\sqrt{5}}{2}$ podemos expressar essas fórmulas do seguinte modo:

$$
F_{n}=\frac{1}{\sqrt{5}} \cdot\left(\alpha^{n}-\beta^{n}\right) \quad \text { e } \quad L_{n}=\alpha^{n}+\beta^{n}
$$

Outra prova para a relação: $L_{n}=F_{n-1}+F_{n+1}$

Para prosseguirmos com a prova é importante saber que:

$$
\begin{aligned}
& \left(\alpha+\alpha^{-1}\right)=\frac{1+\sqrt{5}}{2}+\frac{2}{1+\sqrt{5}}=\frac{(1+\sqrt{5})^{2}+4}{2(1+\sqrt{5})}=\frac{5+\sqrt{5}}{1+\sqrt{5}}=\sqrt{5} \\
& \left(\beta+\beta^{-1}\right)=\frac{1-\sqrt{5}}{2}+\frac{2}{1-\sqrt{5}}=\frac{(1-\sqrt{5})^{2}+4}{2(1-\sqrt{5})}=\frac{5-\sqrt{5}}{1-\sqrt{5}}=-\sqrt{5}
\end{aligned}
$$

Procedendo a prova, a partir das seguintes igualdades, temos:

$$
\begin{aligned}
F_{n-1}+F_{n+1} & =\frac{1}{\sqrt{5}} \cdot\left(\alpha^{n-1}-\beta^{n-1}\right)+\frac{1}{\sqrt{5}} \cdot\left(\alpha^{n+1}-\beta^{n+1}\right) \\
& =\frac{1}{\sqrt{5}} \cdot\left[\alpha^{n}\left(\alpha+\alpha^{-1}\right)-\beta^{n}\left(\beta+\beta^{-1}\right)\right] \\
& =\frac{1}{\sqrt{5}} \cdot\left[\alpha^{n} \cdot \sqrt{5}-\beta^{n} \cdot(-\sqrt{5})\right] \\
& =\frac{1}{\sqrt{5}} \cdot\left(\alpha^{n} \cdot \sqrt{5}+\beta^{n} \cdot \sqrt{5}\right) \\
& =\alpha^{n}+\beta^{n} \\
& =L_{n}
\end{aligned}
$$




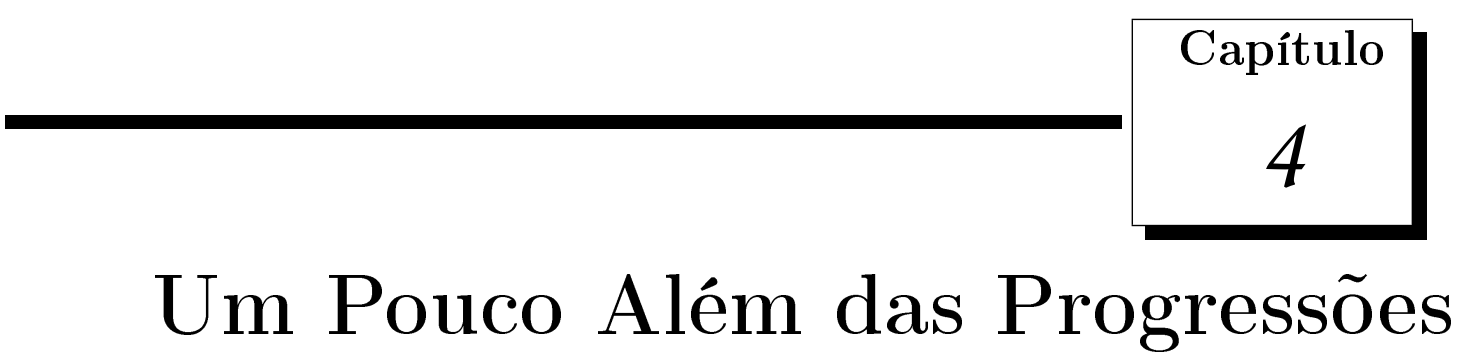

Vimos no primeiro capítulo a formação recursiva de dois dos exemplos mais comuns nos livros didáticos no Brasil. De fato, ao analisarmos três dos principais autores, [7], [12] e [19] vemos que eles, no capítulo sobre sequências, tratam quase que exclusivamente das progressões aritmética e geométrica, ou, simplesmente, PA e PG. No decorrer desse capítulo vamos expandir um pouco os conceitos até agora vistos sobre a PA. As definições, teoremas e demonstrações desta secção baseiam-se fortemente no terceiro capítulo de [17]. Após o embasamento teórico, apresentaremos alguns problemas comuns onde esses conceitos serão utilizados.

\subsection{Somas Polinomiais}

Consideremos as somas da forma:

$$
\sum_{i=1}^{n} i^{k}=1^{k}+2^{k}+3^{k}+\ldots+n^{k}
$$

De modo geral, consideremos a soma

$$
\sum_{i=1}^{n} P(i)
$$

onde $P(i)$ é um polinômio em $i$.

Nessa secção vamos apresentar alguns resultados de somas de polinômios que serão úteis na resolução de diversos problemas cujas soluções sejam recursivas. 
Exemplo 4.1.1. Seja a soma dos $n$ primeiros quadrados inteiros positivos:

$$
1^{2}+2^{2}+3^{2}+\ldots+n^{2}=\sum_{k=1}^{n} k^{2}
$$

Essa soma pode ser calculada do seguinte modo:

$$
\sum_{k=1}^{n}(k+1)^{3}=\sum_{k=1}^{n} k^{3}+3 \sum_{k=1}^{n} k^{2}+3 \sum_{k=1}^{n} k+\sum_{k=1}^{n} 1
$$

As somas $\sum_{k=1}^{n}(k+1)^{3}$ e $\sum_{k=1}^{n} k^{3}$ possuem vários termos em comum e sobre as duas últimas sabemos o resultado:

$$
\begin{aligned}
& \sum_{k=1}^{n}(k+1)^{3}=2^{3}+3^{3}+4^{3}+\ldots+(n+1)^{3} \text { e } \sum_{k=1}^{n} k^{3}=1^{3}+2^{3}+3^{3}+\ldots+n^{3} \\
& \sum_{k=1}^{n} k=\frac{n(n+1)}{2} \quad \text { e } \sum_{k=1}^{n} 1=n
\end{aligned}
$$

Segue que:

$$
\begin{gathered}
(n+1)^{3}=1^{3}+3 \sum_{k=1}^{n} k^{2}+3 \cdot \frac{n(n+1)}{2}+n \\
\Longrightarrow 6 \sum_{k=1}^{n} k^{2}=2(n+1)^{3}-3 n(n+1)-2 n-2 \\
\Longrightarrow 6 \sum_{k=1}^{n} k^{2}=2(n+1)^{3}-3 n(n+1)-2(n+1) \\
\Longrightarrow 6 \sum_{k=1}^{n} k^{2}=(n+1)\left(2(n+1)^{2}-3 n-2\right) \\
\Longrightarrow \sum_{k=1}^{n} k^{2}=\frac{n(n+1)(2 n+1)}{6}
\end{gathered}
$$

Portanto, temos que $1^{2}+2^{2}+3^{2}+\ldots+n^{2}=\frac{n(n+1)(2 n+1)}{6}$.

A soma $1^{2}+2^{2}+3^{2}+\ldots+n^{2}$ dada por $P(n)=\frac{n(n+1)(2 n+1)}{6}=\frac{2 n^{3}+3 n^{2}+n}{6}$ corresponde a um polinômio de terceiro grau em $n$.

O próximo teorema generaliza essa última afirmação. 
Teorema 4.1.

$$
1^{m}+2^{m}+3^{m}+\ldots+n^{m}=\sum_{k=1}^{n} k^{m}
$$

é um polinômio de grau $(m+1)$ em $n$.

Prova: Provaremos por indução em $m$.

Para o caso base da indução $m=1$ a proposição é válida. De fato, como já mostramos no primeiro capítulo (Proposição 1.4.1.) a soma $1+2+3+\ldots+m=\frac{m(m+1)}{2}$ para todo $m$ natural. E a expressão $\frac{m(m+1)}{2}$ é um polinômio de grau $2 \mathrm{em} m$.

Suponhamos agora que o termo geral da soma $1^{m}+2^{m}+3^{m}+\ldots+n^{m}$ seja um polinômio de grau $(m+1)$ em $n$, para todo $m$ natural tal que $m \in 1,2,3, \ldots, p$. Queremos mostrar que essa afirmação é válida para $m=p+1$, ou seja, que $\sum_{k=1}^{n} k^{p+1}$ é um polinômio de grau $(p+2)$ em $n$.

Observemos que $(k+1)^{p+2}=k^{p+2}+(p+2) k^{p+1}+Q(k)$, onde $Q(k)$ é um polinômio de grau $p$ em $k$. Segue que:

$$
\sum_{k=1}^{n}(k+1)^{p+2}=\sum_{k=1}^{n} k^{p+2}+(p+2) \sum_{k=1}^{n} k^{p+1}+F(n),
$$

onde, pela hipótese de indução, $F(n)$ é um polinômio de grau $(p+1)$ em $k$. Simplificando adequadamente a expressão eliminado os termos comuns das duas primeiras somas, obtemos:

$$
\begin{gathered}
(n+1)^{p+2}=1+(p+2) \sum_{k=1}^{n} k^{p+1}+F(n) \\
\Longrightarrow \sum_{k=1}^{n} k^{p+1}=\frac{(n+1)^{p+2}-1-F(n)}{p+2}
\end{gathered}
$$

que é um polinômio de grau $(p+2)$ em $n$.

Finalmente, como $P(m)$ implica $P(m+1)$ podemos afirmar que a expressão geral da soma $1^{m}+2^{m}+3^{m}+\ldots+n^{m}$ forma um polinômio de grau $(m+1)$ em $n$.

Corolário 4.1. Se F é um polinômio de grau $m$, então $\sum_{k=1}^{n} F(k)$ é um polinômio de grau $(m+1) e m n$. 


\subsection{Progressões Aritméticas de Ordem k}

Definição 4.2.1. O operador $\Delta$ dito operador diferença é definido por $\Delta x_{n}=x_{n+1}-x_{n}$.

Segue da definição que uma sequência $\left(x_{n}\right)$ é uma progressão geométrica se, e somente se, $\left(\Delta x_{n}\right)=\left(x_{n+1}-x_{n}\right)$ é constante.

Definição 4.2.2. Uma progressão aritmética é dita de segunda ordem se as diferenças $\Delta x_{n}=x_{n+1}-x_{n}$ formam uma progressão aritmética de razão não-nula.

De modo geral, uma progressão aritmética de ordem $k(k \geq 2)$ é uma sequência na qual as diferenças entre cada termo e o anterior formam uma progressão aritmética de ordem $(k-1)$.

Como exemplos podemos citar:

(a) A sequência $\left(x_{n}\right)=(1,3,6,10,15,21,28, \ldots)$ é uma PA de segunda ordem pois as diferenças $x_{n+1}-x_{n}$ formam a PA $(2,3,4,5,6,7, \ldots)$.

(b) A sequência $\left(x_{n}\right)=(2,3,8,20,42,77,128,198, \ldots)$ é uma PA de terceira ordem, já que as diferenças $x_{n+1}-x_{n}$ formam a sequência $\left(y_{n}\right)=(1,5,12,22,35,51,70, \ldots)$ que por sua vez é uma PA de segunda ordem pois as diferenças $y_{n+1}-y_{n}$ formam a PA $(4,7,10,13,16,19, \ldots)$.

Um caso a ser observado: Seja a sequência cujo termo de ordem $n$ é a soma $S_{n}=$ $x_{1}+x_{2}+\ldots+x_{n}$ dos $n$ primeiros termos de uma progressão aritmética de ordem $k$. A sequência $\left(S_{n}\right)$ é uma PA de ordem $k+1$, já que se aplicarmos o operador diferença, teremos: $\Delta S_{n}=S_{n+1}-S_{n}=x_{n+1}$ que define, portanto uma PA de ordem $k$.

Teorema 4.2. Toda sequência na qual o termo de ordem $n$ é um polinômio em $n$, de grau $k$, é uma progressão aritmética de ordem $k$ e, reciprocamente, se $\left(x_{n}\right)$ é uma progressão aritmética de ordem $k$, então $\left(x_{n}\right)$ é um polinômio de grau $k$ em $n$. Assim,

$$
x_{n}=a_{1} n^{k}+a_{2} n^{k-1}+\ldots+a_{k} n+a_{k+1} \Longleftrightarrow\left(x_{n}\right) \text { é PA de ordem } k \text {. }
$$

Prova: Vamos proceder a prova por indução sobre $k$.

Para o caso base da indução, $k=1$, vemos que:

$$
x_{n}=a n+b \Longleftrightarrow\left(x_{n}\right) \text { é PA de primeira ordem. }
$$


De fato, aplicando o operador diferença: $\Delta x_{n}=x_{n+1}-x_{n}=(a(n+1)+b)-(a n+b)$ obtemos a constante $a$, com $a \neq 0$, que é a razão da PA de primeira ordem. Por outro lado, a PA de primeira ordem $\left(x_{n}\right)$ tem como seu termo geral o polinômio $x_{1}+(n-1) \cdot r$ que é um polinômio de grau 1 em $n$, quando a razão $r$ é não-nula.

Para $k=2$ temos que se $x_{n}=a n^{2}+b n+c, \operatorname{com} a \neq 0$, então:

$$
\Delta x_{n}=x_{n+1}-x_{n}=a(n+1)^{2}+b(n+1)+c-\left(a n^{2}+b n+c\right)=2 a n+(a+b) .
$$

E, se $\Delta x_{n}$ é um polinômio de primeiro grau em $n$ então, $\left(x_{n}\right)$ é uma PA de ordem $k=2$.

Por outro lado, se $\left(x_{n}\right)$ é uma PA de segunda ordem então, a sequência $y_{n}=\Delta x_{n}$ é uma PA de primeira ordem de razão não-nula, conforme a Definição 4.2.2. E pelo Corolário 4.1. a soma $\sum_{i=1}^{n} y_{i}$ é um polinômio de grau $k=2$. Como $y_{n}=\Delta x_{n}$, temos: $y_{1}+y_{2}+\ldots+y_{n-1}+y_{n}=\left(x_{2}-x_{1}\right)+\left(x_{3}-x_{2}\right)+\ldots+\left(x_{n}-x_{n-1}\right)+\left(x_{n+1}-x_{n}\right)=x_{n+1}-x_{1}$

E portanto, se $x_{n+1}-x_{1}$ é um polinômio de grau $k=2$ em $n$, então $x_{n}$ também é um polinômio de grau $k=2 \mathrm{em} n$.

Já demonstramos para o caso base $k=1$ e também para $k=2$.

Suponhamos agora que a afirmação do teorema seja verdadeira para todo $k$ natural tal que $k \in 1,2,3, \ldots, p$. Queremos mostrar que o teorema é verdadeiro para $k=p+1$.

Se $\left(x_{n}\right)$ é uma progressão aritmética de ordem $p+1$, então $y_{n}=\Delta x_{n}=x_{n+1}-x_{n}$ é uma progressão aritmética de ordem $p$ e, pela hipótese de indução, $y_{n}$ é um polinômio de grau $p$ em $n$. Então, $\sum_{k=1}^{n} y_{k}=x_{n+1}-x_{1}$ é um polinômio de grau $p+1$ em $n$, conforme o Corolário 4.1.

Por outro lado, se $x_{n}$ é um polinômio de grau $p+1$ em $n$, então $\left(\Delta x_{n}\right)$ é um polinômio de grau $p$ em $n$. Pela hipótese de indução, $\left(\Delta x_{n}\right)$ é uma progressão aritmética de ordem $p$, ou seja, $\left(x_{n}\right)$ é uma progressão aritmética de ordem $p+1$.

Exemplo 4.2.1. Encontrar a solução da soma:

$$
\sum_{k=1}^{n} k(k-2)
$$


Solução: Pelo Teorema 4.2. a sequência definida por $x_{n}=n(n-2)$ é uma PA de ordem 2 , já que o termo geral é um polinômio de grau 2. Logo, a soma $S_{n}$ de seus $n$ primeiros termos define uma PA de ordem 3, conforme o Corolário 4.1.

Portanto, aplicando a volta do Teorema 4.2, a expressão do termo geral de $S_{n}$ é dada por um polinômio de grau 3 , ou seja, $S_{n}=a n^{3}+b n^{2}+c n+d$, com $a \neq 0$ e $a, b, c, d$ sendo constantes reais. Podemos, escrever o sistema de equações:

$$
\left\{\begin{array}{l}
a+b+c+d=-1 \\
8 a+4 b+2 c+d=-1 \\
27 a+9 b+3 c+d=2 \\
64 a+16 b+4 c+d=10
\end{array}\right.
$$

Resolvendo o sistema encontramos $a=\frac{1}{3}, b=-\frac{1}{2}, c=-\frac{5}{6}$ e $d=0$. Substituindo as constantes encontradas, temos:

$$
S_{n}=\frac{1}{3} n^{3}-\frac{1}{2} n^{2}-\frac{5}{6} n=\frac{2 n^{3}-3 n^{2}-5 n}{6}=\frac{n(n+1)(2 n-5)}{6}
$$

Portanto,

$$
\sum_{k=1}^{n} k(k-2)=\frac{n(n+1)(2 n-5)}{6}
$$

\subsection{O Problema dos Números Poligonais}

$\mathrm{Na}$ Escola de Pitágoras, os pitagóricos atribuíam propriedades aos números. Entre essas haviam os números figurados, que são exemplos de progressões aritméticas de várias ordens. Esses números figurados podem ser representados por relações de recorrências.

Os números poligonais são exemplos de números figurados os quais correspondem à quantidade de pontos arranjados de modo a formar um polígono regular. A sequência é obtida recursivamente iniciando-se de um único ponto. O segundo termo da sequência é obtido acrescentando-se $(k-1)$ pontos de modo que os $k$ pontos acumulados formem um polígono regular de $k$ vértices e portanto, $k$ lados. À partir daí, cada termo da sequência é dado pela quantidade de pontos do polígono com $k$ lados que é sobreposto ao polígono anterior onde dois de seus lados coincidem, e a cada lado possui um ponto a mais do que o polígono anterior. 
Cada sequência é denominada de acordo com o polígono da qual se origina. Por exemplo, se o polígono é um triângulo, a sequência é dita números triangulares; se o polígono é um quadrado, dá-se origem aos números quadrados, e assim sucessivamente.

As figuras a seguir nos ajudam a visualizar como as sequências dos números poligonais se formam.
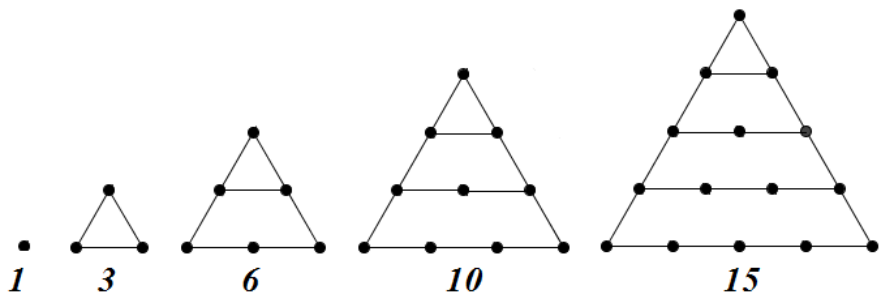

Figura 4.3.1. - Números Triangulares

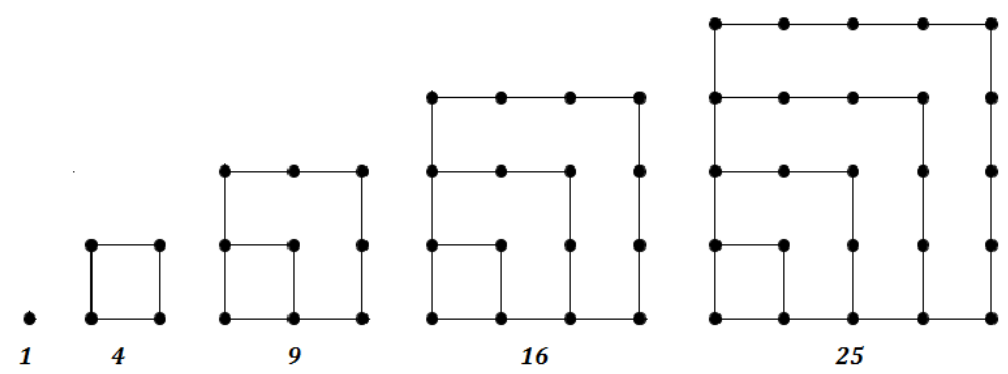

Figura 4.3.2. - Números Quadrados
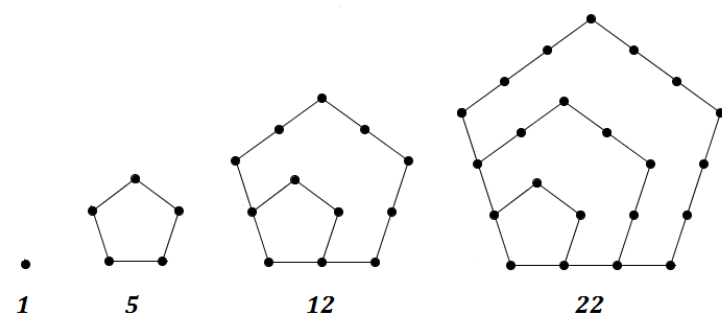

Figura 4.3.3. - Números Pentagonais

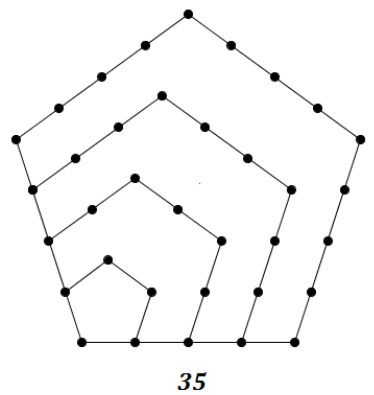

35

Observando as figuras e obedecendo as informações da formação recursiva de cada sequência podemos descrever numericamente as primeiras recorrências de números poligonais. Denotaremos nesse trabalho a sequência dos triangulares por $\left(T_{n}\right)$, os quadrados por $\left(Q_{n}\right)$, os pentagonais por $\left(P_{n}\right)$, os hexagonais por $\left(H_{n}\right)$, os heptagonais por $\left(H p_{n}\right)$, os octogonais por $\left(O_{n}\right)$, os eneagonais por $\left(N_{n}\right)$ e os decagonais por $\left(D_{n}\right)$. Descrevendo numericamente as sequências vemos que:

$$
\begin{aligned}
& \left(T_{n}\right)=(1,3,6,10,15, \ldots) \\
& \left(Q_{n}\right)=(1,4,9,16,25, \ldots) \\
& \left(P_{n}\right)=(1,5,12,22,35, \ldots) .
\end{aligned}
$$


Podemos notar intuitivamente que essas sequências são progressões aritméticas de segunda ordem, já que as diferenças $x_{n+1}-x_{n}$ formam progressões aritméticas de razão não-nulas. É possível notar também que os padrões de crescimento das sequências podem ser aferidos, pois temos as progressões formadas pelas diferenças:

$\operatorname{Em}\left(T_{n}\right):\left(\Delta T_{n}\right)=(2,3,4,5, \ldots)$, cuja razão é $1 . \operatorname{Em}\left(Q_{n}\right):\left(\Delta Q_{n}\right)=(3,5,7,9, \ldots)$, cuja razão é $2 . \operatorname{Em}\left(P_{n}\right):\left(\Delta P_{n}\right)=(4,7,10,13, \ldots)$, cuja razão é 3 .

Com base nessas observações vamos fazer a seguir uma proposição, a qual demonstraremos para que possamos estabelecer a solução para um termo geral seja qual for o polígono original da sequência.

Proposição 4.3.1. Seja $k \in \mathbb{N}, k \geq 3$, o número de vértices do polígono que origina a sequência de números poligonais. Se $\left(x_{n}\right)$ é a sequência do número de pontos que formam o polígono de $k$ vértices, então $\left(x_{n}\right)$ é uma progressão aritmética de segunda ordem.

\section{Demonstração:}

Primeiramente observemos que para formarmos a figura seguinte em cada sequência temos que acrescentar $(k-2)$ lados, haja visto que dois dos lados do polígono anterior coincidem com dois dos lados da nova figura. Ao construirmos a n-ésima figura estaremos acrescentando $(k-2) \cdot n$ pontos. Mas, é necessário subtrair desse número os vértices dos lados acrescentados, para que não se contem duas vezes. Devem ser subtraídos $(k-3)$ vértices.

Assim, o número de pontos acrescentados a uma figura para formar a próxima é $(k-$ $2) \cdot n-(k-3)$. Então temos a equação de recorrência:

$$
x_{n}=x_{n-1}+(k-2) \cdot n-(k-3)
$$

Aplicando o operador diferença $\Delta$, temos que $\Delta x_{n}=x_{n}-x_{n-1}=(k-2) \cdot n-(k-3)$. $\mathrm{E}$ como $k$ é um valor constante em cada sequência, as diferenças entre os termos consecutivos formam uma progressão aritmética.

De posse desse resultado podemos escrever a solução do termo geral de $\left(x_{n}\right)$ para uma sequência de números $k$-gonais, onde $k$ é o número de vértices do polígono. Sabemos, do teorema 4.1, que a expressão do termo geral de uma progressão aritmética de segunda ordem é um polinômio de segundo grau. Assim, $x_{n}=A n^{2}+B n+C$, onde $A, B$ e $C$ 
são constantes arbitrárias. Além disso, temos que o primeiro termo de cada sequência é 1 , o segundo termo é $k$ e o terceiro termo é $3 k-3$. Podemos assim escrever o sistema de equações:

$$
\left\{\begin{array}{l}
A+B+C=1 \\
4 A+2 B+C=k \\
9 A+3 B+C=3 k-3
\end{array}\right.
$$

Resolvendo os sistema chegamos às constantes: $A=\frac{k-2}{2}, B=\frac{4-k}{2}$ e $C=0$. Portanto, a expressão do termo geral dos números k-gonais é dada por:

$$
x_{n}=\frac{k-2}{2} n^{2}+\frac{4-k}{2} n
$$

Agrupando os termos de forma conveniente podemos escrever:

$$
x_{n}=\frac{n[(k-2) n-(k-4)]}{2}
$$

A Tabela 4.3.1 nos apresenta os termos iniciais das primeiras sequências de números poligonais.

Tabela 4.3.1. Números Poligonais

\begin{tabular}{|c|c|c|c|c|c|c|c|c|c|c|}
\hline & Termo Geral & $x_{1}$ & $x_{2}$ & $x_{3}$ & $x_{4}$ & $x_{5}$ & $x_{6}$ & $x_{7}$ & $x_{8}$ & $x_{9}$ \\
\hline Triangulares & $T_{n}=\frac{n(n+1)}{2}$ & 1 & 3 & 6 & 10 & 15 & 21 & 28 & 36 & 45 \\
\hline Quadrados & $Q_{n}=n^{2}$ & 1 & 4 & 9 & 16 & 25 & 36 & 49 & 64 & 81 \\
\hline Pentagonais & $P_{n}=\frac{n(3 n-1)}{2}$ & 1 & 5 & 12 & 22 & 35 & 51 & 70 & 92 & 117 \\
\hline Hexagonais & $H_{n}=\frac{n(4 n-2)}{2}$ & 1 & 6 & 15 & 28 & 45 & 66 & 91 & 120 & 153 \\
\hline Heptagonais & $H p_{n}=\frac{n(5 n-3)}{2}$ & 1 & 7 & 18 & 34 & 55 & 81 & 112 & 148 & 189 \\
\hline Octogonais & $O_{n}=\frac{n(6 n-4)}{2}$ & 1 & 8 & 21 & 40 & 65 & 96 & 133 & 176 & 225 \\
\hline Eneagonais & $N_{n}=\frac{n(7 n-5)}{2}$ & 1 & 9 & 24 & 46 & 75 & 111 & 154 & 204 & 261 \\
\hline Decagonais & $D_{n}=\frac{n(8 n-6)}{2}$ & 1 & 10 & 27 & 52 & 85 & 126 & 175 & 232 & 297 \\
\hline
\end{tabular}

\subsection{Números Piramidais}

Os números piramidais são aqueles figurados em representação espacial. Podem ser representados por esferas ou cubos sobrepostos de modo a formarem pirâmides no espaço, 
formando camadas sucessivas, cuja quantidade em cada camada correspondem aos números poligonais. Os arranjos obtidos pela sobreposição serão classificados de acordo com o polígono que dá origem à sequência piramidal. Desta forma, temos os números piramidais de base triangular, quadrada, pentagonal, hexagonal e assim sucessivamente.

Definição 4.4.1. Números piramidais de base triangular, quadrada, pentagonal e assim sucessivamente são números obtidos pela soma dos n primeiros números poligonais, respectivamente triangulares, quadrados, pentagonais, e assim sucessivamente.

Tendo em vista tal definição é consequente concluir que as sequências dos números piramidais são progressões aritméticas de terceira ordem, uma vez que as diferenças entre seus termos consecutivos formam sequências de números poligonais que, como vimos, são progressões aritméticas de segunda ordem.

Sendo a sequência dos números piramidais uma progressão aritmética de terceira ordem, pelo teorema 4.1, a expressão do termo geral é um polinômio do terceiro grau, ou seja, da forma: $x_{n}=A n^{3}+B n^{2}+C n+D$, onde $A, B, C$ e $D$ são constantes reais e $A \neq 0$. Pela solução encontrada na última secção temos que os primeiros quatros números poligonais são $1, k, 3 k-3$ e $6 k-8$, onde $k$ é o número de vértices e lados do polígono que dá origem à sequência. Do mesmo modo, as sequências dos números piramidais se desenvolverão de acordo com o polígono da base com $k$ lados. Segue da definição que os quatro primeiros números piramidais são $1, k+1,4 k-2$ e $10 k-10$. Com base nessas informações podemos escrever o seguinte sistema:

$$
\left\{\begin{array}{l}
A+B+C+D=1 \\
8 A+4 B+2 C+D=k+1 \\
27 A+9 B+3 C+D=4 k-2 \\
64 A+16 B+4 C+D=10 k-10
\end{array}\right.
$$

Resolvendo o sistema temos: $A=\frac{k-2}{6}, B=\frac{1}{2}, C=\frac{5-k}{6}$ e $D=0$. Assim, a solução do termo geral dos números piramidais é dada por:

$$
x_{n}=\left(\frac{k-2}{6}\right) n^{3}+\frac{1}{2} n^{2}+\left(\frac{5-k}{6}\right) n
$$

Ou ainda:

$$
x_{n}=\frac{n}{6} \cdot\left[(k-2) n^{2}+3 n+5-k\right]
$$


A próxima tabela apresenta os termos iniciais das primeiras sequências piramidais de acordo com o polígono da base da pirâmide.

Tabela 4.4.1 Números Piramidais

\begin{tabular}{|c|c|c|c|c|c|c|c|c|c|}
\hline Base & Termo Geral & $x_{1}$ & $x_{2}$ & $x_{3}$ & $x_{4}$ & $x_{5}$ & $x_{6}$ & $x_{7}$ & $x_{8}$ \\
\hline Triangular & $x_{n}=\frac{n(n+1)(n+2)}{6}$ & 1 & 4 & 10 & 20 & 35 & 56 & 84 & 120 \\
\hline Quadrada & $x_{n}=\frac{n(n+1)(2 n+1)}{6}$ & 1 & 5 & 14 & 30 & 55 & 91 & 140 & 204 \\
\hline Pentagonal & $x_{n}=\frac{n^{2}(n+1)}{2}$ & 1 & 6 & 18 & 40 & 75 & 126 & 196 & 288 \\
\hline Hexagonal & $x_{n}=\frac{n(n+1)(4 n-1)}{6}$ & 1 & 7 & 22 & 50 & 95 & 161 & 252 & 372 \\
\hline Heptagonal & $x_{n}=\frac{n(n+1)(5 n-2)}{6}$ & 1 & 8 & 26 & 60 & 115 & 196 & 308 & 456 \\
\hline Octogonal & $x_{n}=\frac{n(n+1)(6 n-3)}{6}$ & 1 & 9 & 30 & 70 & 135 & 231 & 364 & 540 \\
\hline Eneagonal & $x_{n}=\frac{n(n+1)(7 n-4)}{6}$ & 1 & 10 & 34 & 80 & 155 & 266 & 420 & 624 \\
\hline Decagonal & $x_{n}=\frac{n(n+1)(8 n-5)}{6}$ & 1 & 11 & 38 & 90 & 175 & 301 & 476 & 708 \\
\hline
\end{tabular}




\section{Capítulo 5 \\ Aplicações de Recorrências no Ensino Médio}

Neste capítulo apresentaremos a experiência de um trabalho sobre as recorrências com alunos de uma escola pública do Ensino Médio no Distrito Federal. Abordaremos alguns exercícios apresentados aos alunos e que exploram o conhecimento das recorrências e o uso das soluções encontradas nos capítulos anteriores. Entre os objetivos das atividades submetidas aos alunos estavam a exploração do pensamento algébrico e a procura de padrões em sequências dadas.

Além dos exercícios e das soluções propostas pelo autor, vamos expor relatos dos alunos. Eles relataram suas percepções dos problemas, as dificuldades encontradas, e em alguns casos, soluções alternativas para um mesmo problema. Quando trabalhamos o tema das recorrências com os alunos esperamos que pela observação dos problemas eles possam enxergar uma forma recursiva, uma sequência embutida, assim estimularem o desenvolvimento do raciocínio e o exercício da percepção matemática.

\subsection{Metodologia das Aplicações em Sala de Aula}

O trabalho foi realizado com alunos do $2^{\circ}$ ano do Ensino Médio da Educação Básica de uma escola pública do Distrito Federal. O processo de aplicação do tema das sequências numéricas em sala de aula ocorreu em três turmas, que denominaremos A, B e C. Na turma A havia 37 alunos, na turma B, 37 e na turma C, 35. No total, 109 alunos participaram desse processo. Os participantes estavam na faixa etária dos 15 e 16 anos. Durante o período de aplicação houve evasão escolar e índice de faltas excessivas, acima de 50\%, por parte de 12 dos 109 alunos. 
O projeto em questão foi aplicado durante as aulas de um componente curricular denominado Projeto Interdisciplinar, específico da grade acadêmica da Secretaria de Educação do Distrito Federal. Esse componente possibilita ao professor desempenhar trabalhos sobre temas diversificados, tais como Redação, Filosofia, Cidadania e múltiplos temas transversais. Quando cabe a um professor de Matemática este componente, esse pode atuar com temas matemáticos para complementação e revisão de conteúdos.

Para desenvolver a aplicação do tema de sequências numéricas tivemos um encontro semanal ao longo de quatro meses com cada uma das três turmas participantes.

Alguns exemplos do escopo metodológico da aplicação do conteúdo de sequências numéricas foram as aulas expositivas e a realização de debates em pequenos grupos e com toda a turma, nas quais fomentamos discussões e a troca de ideias acerca do tema, principalmente no que tocava a procura por padrões e modelos recursivos. Durante as aulas expositivas, além das apresentações discursivas, propusemos a realização de várias listas de exercícios, expusemos imagens e figuras que remetiam às recorrências.

Abordamos basicamente três linhas de pensamento e discussão, sendo a primeira voltada à análise das recorrências propriamente ditas, a segunda estava relacionada à identificação de padrões de formação dessas sequências e a terceira é caracterizada pela descrição algébrica das sequências analisadas.

Nos primeiros três encontros em cada turma participante, apresentamos alguns exemplos de sequências descritas numericamente com o intuito de que os alunos encontrassem o padrão de formação dessas sequências. Como por exemplo, encontrar o padrão de formação das sequências: $(1,2,5,14,41,122,365, \ldots)$ e $(1,1,2,3,5,8,13,21,34, \ldots)$. Esses exercícios representaram o primeiro contato dos estudantes com a temática de sequências numéricas, visto que segundo o que responderam em questionário, apenas dez dos alunos haviam estudado sequências numéricas na escola. Exercícios aplicados com esse propósito constituem um importante instrumento para o desenvolvimento do pensamento algébrico dos estudantes, segundo as Orientações Curriculares para o Ensino Médio (2006), conforme o trecho a seguir relatado:

"[...] colocar os alunos em um processo de aprendizagem que valorize o raciocínio matemático - nos aspectos de formular questões, perguntar-se sobre a existência de solução, estabelecer hipóteses e tirar conclusões, apresentar exemplos e contraexemplos, generalizar situações, abstrair regularidades, criar modelos, argumentar com fundamentação lógico-dedutiva." ([4], p. 70) 
A grande maioria dos estudantes respondeu que nunca havia estudado esse conteúdo. Apesar de os componentes curriculares de progressão aritmética e geométrica constituírem parte do programa curricular do $1^{\circ}$ ano do Ensino Médio, segundo eles, o tema não tinha sido apresentado no ano anterior. Nesses primeiros encontros apresentamos também a notável sequência de Fibonacci, através da explanação de exemplos descritos e da apresentação de imagens. A sequência de Fibonacci, bem como os demais exemplos de sequências apresentados, estimulam o pensamento algébrico, conforme preconiza PORTANOVA et al. (2005) quando relata o seguinte:

"O pensamento algébrico é desenvolvido a partir de estudos básicos empreendidos na área da aritmética, uma vez que o aluno já perceba a existência de diferentes conjuntos numéricos e das operações possíveis de se realizar entre os seus elementos." ([21], p. 24)

A partir da inicialização do estímulo do pensamento algébrico, nos três encontros seguintes com as turmas participantes do projeto, começamos a trabalhar sistematicamente a escrita algébrica das sequências. Introduzimos as noções de equações de recorrências lineares de primeira, segunda e terceira ordem, homogêneas e não homogêneas. Propusemos aos alunos algumas listas de exercícios que objetivavam a descoberta da lei de recorrência e a descrição numérica das sequências a partir de equações de recorrências.

Como exemplo de exercícios propostos, pedimos que:

a) Escrevessem os próximos três termos da sequência: $(1,2,4,7,11,16, \ldots)$.

b) Descrevessem numericamente os oito primeiros termos de sequências dadas as equações de recorrência. Como por exemplo: $x_{n+2}=2 x_{n+1}-x_{n}+3$, com $x_{1}=1$ e $x_{2}=2$ e $x_{n+1}=x_{n}+3^{n}, \operatorname{com} x_{1}=1$. Paralelamente, exercitamos com os alunos o processo inverso: através da observação da sequência a posterior dedução das equações correspondentes. Como por exemplo: Indicar uma equação de recorrência da sequência: $(1,2,4,7,11,16, \ldots)$.

Nessa etapa em particular, verificamos que, apesar de haver limitações por boa parte dos alunos, eles foram capazes de identificar e descobrir padrões de formação das sequências numéricas. Entre as limitações podemos citar a falta, ou ainda, as falhas dos pré-requisitos necessários para a compreensão lógico-matemática e até mesmo a falta de envolvimento, empenho e habilidade em compreender de cada aluno particularmente. Nesse contexto, apreendemos que a grande maioria dos estudantes apresentou muita dificuldade em realizar a descrição das equações dadas as sequências numéricas. 
Mesmo em vista das dificuldades, prosseguimos com o trabalho objetivando sempre a melhoria do pensamento algébrico. Sobre essa questão BECHER (2009) define que:

"[...] o pensamento algébrico consiste em um conjunto de habilidades cognitivas que contemplam a representação, a resolução de problemas, as operações e análises matemáticas de situações tendo as ideias e conceitos algébricos como seu referencial. " ([2], p. 22)

A partir da identificação dos problemas, realizamos algumas intervenções individualizadas e em pequenos grupos para esclarecer o passo a passo necessário para que os alunos conseguissem descrever algebricamente as sequências. Para isso, utilizamos o modelo da tutoria, onde alguns estudantes multiplicadores participavam como monitores de outros alunos com maiores dificuldades, na tentativa de atingirmos os objetivos das orientações e do esclarecimento acerca do tema e minimizarmos as dúvidas. Apresentamos também, em um notebook a formação de sequências em planilhas eletrônicas, no Microsoft Excel 2010 do pacote Microsoft Office. A apresentação era bem vista por parte dos alunos, porém a ampliação da participação com computadores esbarrou na falta de laboratório de informática funcionando. Ficamos, portanto, com a visualização em um aparelho apenas, mas que foi de grande valia para a experiência.

Ao longo do curso desse projeto, abrimos espaço para a realização de avaliações, as quais foram desenvolvidas através de trabalhos individuais e em grupos em sala de aula e por meio de listas de exercícios a serem respondidas em momentos extra-classe, possibilitando aos alunos pensarem com mais tempo e menos pressão. A partir das avaliações realizadas, pudemos concluir que em duas das turmas participantes obtivemos um bom retorno, conforme o esperado. Contudo, uma turma de alunos apresentou certa rejeição em relação ao tema proposto, os estudantes dessa turma apresentaram maior resistência ao trabalho e recuaram diante das dificuldades, ao contrário das demais turmas que se sentiram estimuladas pelo desafio da novidade e pela dificuldade do tema. Aferimos das avaliações o índice de aprovação nas atividades propostas, onde esperávamos uma média mínima de 50\%. A turma A apresentou um índice de 83,8\% de aprovação, na turma B o índice foi de $94,6 \%$ e na turma C, onde não houve grande envolvimento, o índice de aprovação foi de $48,5 \%$.

Após as primeiras avaliações, estudamos nos encontros subsequentes sequências como a das somas dos primeiros $n$ números naturais, os números triangulares e quadrados; a sistematização das progressões aritméticas e geométricas (PA e PG). 
Nos últimos encontros debatemos sobre umas questões que foram respondidas acerca da experiência com esse trabalho. Quando questionados quanto a capacidade de percepção de padrões numéricos, perguntamos se era ruim ou péssima, regular, boa ou ótima; os resultados do questionário: $3 \%$ ruim ou péssima percepção, $3 \%$ ótima percepção, $37 \%$ boa percepção e $57 \%$ percepção regular.

Fizemos outras indagações a respeito do estudo, as quais os alunos responderam aberta e discursivamente. Solicitamos também que não se identificassem na folha do questionário. Perguntados sobre as principais dificuldades encontradas no estudo, os alunos relataram a dificuldade de interpretação, raciocínio e a falta de interesse. Mas as respostas mais recorrentes ao questionário foram a respeito das fórmulas e descrição algébrica, a qual um aluno se referiu como: "a mistura de letras com números". Os que responderam foram unânimes na opinião de que deveriam ser trabalhados mais exercícios sobre a procura de padrões nas aulas de Matemática. Relataram também que através do estudo de sequências melhoraram o raciocínio lógico. Segundo eles, esse desenvolvimento possibilitou uma maior capacidade na resolução de problemas, inclusive de problemas que não estão diretamente relacionados com as sequências numéricas.

No fim do questionário pedimos para que eles descrevessem sua experiência com o estudo de recorrências. $20 \%$ dos alunos deixaram em branco essa parte e não expuseram sua experiência. Os que responderam, relataram que a experiência foi boa e produtiva. Que tiveram dificuldades no início pelo desconhecimento do assunto, porém o mesmo foi ficando mais simples e interessante a medida que conheciam fatos novos e aprendiam com os exercícios. Alguns descreveram que conseguiram entender melhor questões da OBMEP (Olimpíada Brasileira de Matemática para Escolas Públicas), prova que realizaram durante o curso das aplicações dessas atividades. Embora não fosse o principal objetivo, podemos sugerir que esse estudo de recorrências seja trabalhado com turmas da Educação Básica que estejam se preparando para Olimpíadas.

Nos últimos dias do processo de aplicação, tivemos encontros com um grupo de seis alunos, que apresentaram melhores desempenhos nas atividades propostas. Fizemos exposição de exercícios mais complexos como a dedução das fórmulas da soma dos $n$ primeiros quadrados e $n$ primeiros cubos naturais; e, propriedades da sequência de Fibonacci. Informamos que esses temas, apesar de não serem muito explorados nas aulas de Matemática, estão presentes em questões de olimpíadas nacionais e internacionais, assim como em provas de vestibulares para faculdades como o IME (Instituto Militar de Engenharia) e o ITA (Instituto Tecnológico de Aeronáutica). 
Ressaltamos que a foram respeitadas as percepções particulares. Sobre esse leque de possibilidades interpretativas, FIORENTINI (1993) comenta:

"[...] não existe uma única forma de se expressar o pensamento algébrico. Ele pode expressar-se através da linguagem natural, através da linguagem aritmética, através da linguagem geométrica ou através da criação de uma linguagem específica para esse fim, isto é, através de uma linguagem algébrica, de natureza estritamente simbólica." ([9], p. 88)

Nas seguintes subsecções apresentaremos alguns dos exercícios propostos, os quais expusemos e resolvemos para estimular o desafio da ampliação de ideias por parte dos alunos. Estes fizeram suas observações que também destacaremos a seguir.

\subsection{Problemas Propostos Envolvendo Recorrências}

Problema 5.1.1. Sequências Recursivas

Exercício 5.1.1. Encontrar a solução da recorrência: $x_{n+2}=2 x_{n+1}-x_{n}+3$, onde $x_{1}=1$ e $x_{2}=2$.

Solução: A equação pode ser reescrita como $x_{n+2}-2 x_{n+1}+x_{n}=3$ e a solução é um certo $x_{n}=a_{n}+z_{n}$. A equação característica é $x^{2}-2 x+1=0$, cujas raízes são iguais, $\alpha=\beta=1$. Assim, a solução da parte homogênea é da forma $a_{n}=A+n B$, com $A$ e $B$ sendo constantes arbitrárias.

Precisamos determinar uma solução particular $z_{n}$ da equação $x_{n+2}-2 x_{n+1}+x_{n}=3$. Para que a equação se iguale a 3 , tentemos o polinômio constante $z_{n}=C$. Mas, substituindo na equação chegamos a uma igualdade impossível: $C-2 C+C=3$. Aplicamos, então o aumento do grau do polinômio fazendo $z_{n}=n C$. Mais uma vez, substituindo a suposta solução $z_{n}$ na equação, chegamos a mais uma igualdade impossível: $(n+2) C-2(n+1) C+n C=3$. Precisamos, aumentar o grau do polinômio, ainda mais uma vez, fazendo, portanto: $z_{n}=n^{2} C$.

Finalmente, fazendo a substituição: $(n+2)^{2} C-2(n+1)^{2} C+n^{2} C=3$, agrupando adequadamente os termos, chegamos à igualdade:

$$
n^{2} C+4 n C+4 C-2 n^{2} C-4 n C-2 C+n^{2} C=3 \Longrightarrow 2 C=3 \Longrightarrow C=\frac{3}{2} .
$$

A solução da recorrência $x_{n}$ é a soma $a_{n}+z_{n}$. Portanto, $x_{n}=A+n B+n^{2} \cdot \frac{3}{2}$. 
Se, $x_{1}=1$ e $x_{2}=2$, então:

$$
\left\{\begin{array}{l}
A+B+\frac{3}{2}=1 \\
A+2 B+6=2
\end{array}\right.
$$

Segue do sistema que $A=3$ e $B=-\frac{7}{2}$. E, portanto, a solução procurada é:

$$
x_{n}=3-\frac{7 n}{2}+\frac{3 n^{2}}{2}, \text { ou seja: } x_{n}=\frac{3 n^{2}-7 n+6}{2} .
$$

Descrevendo numericamente os primeiros termos dessa recorrência, temos:

$$
\left(x_{n}\right)=\{1,2,6,13,23,36,52,71, \ldots\} .
$$

\section{Problema 5.1.2. Aplicação em Matemética Financeira}

O exercício a seguir nos dá uma outra aplicação do estudo das recorrências - a Matemática Financeira. Nesse trabalho não trataremos desse tema diretamente, mas podemos verificar um simples caso que resolveremos com os conhecimentos obtidos no primeiro capítulo.

Exercício 5.1.2. Uma aplicação financeira rende juros de $1 \%$ ao mês, porém a cada mês, a partir do segundo é cobrada uma taxa administrativa no valor de $\mathrm{R} \$ 10,00$. Considere que um investidor aplicou $\mathrm{R} \$ 5000,00$ de 02 de janeiro de 2015 até 02 de janeiro de 2016 sem fazer movimentações. Qual será o saldo da aplicação ao final desse prazo?

Solução: O rendimento segue uma recorrência linear de $1^{\mathrm{a}}$ ordem, pois o saldo de um mês depende do saldo do mês anterior. Além disso, a recorrência é não-homogênea pois existe um termo independente do saldo, que é a taxa administrativa.

Os dados do exercício nos fornece uma recorrência de equação $x_{n+1}=1,01 \cdot x_{n}-10$, onde $x_{1}=5000$ e $x_{n}$ indica o saldo da aplicação no mês $n$.

Como os coeficientes da equação são constantes reais, podemos usar o resultado do Teorema 1.2. para encontrar a solução.

A solução é da forma $x_{n}=\alpha \cdot a^{n-1}+\beta$, com $\alpha$ e $\beta$ constantes. Basta conhecer dois termos da sequência e resolver o sistema em $\alpha$ e $\beta$.

$$
\left\{\begin{array}{l}
x_{1}=\alpha+\beta=5000 \\
x_{2}=1,01 \alpha+\beta=5040
\end{array}\right.
$$


Fazendo $x_{2}-x_{1}$, temos que $0,01 \cdot \alpha=40 \Longrightarrow \alpha=4000$ e $\beta=1000$.

Assim, a solução da recorrência é $x_{n}=4000 \cdot(1,01)^{n-1}+1000$.

Seja janeiro/2015 o mês 1, fevereiro/2015 o mês 2, e assim sucessivamente até dezembro/2015 o mês 12 e janeiro/2016 o mês 13 da aplicação.

Fazendo $n=13$, usando a calculadora para calcular $(1,01)^{12}$, o saldo em janeiro de 2016 será de $\mathrm{R} \$ 5507,30$.

Observação: Essa aplicação fictícia só faria jus a obtenção de algum lucro, um investimento no valor acima de $\mathrm{R} \$ 1000,00$, devido à cobrança da taxa.

Problema 5.1.3. Sobre os números de Fibonacci

A seguir, teremos como exercícios propostos a demonstração de algumas propriedades dos números de Fibonacci. Tratamos dessa sequência no terceiro capítulo, onde descrevemos sua equação de recorrência: $F_{n+2}=F_{n+1}+F_{n}$, com $F_{1}=F_{2}=1$.

Apresentamos uma solução para o termo geral:

$$
F_{n}=\frac{1}{\sqrt{5}} \cdot\left(\frac{1+\sqrt{5}}{2}\right)^{n}-\frac{1}{\sqrt{5}} \cdot\left(\frac{1-\sqrt{5}}{2}\right)^{n}
$$

Descrevendo numericamente seus primeiros termos, temos:

$$
\left(F_{n}\right)=(1,1,2,3,5,8,13,21,34,55,89,144,233,377,610, \ldots)
$$

Exercício 5.1.3. Seja a sequência de Fibonacci $\left(F_{n}\right)$, como vimos no terceiro capítulo, tal que $F_{n+2}=F_{n+1}+F_{n}$, com $F_{1}=F_{2}=1$. Vamos mostrar algumas de suas propriedades.

(a) A soma dos $n$ primeiros quadrados dos números de Fibonacci é igual ao produto entre o n-ésimo e o $(n+1)$-ésimo número de Fibonacci. Ou seja:

$$
\sum_{k=1}^{n}\left(F_{k}\right)^{2}=F_{n} \cdot F_{n+1}
$$

Prova: Pela definição dos termos de Fibonacci temos que $\left(F_{1}\right)^{2}=F_{1} \cdot F_{2}=1$ e que para todo $n \geq 2$, como $F_{n+1}=F_{n}+F_{n-1}$ :

$$
\left(F_{n}\right)^{2}=F_{n} \cdot F_{n}=F_{n} \cdot\left(F_{n+1}-F_{n-1}\right)=F_{n} F_{n+1}-F_{n-1} F_{n}
$$


Por essa relação de recorrência, podemos escrever as igualdades:

$$
\begin{aligned}
& \left(F_{1}\right)^{2}=F_{1} F_{2} \\
& \left(F_{2}\right)^{2}=F_{2} F_{3}-F_{1} F_{2} \\
& \left(F_{3}\right)^{2}=F_{3} F_{4}-F_{2} F_{3} \\
& \quad \vdots \\
& \left(F_{n}\right)^{2}=F_{n} F_{n+1}-F_{n-1} F_{n}
\end{aligned}
$$

Somando-se os termos e efetuando-se as devidas operações chegamos ao resultado:

$$
\sum_{k=1}^{n}\left(F_{k}\right)^{2}=F_{n} \cdot F_{n+1}
$$

(b) A soma dos $n$ primeiros termos com indices impares da sequência de Fibonacci é igual ao 2n-ésimo número de Fibonacci. Ou seja:

$$
\sum_{k=1}^{n} F_{2 k-1}=F_{2 n}
$$

Prova: Vamos provar pelo princípio de indução. Primeiramente, observemos que a proposição é verdadeira para o caso base da indução $n=1$, pois temos $F_{1}=F_{2 \cdot 1}=F_{2}=1$. Para $n=2$, também é válida, uma vez que $F_{1}+F_{3}=F_{4}=3$.

Agora, supomos que a proposição seja válida para todo natural $k \in\{1,2,3, \ldots, n\}$, então a prova estará completa se, a partir da hipótese de indução, válida até um certo $n$, a proposição for verdadeira também para $(n+1)$. Por hipótese, temos que a soma dos $n$ primeiros termos com índice ímpar é:

$$
F_{1}+F_{3}+F_{5}+\ldots+F_{2 n-1}=F_{2 n}
$$

E se somarmos à ambos os lados da igualdade o próximo termo dessa subsequência, obteremos:

$$
F_{1}+F_{3}+F_{5}+\ldots+F_{2 n-1}+F_{2 n+1}=F_{2 n}+F_{2 n+1}=F_{2 n+2}=F_{2(n+1)}
$$

A igualdade $F_{2 n}+F_{2 n+1}=F_{2 n+2}$ provém da própria relação de recorrência de Fibonacci. Visto que a validade de $P(n)$ implica na validade de $P(n+1)$, podemos concluir a prova, afirmando que a proposição é verdadeira para todo $n$ natural. 
E se quisermos somar os $n$ primeiros termos de Fibonacci com indice par?

À princípio, podemos observar que na soma $F_{2}+F_{4}+F_{6}+\ldots+F_{2 n}$ o termo $F_{2 n}$ é igual a soma $F_{1}+F_{3}+F_{5}+\ldots+F_{2 n-1}$, como provamos no item anterior. Então, é indutivo dizer que:

$$
F_{2}+F_{4}+F_{6}+\ldots+F_{2 n-2}+F_{2 n}=F_{1}+F_{2}+F_{3}+F_{4}+\ldots+F_{2 n-2}+F_{2 n-1}
$$

Vamos verificar esse fato no próximo item dessa lista.

(c) A soma dos $n$ primeiros termos com indices pares da sequência de Fibonacci é igual a soma de todos os termos anteriores ao 2 -ésimo número de Fibonacci. Ou seja:

$$
\sum_{k=1}^{n} F_{2 k}=\sum_{k=1}^{2 n-1} F_{k}
$$

Prova: Vamos provar por indução em $n$. De fato, a proposição é verdadeira para o caso base da indução $n=1$, pois temos $F_{2}=F_{1}=1$. Para $n=2$, também é válida, uma vez que $F_{2}+F_{4}=F_{1}+F_{2}+F_{3}=4$.

Supondo que a proposição seja válida para todo natural $k \in\{1,2,3, \ldots, n\}$. Provaremos que é verdadeira para todo $n$ natural se a validade de $P(n)$ implicar na validade de $P(n+1)$. Partindo da hipótese de indução, a igualdade seguinte é verdadeira até um certo $n$ :

$$
F_{2}+F_{4}+F_{6}+\ldots+F_{2 n-2}+F_{2 n}=F_{1}+F_{2}+F_{3}+F_{4}+\ldots+F_{2 n-2}+F_{2 n-1}
$$

Agora vamos somar à ambos os lados da igualdade o próximo termo da subsequência: $F_{2}+F_{4}+F_{6}+\ldots+F_{2 n-2}+F_{2 n}+F_{2 n+2}=F_{1}+F_{2}+F_{3}+F_{4}+\ldots+F_{2 n-2}+F_{2 n-1}+F_{2 n+2}$

Mas, pela relação de recorrência de Fibonacci: $F_{2 n+2}=F_{2 n+1}+F_{2 n}$. Portanto, a igualdade pode se reescrita:

$$
F_{2}+F_{4}+F_{6}+\ldots+F_{2 n}+F_{2(n+1)}=F_{1}+F_{2}+F_{3}+F_{4}+\ldots+F_{2 n}+F_{2(n+1)-1}
$$

Como a igualdade é verdadeira também para um $k=n+1$ temos que a proposição é verdadeira para todo $n$ natural. 
Problema 5.1.4. Sequências dentro de outras sequências

Exercício 5.1.4. Encontrar uma solução para a expressão do termo geral da sequência $\left(x_{n}\right)=(1,5,15,34,65,111,175, \ldots)$ formada recursivamente conforme a ilustração a seguir:

$$
\begin{aligned}
& x_{1}=1 \\
& x_{2}=2+3 \\
& x_{3}=4+5+6 \\
& x_{4}=7+8+9+10 \\
& x_{5}=11+12+13+14+15 \\
& \vdots
\end{aligned}
$$

Solução: Primeiramente devemos observar que o termo da n-ésima linha é a soma de exatamente $n$ números naturais consecutivos, formando uma progressão aritmética de razão 1. Como vimos na Proposição 1.4.2, a soma de $n$ termos em PA é dada pela fórmula $S_{n}=\frac{\left(x_{1}+x_{n}\right) \cdot n}{2}$, onde $x_{1}$ e $x_{n}$ são o primeiro e o último termo, respectivamente.

O próximo passo da resolução é o destacamento de duas sequências. A sequência $\left(y_{n}\right)$ dos primeiros termos de cada soma e a sequência $\left(z_{n}\right)$ dos últimos termos de cada soma.

Pela recursividade da recorrência $\left(x_{n}\right)$, onde cada termo possui na sua soma um número natural a mais que na soma do termo anterior, podemos deduzir as sequências $\left(y_{n}\right)$ e $\left(z_{n}\right)$. Descrevendo os primeiros termos de cada uma delas, temos: $\left(y_{n}\right)=(1,2,4,7,11,16, \ldots)$ e $\left(z_{n}\right)=(1,3,6,10,15,21, \ldots)$.

Precisamos encontrar as soluções de $\left(y_{n}\right)$ e $\left(z_{n}\right)$. Vamos resolver cada recorrência.

$$
\begin{array}{cc}
y_{1}=1 & z_{1}=1 \\
y_{2}=y_{1}+1 & z_{2}=z_{1}+2 \\
y_{3}=y_{2}+2 & z_{3}=z_{2}+3 \\
y_{4}=y_{3}+3 & z_{4}=z_{3}+4 \\
\vdots & \vdots \\
y_{n}=y_{n-1}+(n-1) & z_{n}=z_{n-1}+n
\end{array}
$$

Fazemos a soma telescópica das equações de cada recorrência usando o resultado da Proposição 1.4.1. para somar os números naturais. Simplificamos adequadamente para encontrar as soluções:

$$
y_{n}=1+\frac{n(n-1)}{2} \quad \text { e } \quad z_{n}=\frac{n(n+1)}{2}
$$


Prosseguindo com a resolução da recorrência $\left(x_{n}\right)$, temos que cada termo $x_{n}$ é a soma de $n$ números naturais consecutivos, onde o primeiro termo dessa soma é $y_{n}$ e o último é $z_{n}$.

Aplicando então o resultado da Proposição 1.4.2. temos $x_{n}=\frac{\left(y_{n}+z_{n}\right) \cdot n}{2}$.

Portanto a solução $x_{n}$ é dada por:

$$
x_{n}=\frac{\left(1+\frac{n(n-1)}{2}+\frac{n(n+1)}{2}\right) \cdot n}{2} \Longrightarrow x_{n}=\frac{n \cdot\left(n^{2}+1\right)}{2} \Longrightarrow x_{n}=\frac{n^{3}+n}{2}
$$

Quando apresentamos esse exercício aos alunos, solicitamos a princípio que eles encontrassem os termos $x_{10}$ e $x_{20}$. Em seguida, para que fossem instigados a procurarem por uma solução mais prática, pedimos que calculassem o valor de $x_{100}$. Depois que alguns calcularam $x_{10}$ e $x_{20}$ do modo mais trabalhoso, desenvolvemos com eles a solução desse problema e reforçamos a necessidade de sempre procurar uma solução geral.

Aplicando a solução que encontramos $x_{n}=\frac{n^{3}+n}{2}$, obtemos:

$$
x_{10}=505, \quad x_{20}=4010 \quad \text { e } \quad x_{100}=500050 .
$$

\section{Problema 5.1.5. Somas Polinomiais}

Exercício 5.1.5. Encontrar uma solução para a expressão do termo geral da soma dos $n$ primeiros cubos de números naturais:

$$
1^{3}+2^{3}+3^{3}+4^{3}+\ldots+n^{3}
$$

Solução: Pelo Teorema 4.2 a expressão da soma dos $n$ primeiros cubos naturais é um polinômio do quarto grau em $n$. Então, segundo o Teorema a solução procurada é da forma: $A n^{4}+B n^{3}+C n^{2}+D n+E$, onde $A, B, C, D$ e $E$ são constantes reais arbitrárias e $A \neq 0$.

Escrevendo o sistema de equações para as primeiras cinco somas de cubos naturais, temos:

$$
\left\{\begin{array}{llllll}
\mathrm{A} & +\mathrm{B} & +\mathrm{C} & +\mathrm{D}+\mathrm{E}=1 \\
16 \mathrm{~A} & +8 \mathrm{~B}+4 \mathrm{C}+2 \mathrm{D}+\mathrm{E}=9 \\
81 \mathrm{~A} & +27 \mathrm{~B}+9 \mathrm{C}+3 \mathrm{D}+\mathrm{E}=36 \\
256 \mathrm{~A}+64 \mathrm{~B}+16 \mathrm{C}+4 \mathrm{D}+\mathrm{E}=100 \\
625 \mathrm{~A}+125 \mathrm{~B}+25 \mathrm{C}+5 \mathrm{D}+\mathrm{E}=225
\end{array}\right.
$$


Resolvendo o sistema encontramos os valores: $A=\frac{1}{4}, B=\frac{1}{2}, C=\frac{1}{4}$ e $D=E=0$.

Então, a soma dos $n$ primeiros cubos naturais é dada por:

$$
\frac{n^{4}}{4}+\frac{n^{3}}{2}+\frac{n^{2}}{4} \Longrightarrow \frac{n^{4}}{4}+\frac{2 n^{3}}{4}+\frac{n^{2}}{4} \Longrightarrow \frac{n^{2}(n+1)^{2}}{4} \Longrightarrow\left[\frac{n(n+1)}{2}\right]^{2}
$$

Assim como procedemos no quarto capítulo, quando usamos somatórios para encontrar a fórmula da soma nos $n$ primeiros quadrados perfeitos, vamos descrever uma solução alternativa para o último exercício.

Outra solução: Consideremos a igualdade dos somatórios:

$$
\sum_{k=1}^{n}(k+1)^{4}=\sum_{k=1}^{n} k^{4}+4 \sum_{k=1}^{n} k^{3}+6 \sum_{k=1}^{n} k^{2}+4 \sum_{k=1}^{n} k+\sum_{k=1}^{n} 1
$$

As somas $\sum_{k=1}^{n}(k+1)^{4}$ e $\sum_{k=1}^{n} k^{4}$ possuem vários termos em comum e as três últimas já obtivemos o resultado durante o trabalho.

$$
\begin{gathered}
\sum_{k=1}^{n}(k+1)^{4}=2^{4}+3^{4}+4^{4}+\ldots+(n+1)^{4} \text { e } \sum_{k=1}^{n} k^{4}=1^{4}+2^{4}+3^{4}+\ldots+n^{4} \\
\sum_{k=1}^{n} k^{2}=\frac{n(n+1)(2 n+1)}{6} \text { e } \sum_{k=1}^{n} k=\frac{n(n+1)}{2} \quad \text { e } \sum_{k=1}^{n} 1=n
\end{gathered}
$$

Simplificando adequadamente, reescrevemos a igualdade:

$$
\begin{gathered}
(n+1)^{4}=1^{4}+4 \sum_{k=1}^{n} k^{3}+6 \cdot \frac{n(n+1)(2 n+1)}{6}+4 \cdot \frac{n(n+1)}{2}+n \\
\Longrightarrow 4 \sum_{k=1}^{n} k^{3}=(n+1)^{4}-n(n+1)(2 n+1)-2 n(n+1)-(n+1) \\
\Longrightarrow 4 \sum_{k=1}^{n} k^{3}=(n+1)^{4}-(n+1)[n(2 n+1)+2 n+1] \\
\Longrightarrow 4 \sum_{k=1}^{n} k^{3}=(n+1)^{4}-(n+1)^{2}(2 n+1) \\
\Longrightarrow 4 \sum_{k=1}^{n} k^{3}=(n+1)^{2}\left[(n+1)^{2}-(2 n+1)\right] \\
\Longrightarrow 4 \sum_{k=1}^{n} k^{3}=(n+1)^{2}\left[n^{2}+2 n+1-(2 n+1)\right]
\end{gathered}
$$




$$
\Longrightarrow 4 \sum_{k=1}^{n} k^{3}=n^{2}(n+1)^{2} \Longrightarrow \sum_{k=1}^{n} k^{3}=\frac{n^{2}(n+1)^{2}}{4} \Longrightarrow \sum_{k=1}^{n} k^{3}=\left[\frac{n(n+1)}{2}\right]^{2}
$$

Portanto, temos que $1^{3}+2^{3}+3^{3}+\ldots+n^{3}=\left[\frac{n(n+1)}{2}\right]^{2}$. Esse é um polinômio do quarto grau em $n$.

\section{Problema 5.1.6. Torre de Hanói}

Depois de apresentarmos aos alunos o exemplo da Torre de Hanói, comentamos sobre uma antiga lenda relatada por OLIVEIRA \& FERNÁNDEZ (2012):

"[...] Diz uma antiga lenda que na origem dos tempos, em um templo de Hanói, foram colocados 64 discos perfurados, de ouro puro e de diâmetros diferentes ao redor de três hastes feitas de diamantes. Muitos sacerdotes moviam os discos, respeitando as seguintes regras: eles começam empilhados em ordem crescente de acordo com seu tamanho [...]. Os discos podem ser deslocados de uma coluna para qualquer outra, sendo que nunca pode ser colocado um disco maior em cima de um menor e a cada segundo os sacerdotes movem um disco. Quando os sacerdotes transportassem todos os discos de uma coluna para outra, o mundo se acabaria. " ([18], p. 223)

Diante da citação dessa lenda e da solução encontrada de que para se mover $n$ discos no jogo são necessários no mínimo $2^{n}-1$ movimentos. Propomos então, um problema que pode ser comentado para se verificar o quão grande pode ser este número.

Suponhamos que a lenda fosse verdadeira e que os sacerdotes tivessem começado o jogo a dez mil anos, e ainda, que eles demorassem um segundo para fazer cada movimento, quanto tempo ainda restaria ao planeta Terra?

Nessa situação hipotética sendo 64 discos a serem movimentados, obedecendo-se as regras do jogo precisariam de no mínimo $2^{64}-1$ movimentos para transportar toda a pilha de discos. Sendo assim, demorariam $2^{64}-1$ segundos, tempo este que equivale a 18.446.744.073.709.551.615 segundos, ou mais de 307 quatrilhões de minutos, ou mais de 5 quatrilhões de horas, ou ainda mais de 213,5 trilhões de dias, ou "pouco mais" de 584,5 bilhões de anos. Considerando que se passaram dez mil anos desde que começaram os movimentos, ainda restaria a Terra cerca de 584.542.036.090 anos, 7 meses e 15 dias. 


\subsection{Análise de Alunos Sobre Algumas Questões}

Propondo esses exercícios aos alunos podemos notar a percepção de várias visões de um mesmo problema. Essas observações proporcionam ao aluno exercitar o pensamento algébrico e as noções intuitivas que o ajudarão nas diversas áreas do conhecimento, e consequentemente, na melhor percepção do mundo que o cerca.

\section{Relato sobre o Problema 5.1.1.}

Observando a sequência $\left(x_{n}\right)=\{1,2,6,13,23,36,52,71, \ldots\}$, o aluno "A" apontou que $x_{2}=x_{1}+1, x_{3}=x_{2}+4, x_{4}=x_{3}+7, x_{5}=x_{4}+10, x_{6}=x_{5}+13$, etc. Assim ele pôde identificar que a sequência obtida pela equação do exercício 4.1.1., apesar de ser uma recorrência de $2^{\mathrm{a}}$ ordem pode ser vista como uma de $1^{\mathrm{a}}$ ordem. Observemos que cada termo, a partir do segundo, pode ser obtido somando-se o anterior a um elemento da progressão aritmética $\left(a_{n}\right)=(1,4,7,10,13, \ldots)$ cuja razão é 3 e onde $a_{1}=1$.

Após apresentar sua observação foi proposto ao aluno: encontrar a equação da mesma recorrência, só que agora como uma de $1^{\mathrm{a}}$ ordem como observado; e em seguida que solucionasse a equação encontrada, a fim de comparar as soluções. A seguir, reproduziremos as respostas encontradas pelo aluno e discutidas com os demais em sala de aula.

Solução do aluno: Vamos considerar a PA $(1,4,7,10,13, \ldots)$, onde o termo geral é dado por: $a_{n}=1+(n-1) \cdot 3$, ou seja, $a_{n}=3 n-2$. A partir do segundo termo da recorrência $x_{n}$, cada termo é obtido pela soma do termo anterior com um elemento da referida PA, de modo que: $x_{n+1}=x_{n}+a_{n}$, a equação da recorrência pode ser $x_{n+1}=x_{n}+3 n-2$.

Resolvendo a equação, observando que os termos independentes, a partir do segundo termo da recorrência, formam uma PA de razão 3:

$$
\begin{gathered}
x_{1}=1 \\
x_{2}=x_{1}+1 \\
x_{3}=x_{2}+4 \\
x_{4}=x_{3}+7 \\
\vdots \\
x_{n}=x_{n-1}+3(n-1)-2
\end{gathered}
$$

Somando-se as equações e simplificando adequadamente temos:

$$
x_{n}=1+(1+4+7+\cdots+3(n-1)-2) .
$$


Somando os termos da PA usando o resultado $S_{n}=\frac{\left(x_{1}+x_{n}\right) \cdot n}{2}$, obtém-se:

$$
S=\frac{(1+3(n-1)-2) \cdot(n-1)}{2} \Longrightarrow S=\frac{(3 n-4) \cdot(n-1)}{2} \Longrightarrow S=\frac{3 n^{2}-7 n+4}{2}
$$

Finalmente, substituindo o resultado da soma em $x_{n}$ chegamos à solução:

$$
x_{n}=1+\frac{3 n^{2}-7 n+4}{2} \Longrightarrow x_{n}=\frac{3 n^{2}-7 n+6}{2} .
$$

Observemos que esta solução é a mesma encontrada no Exercício 5.1.1.

\section{Relato sobre o Problema 5.1.5.}

Ao descrevermos juntamente com os alunos a sequência das somas dos $n$ primeiros cubos naturais no Exercício 5.1.4, alguns alunos puderam observar fatos relevantes. "Tem alguma coisa nessa sequência. Os números são quadrados perfeitos." - observou o aluno "B". Ele se referia a $(1,9,36,100,225, \ldots)$.

Então nós começamos a verificar quais quadrados, especificamente, lá estavam presentes. Encontraram, portanto, os valores: $1^{2}, 3^{2}, 6^{2}, 10^{2}$ e $15^{2}$. "Essa sequência nós já vimos em outras aulas!" - exclamou o aluno "C". Depois de algumas observações e tentativas de classificação, o aluno "A" lembrou: "Esses são aqueles números que vão formando montinhos". Revisando as anotações, os alunos verificaram que se tratava dos números triangulares.

Então, sugerimos que formulassem uma expressão que caracterizasse a soma:

$$
1^{3}+2^{3}+3^{3}+4^{3}+\ldots+n^{3}
$$

E sob a orientação do professor descreveram que a soma é dada pelo quadrado do n-ésimo número triangular. Ou seja:

$$
1^{3}+2^{3}+3^{3}+4^{3}+\ldots+n^{3}=\left[\frac{n(n+1)}{2}\right]^{2}
$$

Porém, os alunos foram indagados a respeito da validade desse resultado para todo $n$ natural, visto que só foram observados os cinco primeiros termos $(1,9,36,100,225, \ldots)$. Então, foi-lhes apresentada a prova de tal afirmação pelo Princípio de Indução Finita. A qual reproduziremos a seguir. 


\section{Prova por indução em $n$ :}

Seja a proposição $P(n): 1^{3}+2^{3}+3^{3}+4^{3}+\ldots+n^{3}=\left[\frac{n(n+1)}{2}\right]^{2}$

Para $n=1$, caso base da indução, verificamos a validade já que o primeiro cubo natural é 1 e que $\left[\frac{1(1+1)}{2}\right]^{2}=1$.

Suponhamos agora, que $P(n)$ seja válida para todo $k=\{1,2,3,4, . ., n\}$. Queremos mostrar que $P(n) \Longrightarrow P(n+1)$. Ou seja, que usando a hipótese de indução mostremos que a proposição é verdadeira para um $k=n+1$. De fato, partindo da hipótese e somando o próximo cubo a ambos os lados da igualdade, obtemos:

$$
1^{3}+2^{3}+3^{3}+4^{3}+\ldots+n^{3}+(n+1)^{3}=\left[\frac{n(n+1)}{2}\right]^{2}+(n+1)^{3}
$$

Agrupando adequadamente os termos, chegamos à sequência lógica:

$$
\begin{gathered}
\frac{n^{2}(n+1)^{2}+4(n+1)^{3}}{4} \Longrightarrow \frac{(n+1)^{2}\left[n^{2}+4(n+1)\right]}{4} \Longrightarrow \frac{(n+1)^{2}\left(n^{2}+4 n+4\right)}{4} \\
\Longrightarrow \frac{(n+1)^{2}(n+2)^{2}}{4} \Longrightarrow\left(\frac{(n+1)(n+2)}{2}\right)^{2}
\end{gathered}
$$

Portanto, como a validade de $P(n)$ implica na validade de $P(n+1)$ temos que a proposição é verdadeira para todo $n$ natural.

A observação de que a sequência da soma dos cubos é igual a dos quadrados dos números triangulares foi importante para que os alunos vissem a interligação entre recorrências, que a princípio são formadas à partir de ideias diferentes. 


\section{Considerações Finais}

Esse trabalho teve como objetivo apresentar uma proposta de estudo das recorrências. Discorremos sobre vários tipos de sequências recursivas, exemplos clássicos e aplicações em diversas áreas da Matemática. Fomos além da noção das progressões aritméticas e geométricas que, como vimos no corpo desse trabalho, na maioria dos livros didáticos são as únicas sequências a serem exploradas sistematicamente. Apesar de não fazer parte dos currículos na maioria das escolas de Ensino Médio, o tema das recorrências pode ser de grande ajuda para se trabalhar o pensamento cognitivo dos alunos.

Exploramos as recorrências lineares de primeira e segunda ordens. Apresentamos resultados que nos deram suporte para resolução de outros problemas relacionados a crescimento recorrente. Tais resultados foram temas de aulas na aplicação externa do conteúdo desse trabalho. Correlacionamos outras áreas com as recorrências, explorando problemas e casos específicos, como as Combinações. Essas relações podem chamar a atenção dos alunos quanto à interligação de diversos ramos da Matemática.

Mostramos também exemplos clássicos de recorrências, como a famosa sequência de Fibonacci. Os estudantes mais interessados em Matemática a conhecem por lerem sobre ela em revistas [1], na Internet e em livros de curiosidades matemáticas [22]. Nesse trabalho, discorremos sobre propriedades desta sequência e fizemos um breve comentário sobre os números de Lucas, estabelecendo inclusive, a relação entre as duas sequências.

Através da experiência relatada no último capítulo, pudemos entender que o trabalho com recorrências em escolas públicas tem o potencial de tornar-se útil sob vários aspectos. Principalmente, no que tange ao exercício da busca por modelos matemáticos e a percepção algébrica para sistematização dos modelos encontrados. Reforçamos ao leitor desse trabalho o avanço obtido por muitos alunos que puderam ter acesso a um tema às vezes reservado apenas a polos de treinamentos. Foi gratificante a simples associação do tema estudado durante alguns meses, e em um único encontro semanal, com outros exercícios 
das aulas tradicionais de Matemática, questões de Olimpíada e revisões para vestibulares.

Referenciamos com várias citações bibliográficas a importância de se dedicar tempo à observação, à procura de padrões, à discussão acerca de resultados encontrados, à intuição e dedução de modelos matemáticos. Sugerimos que a experiência seja repetida sempre que for possível, e que os professores de Matemática estimulem seus alunos quanto a essas atividades. Que os mesmos utilizem, como apresentamos nesse trabalho, as sequências numéricas. Sugerimos ainda que o tema seja explorado sob a luz dos recursos computacionais. Acreditamos que será de grande proveito as ideias disponibilizadas nesse trabalho de pesquisa.

Finalizamos ressaltando que esse trabalho sobre as recorrências e suas aplicações pode ser uma excelente alternativa de estudo para professores da Educação Básica, para temas de cursos de formação docente, para alunos de graduação e pós-graduação, que desejem expandir seu conhecimento. E, por conseguinte, melhorarmos os rumos da educação matemática no Brasil. 


\section{Referências Bibliográficas}

[1] ÁVILA, Geraldo. Retângulo Áureo, Divisões Áureas e Sequencia de Fibonacci, Revista do Professor de Matemática, no 06. Rio de Janeiro: SBM, 2002.

[2] BECHER, E. L. Características do Pensamento Algébrico de Estudantes do $1^{o}$ ano do Ensino Médio. Dissertação (Mestrado em Educação Matemática). Canoas, Universidade Luterana do Brasil, 2009.

[3] BOYER, Carl B. História da Matemática. Tradução: Elza F. Gomide. 2a ed. São Paulo: Edgard Blücher, 1996.

[4] BRASIL. Orientações Curriculares para o Ensino Médio: Ciências da Natureza, Matemática e suas Tecnologias. Brasília: Ministério da Educação, Secretaria de Educação Básica, 2006.

[5] BRASIL, Secretaria de Educação Fundamental. Parâmetros Curriculares Nacionais: Matemática. Brasília: Ministério da Educação/Secretaria de Educação Fundamental, 1998.

[6] BRASIL, Secretaria de Educação Média e Tecnológica. PCN+Ensino Médio - Orientações Educacionais complementares aos Parâmetros Curriculares Nacionais: Linguagens, códigos e suas tecnologias. Brasília: Ministério da Educação/Secretaria de Educação Média e Tecnológica, 2002.

[7] DANTE, Luiz R. Matemática: Contexto e Aplicações: Volume 1. São Paulo: Ática, 2011.

[8] DANTE, Luiz R. Matemática: Contexto e Aplicações: Volume 3. São Paulo: Ática, 2011.

[9] FIORENTINI, D.; MIORIM, M. A.; MIGUEL, A. Contribuições para um repensar: a educação algébrica elementar. Pro-Posições, Vol. 4, nº 1, p.78-90, mar.1993. Campinas, 1993. 
[10] GARBI, Gilberto, Uma pequena pérola de Euler, Revista do Professor de Matemática, $\mathrm{n}^{\circ}$ 50. Rio de Janeiro: SBM, 2002.

[11] GOMES, Olimpio R.; SILVA, Jhone C. Estruturas Algébricas para Licenciatura: Introdução à Teoria dos Números. Brasília: Edição do Autor, 2008.

[12] IEZZI, Gelson; et al. Matemática: Ciência e Aplicações: Volume 1. 4a ed. São Paulo: Atual, 2006.

[13] LIMA, Elon L.; et al. A Matemática do Ensino Médio: Volume 1. $6^{\text {a }}$ ed. Rio de Janeiro: SBM, 2006.

[14] LIMA, Elon L.; et al. A Matemática do Ensino Médio: Volume 2. $6^{\text {a }}$ ed. Rio de Janeiro: SBM, 2006.

[15] MOREIRA, Carlos G.. Sequências Recorrentes. Disponível em: http://www.bienasbm.ufba.br/M55.pdf . Acesso em 14/02/2014.

[16] MORGado, Augusto C.; CARvalhO, Paulo C. P. Matemática Discreta: Coleção PROFMAT. Rio de Janeiro: SBM, 2014.

[17] MORGADO, Augusto C.; et al. Análise Combinatória e Probabilidade, Coleção do Professor de Matemática. Rio de Janeiro, SBM, 1991.

[18] OLIVEIRA, Krerley I. M.; FERNÁNDEZ, Adán J. C. Iniciação à Matemática: um curso com problemas e soluções. $2^{\mathrm{a}}$ ed. Rio de Janeiro: SBM, 2012.

[19] PAIVA, Manoel. Matemática Paiva: Volume 1. São Paulo: Moderna, 2009.

[20] POOLE, David. Álgebra Linear. Tradução: Martha Salerno Monteiro et. al. São Paulo: Thomson, 2006.

[21] PORTANOVA, Ruth. Um currículo de matemática em movimento. Porto Alegre: EDIPUCRS, 2005.

[22] STEWART, Iam. Almanaque das Curiosidades Matemáticas. Tradução: Diego Alfaro. Rio de Janeiro: Zahar, 2008. 